\title{
An Intrusive and Corrective Government: Political Rationalities and the Governance of the Plains Aboriginals, 1870-1890.
}

\author{
Bryan Richard Hogeveen
}

A Thesis Submitted to the Faculty of Graduate Studies in Partial Fulfilment of the Requirements for the Degree of:

\section{Master of Arts}

Department of Sociology

University of Manitoba

Winnipeg, Manitoba

C) Bryan R. Hogeveen, 1998 
National Library of Canada

Acquisitions and Bibliographic Services

395 Wellington Street Ottawa ON K1A ON4 Canada
Bibliothèque nationale du Canada

Acquisitions et services bibliographiques

395. ne Wellington Ottawa ON KIA ONA Canada
The author has granted a nonexclusive licence allowing the National Library of Canada to reproduce, loan, distribute or sell copies of this thesis in microform, paper or electronic formats.

The author retains ownership of the copyright in this thesis. Neither the thesis nor substantial extracts from it may be printed or otherwise reproduced without the author's permission.
L'auteur a accordé une licence non exclusive permettant à la Bibliothèque nationale du Canada de reproduire, prêter, distribuer ou vendre des copies de cette thèse sous la forme de microfiche/film, de reproduction sur papier ou sur format électronique.

L'auteur conserve la propriété du droit d'auteur qui protège cette thèse. $\mathrm{Ni}$ la thèse ni des extraits substantiels de celle-ci ne doivent être imprimés ou autrement reproduits sans son autorisation. 


\section{AR IASTRUSIVE AID CORRECTIVE GOVERRMETT:

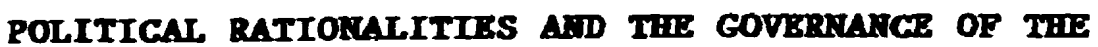 \\ PLAIMS ABORIGIMAIS, 1870-1890}

BY

BRYAN RICHARD BOGEVEEN

A Thesis submitted to the Faculty of Graduate Studies of the University of Manitoba in partial fulfillment of the requirements of the degree of

\section{MASTER OF ARTS}

Bryan Richard Hogeveen 1998

Permission has been granted to the LIBRARY OF THE UNTVERSITY OF MLANITOBA to lend or sell copies of this thesis, to the NATIONAL LIBRARY OF CANADA to microfilm this thesis and to lend or sell copies of the film, and LIBRARY MICROFILMS to publish an abstract of this thesis.

The author reserves other publication rights, and neither the thesis nor extensive extracts from it may be printed or other-wise reproduced without the author's written permission. 


\section{Abstract}

In this work I have applied post-colonial theory and Foucault's ideas on government to analyse colonial governmentality and its impact on the Aboriginals of the Canadian prairies. Most often, historians who have undertaken work in the field of Aboriginal/Government relations have attempted to unravel the ideological representations which constructed the Aboriginals as other, along with highlighting how State policy marginalized Canada's indigenous people. My research has endeavoured to move the analysis of Aboriginal governance beyond ideology and centralized State power by considering how the indigenous peoples were defined, divided out, and excluded from Euro-Canadian society. More specifically, I have tried to reveal how the traditional modes of Aboriginal life were structured in diverse ways by both the political rationality of the Hudson's Bay Company and the $19^{\text {th }}$ century Canadian liberal rationality of government. In so doing, I endeavoured to discern how law and practices of government, such as, techniques to govern consumption and agricultural programmes, intruded into the lives of the Aboriginal peoples. By interrogating the practices and programmes by which the rationality of $19^{\text {th }}$ century liberal government structured the modes of plains Aboriginals life I have attempted to come to a unique understanding of Aboriginal/government relations. 


\section{Contents}

Acknowledgements $\quad$ i

Introduction $\quad 1$

1. Liberalism, the Canadian State, and Governmentality: 17 the Search for Principles

2. Security of Knowledge Through Discourse and the Intrusion 38 of Settlement: Liberal Antecedents

3. The Emerging Canadian State: Liberal Premises, Illiberal 66 Tendencies

4. Intrusion of a Mode of Life: Subjection of the Normal 87

5. Governing the Choice of Actions: Law; Consumption; 100 and Individualization

6. Knowledge, the Requisite of Government: Agents, Police and Reports

7. Accumulating Knowledge: Statistics, Reports and 143

Correspondence

$\begin{array}{lr}\text { Conclusion } & 162\end{array}$

$\begin{array}{ll}\text { Notes } & 175\end{array}$

$\begin{array}{ll}\text { References } & 177\end{array}$ 


\section{Acknowledgments}

The debt one incurs while writing a Master of Arts thesis is particularly far-reaching. Not only are there academic contributions to recognize, there are also the unselfish encouragement and patience of individuals along the way. Here, in these few short paragraphs, I would like to recognize these significant contributions to this project.

First, I would particularly like to express my heartfelt appreciation, and give recognition to the patience, diligence, intellectual and personal guidance, and encouragement of my supervisor Russell Smandych. I must also mention his significant contribution for reading my earliest drafts of proposals and papers. It was in Russell's reflections on these earliest ideas that this project and my thinking took its shape. I must also thank him for his friendship and support in matters not related to this project. In so few words it is impossible to express the sense of gratitude I feel for the many personal, educational, and professional contributions Russell has made to my life. For all of this, and so much more, I am truly and sincerely grateful.

The crucial work of thesis committee members remains largely unheralded. In my case the helpful and insightful responses of Dan Albas and Fred Shore were greatly appreciated. The merits this thesis project contains are in no small part due to their comments and criticisms. The challenges these individuals offered early on provided me with the opportunity to reshape, both my thinking and this thesis project into a substantively and 
theoretically bolder work.

There would be no finished thesis project here before you without the extensive contributions of my life partner Joanne Minaker. I would like to thank her for the endless repetition of reading, editing, and discussions surrounding the content of this work that fell on her shoulders, which she completed with precision and without complaint. I am also indebted to Joanne for her unconditional support of my work, of me, and the myriad of directions our lives have taken us. To this work, and my life, Joanne has given me more than what is possible to communicate. Thank you Joanne, for all that you are.

Finally, I would like to mention the contributions of my parents, Gerry and Tine Hogeveen. Throughout my life, through my hockey "career," through all the pit falls and perils, and now in the pursuit of a Master of Arts degree, their support has been never ending. They have been there for me, caught me when I have fallen, picked me up again, and lent their strength to all that I have done. I want to generally thank them for being who they are and supporting me in all my life pursuits. 


\section{Introduction}

In recent years, following the seminal work of Franz Fanon (1963) and Edward Said (1979), there has been an outpouring of theoretical work concerning Europe's colonial past. This emergent work, which runs under the rubric of "post-colonial" theory, has shifted the manner in which the image of the colonized, their forms of customary law, and mode of life. have been thought about and theorized. Central to the post-colonial mode of inquiry is the assumption that indigenous writers have been excluded from participation in the construction and constitution of their unique cultural development. Until recently, this stream of inquiry was primarily concerned with "literary studies which discerned how the other was constructed and deconstructed through literature and documents" (Pfeifer, 1996: 6). Post colonial analysis constitutes an essential undertaking for researchers hoping to understand colonialism, the governance of the indigenous other, and the cultural inscription inherent to the colonial project. Recently, elements of post-colonial thought have been taken into account in governmentality studies (Scott, 1995; Smandych and Linden, 1996; Smandych and McGillivray, 1998; O'Malley, 1996; Ronsbo, 1997; Ibrahim, 1997). In this work I seek to apply a post-colonial analysis and Foucault's ideas on government to the study of colonial governmentality in the context of the aboriginals in the prairie region of Canada from 1870 1890. 


\section{Terminology}

The problem which confronts me in this thesis project takes as its object the situated political rationalities of colonial governmentality. What I am concerned to bring about is an understanding of the mechanics through which government sought to order and organize a domain constituted around the aboriginal peoples. To avoid confusion and misunderstanding I would like to clarify the conceptual usage of the term aboriginal peoples.

Today, as outlined in the Canadian constitution, the term "Aboriginal" refers to and recognizes the Indian, Inuit and Metis as the "aboriginal peoples". Aboriginal, here in this thesis, refers to those nations and bands who first inhabited the space of land now referred to as Canada. For the purposes of this thesis project I do not consider those techniques of government which governed the lives of the Metis. The reasons for this are two fold. First, the history of the Metis' experience and relations with government, both the Hudson's Bay Company and later the liberal Canadian state, follow quite different patterns from the aboriginals. Secondly, in the period of history in which I have situated this study the Metis people were not considered "aboriginal" but rather "half breeds". This definition, or conceptualization, reflects a belief on the part of the European colonizers that since the Metis people were half "white" they were of better character than the aboriginals (see chapter 3 ).

\section{The Existing Literature}

Before I move onto a detailed analysis of the $19^{\text {th }}$ century government of plains aboriginals, it would prove beneficial for the reader that I situate the approach I have taken 
in relation to the existing historical surveys of the colonial and liberal government of aboriginals. In this regard, John Tobias' (1976) article, "Protection, Civilization, Assimilation" has been the model for historians who have delineated the policies of government. The tale of government intervention into the lives of the aboriginals in Canada finds its origin. according to Tobias, in the years which predate confederation. "Protection of the Indian was the first principle of imperial Indian policy having its roots in the eighteenth-century European struggle for empire in North America" (Tobias. 1976: 127). The British colonial government adopted the policy of protecting the indigenous people in order to secure their traditional lands from encroachment by settlers and to paternally guard them from fraudulent trading practices which were characteristic of much of the aboriginal/Eurocolonial economic dealings (Tobias, 1983). In subsequent years a boundary line was drawn which divided the aboriginal lands from those of the colonists. The Euro-colonial settlers were not to intrude into this space for any reason, except where the boundary was altered by treaties maae between the Crown and the aboriginals (Upton, 1973). These policies, adopted by the British in 1745-61, were enshrined in law with their incorporation in the Royal Proclamation of 1763 (Boldt, 1993). The policy of protection, according to Tobias (1976). was the end pursued by government until confederation when the end shifted to the "assimilation" of the aboriginal peoples.

The course taken by Tobias (1976), when attending to government policy to manage aboriginal peoples has been emulated by others who have traced the evolution of Indian policy from its "origin" to its present configuration. Articles such as Upton's (1973) "The Origins of Canadian Indian Policy," Surtees' (1969) "The Development of an Indian Reserve 
Policy in Canada." Milloy's (1986) "The early Indian Acts: Developmental Strategy and Constitutional Change," and Hoxie's (1984) book, A Final Promise: The Campaign to Assimilate the Indians are such examples. While these are all important works for understanding the governance of aboriginals, the identification of epistemological breaks and ruptures that "valorize" the distinctiveness of epochs, in the end, can only suppress their continuity across time. The level of generality necessary in taking on long periods of history blurs the more immediate social, cultural, and historical changes, alterations, ruptures, and the sedimented nature of policy and practices of government. Too, in taking on the longe duree of history, the regional differences of contact, resistance, and cultural heritage among and between aboriginal nations is dismissed for being trivial in relation to the overall policy of government. The authors of such "sequenced" constructions of the historical field of government practices offer an oversimplified arrangement of heterogeneous events and processes which are complex, continuous, ever changing, and being replaced (Garland, 1985).

To address the overgeneralized quality of the literature, historians have recently approached their analyses of governing aboriginals by contemplating single practices of government and the agents who were instrumental in shaping these policies (Jackson and Galli, 1977; Larmour, 1980; Titley, 1986). Jim Miller's (1996a) detailed analysis of the schooling of aboriginal children is an illustration. Others have taken on different practices of government, such as agriculture (Carter, 1990; 1983; Dyck, 1986; MacQuillan, 1980) the ration system (Tobias, 1983; Satzewich, 1997), and the practice $c \cdot f$ administering passes for aboriginals to leave the reserves (Baron, 1988; Cadzow, 1985). Still other historians have 
considered single cause explanations to discern the interactions between government and aboriginal (Dyck, 1991).

In their combination, these studies expand the knowledge pertaining to the government of aboriginal peoples. In isolation. however, they yield little insight. Rather, the practices. policies, conditions of life, the impact of the Hudson's Bay Company (HBC), all had a sculpting influence on the mode of aboriginal life. To consider one practice. one condition of life, or one agent of government as the reason why the aboriginals resisted, accommodated, or rejected government intrusions into their lives will not lead to a fuller understanding of the government programme.

It is in relation to these methodological concerns that I have situated this thesis project. It is an attempt to address a number of methodological and theoretical issues which have converged upon historians of "post-colonial" regimes of government. While I am sympathetic throughout to the discourse of the writers cited above, and the post-colonial concern for the violent literary construction of the indigenous "other", I have situated the government of aboriginals within a divergent theoretical framework. I do so by considering the relevance of Michel Foucault's later writings to an understanding of the governance of the aboriginals of the Canadian Plains.

\section{Foucault and Governmentality}

Sociological criticisms of Foucault's work have often centred around two seemingly damaging charges. The first concerns his illustration of the process by which individuals. who become caught up in the network of discipline, are rendered into "docile bodies" (Foucault, 1977). In his later work on governmentality, and in his trilogy on The History of 
Sexuality, Foucault seems to have addressed the first of these criticisms. In this later work, Foucault (1983) stresses the importance of a free subject as the material that government seeks to shape. In this conception of government the individual is constructed as an active subject who is capable of choice among a field of available actions. It is choice that government seeks to structure in relation to a desired objective.

The second reproach has been offered by structuralist commentators who have dismissed Foucault's work for its lack of attention to the state by pointing to this often quoted statement: "it is necessary to cut off the king's head" (Foucault, 1980). This statement. however, does not accurately portray his later work concerning governmentality. A more accurate insight is suggested when he states that "it is certain in contemporary societies the state is not simply one of the forms or specific situations of the exercise of power - even if it is the most important - but in a certain way all other forms of power relations must refer to it" (Foucault, 1983: 224). Here Foucault situates state power as central in organizing the field of dispersed powers in liberal political regimes while, at the same time, he denies the role of the state as a necessary and fundamental institution in the governing of populations. While sociology is hesitant to fully embrace Foucault's work, the valuable insights contained in his studies add a new dimension to this discipline.

\section{Governmentality and Sociology}

In recent years there has been an impressive scholarship which has extended Foucault's work on governmentality to many diverse fields of inquiry, including: new forms of governance (O'Malley, 1996b; Pratt, 1996); accounting practices as techniques of government (Rose and Miller, 1992; Miller and Rose, 1990); criminal justice processes 
(Hunt and Wickham, 1994; Pavlich, 1996a, 1996b; Stenson, 1993; Garland, 1996); the use of accumulated statistics to govern populations (Hacking, 1986; 1990; 1991; Rose, 1995); and governing populations through neo-liberal techniques (cf. Barry, Osbourne, and Rose. 1996). However, in this extensive literature there have been few attempts to situate Foucault's position alongside contemporary sociology. Some authors - most notably Rose and Miller (1992) and Gordon (1991) - have stressed the incompatibility of this work with sociology, while others (Garland, 1997; Sharp, 1995; Lacombe, 1993; Dean. 1994a, 1991) have underscored, not only the compatibility of Foucault with sociological inquiry, but also its importance, by locating it alongside influential thinkers, such as, Anthony Giddens, Norbert Elias, Max Weber, Emile Durkheim and Erving Goffman. There is still a stream of thought within sociology that views Foucauit's anti-totalising pluralism as irreconcilable within this discipline. Perhaps it is this observation that provides Foucault's work its relevance for sociology.

In Foucault's writings one would have difficulty in shackling his analysis within the contemporary discipline of sociology, and would have an even harder task to find where he explicitly makes reference to colonial techniques of government. What is it about Foucault's work which renders it valuable to sociology? One of the strengths of Foucault's work is the fact that his writings included and intruded into many different subjects - sexuality, prisons, madness, medicine - which have blurred the hollowed walls separating the disciplines. In following Foucault's lead social scientists have now transgressed these confines and incorporated many relevant ideas and methods across disciplines from geography, to comparative literature, to sociology. When pigeon holed within the discipline of sociology. 
or any other for that matter, analysis is obstructed by the discourse and margins of the school of thought. Rather, as Stenson (1996) has argued, this "cross fertilization" of ideas is what provides governmentality studies with their critical edge. A second strength of Foucault's work derives from the first, and relates to the content of his later writings (Bell, 1993). In these writings one finds the common intersection between sociology, aboriginal people, and government. Even though Foucault did not make explicit mention of "post-colonial" governmentality, and the association between the two are not readily apparent. the antitotalising stance of the concepts derived from his work endorses this connection. Political rationalities, practices, techniques, and knowledge, are all concepts which Foucault developed in relation to European governmentality, but also - as will be seen in the following chapters - highlight the $19^{\text {th }}$ century Canadian programme of intruding into, and shaping, the mode of life of the plains' aboriginals. This revised theorizing about Canada's colonial past will enable me to excavate an original understanding of the complex relationship between and among regimes of government, strategies to facilitate their ends, and their relations with the aboriginals' mode of life.

\section{Rationality of Government: Foucault's Genealogy of the Modern State}

In Foucault's (1991; 1988a; 1988b: 1988c; 1983; 1981a; 1981b) analysis of governmentality, he adopted a unique approach to the understanding of government. Government refers to the ways in which the state's dispersed administrative organization manages a free and active population through practices which seek to structure their choice of actions in relation to a desired end. In order to understand the complex of practices disposed to govern contemporary populations, Foucault endeavoured to discern how, under 
successive regimes of government, definite ways of managing populations became linked up with the ends pursued by the specific form of state organization. Foucault analyzed three "regimes" of government which can be distinguished by, what he refers to as, their rationality. It refers to a concept that addresses a manner of thinking about government that is embodied in a distirct set of objectives (ends), and practices (means) disposed to realize them, which is situated within a material reality that is the target of government (domain). An important distinction to make is that rationality is differentiated by the regime of governmental organization it is situated in. In order to further elaborate these last statements I will now consider the genealogy proposed by Foucault of the modern liberal rationality of government.

The way in which states govern, both in contemporary society and historically, is organized around a series of rationalities, each of which is distinctive in terms of the ends it pursues, the means disposed to reach it, and the domain which is governed. Foucault's genealogy of the modern regime of government traces its emergence from "pastoral" rationality to the current liberal one. While Foucault does not distress to specify the origins of the modern regime of government he is concerned with the transformations and continuities between successive rationalities which have conditioned the present configuration.

Foucault undertakes his genealogy by commencing his analysis with a form of government rationality referred to as pastoral power. The term pastorship is a powerful metaphor for a type of political rationality that invokes images of pastors or ministers who are "Shepards of men" that guide and shape a group of followers in relation to truth which 
is embodied in the word of God. One of the distinct intricacies of this form of political rationality concerns the domain it sets out to govern. The Shepard governs over a flock as opposed to the sovereign concern for territorial space. To the Shepard, land is of minor importance in relation to the spiritual well-being of their flock.

The essential component of pastoral power is that it governs in relation to truth. Truth, is not concerned with the manifestations of contents to which it is necessary to attribute the values of right and wrong. It is the presentation of a discursive knowledge imbedded through and through with practices of government for its realization in the lives of individuals. Truth concerns much more than true and false, it relates to the practices which facilitate its intrusion into the lives of the flock. Consider for example the instrument of the pastor: the Bible. The Bible contains certain discursive projections concerning the ways in which individuals should conduct their secular lives while at the same time permitting the individual to prepare themselves for their spiritual life. By intruding this truth into the lives of the flock the pastor disposes practices of government. In relation to this form of government the most essential practice of the pastor is surveillance and knowledge concerning the population. By having knowledge of the spiritual state of each and all individuals in the flock the pastor is then qualified to effectively govern this domain.

Pastoral power is a formulation of political rationality which finds its roots in Hebrew and Christian spirituality. The form of government practices invested in the pastor consists of the formulation of knowledge concerning the spiritual state of a flock who are capable of choice among available actions. It is the responsibility of the pastor, through knowledge, to structure this choice in the direction of the truth contained in the discourse of the Bible. What 
becomes of importance here is the introduction of an individual who is free and makes active choices about the direction taken by their lives. It is this material - the freedom of the individual - that is governed by the pastor. The soul of the individual is not naturally predisposed to accept the truth embodied in the Bible, rather, the individual has freedom of choice. It is the charge of the pastor to structure this choice through practices in the direction of the spiritual salvation of each and all members of their flock. In contrast to the government of souls characterized by the pastoral rationality of government, the second form of rationality discussed by Foucault problematizes the security of its own existence. For the first time, with the emergence of the reason of state, government reflects on the secular art of govemment. Foucault (1988c) proposes that this shift in the rationality of government was the consequence of two interrelated processes, the Reformation and the end of Feudal relations. First. the Reformation called into question the relations of pastorship and salvation; and secondly, the crisis in Feudalism and the long devolution of authority shifts the responsibility of rule from the sovereign lord to the territorial administrative states. This regime of government formed its rationality in opposition to the model of God imposing His will on the people and shifted its concerns to the security of itself in relation to its adversaries. The end governed by the state was denoted in terms of its relational durability. In relation to the end pursued by the reason of state, "police," a corresponding rationality, emerged alongside it.

The rationality of the police conducted its form of government on the premise that there could never be enough government. Police constitute a science of endless control which tends to the weaknesses of the social order through the accumulation of knowledge and 
endless intervention. For the purposes of the state's military machine, the rationality of the Police concerns the realization that the population should be as numerous and healthy as possible. To this end, an arrangement of surveillance is disposed in the form of statistics. Ian Hacking $(1986 ; 1990 ; 1991)$ has convincingly shown that in order to render the profile of the population knowabie and measurable, the state required an "avalanche of printed numbers" in the form of statistics. It follows that the utopian vision of police is like the flawless working of the clock, with its minutiae of details all installed and carefully scrutinized (through statistics). If the clock (the social world) should some how fail, with the watchmakers tools it can be modified. From this point forward, knowledge of the secular strength of the state, the use of informational techniques, and the development of practices for the security of the state, has comprised essential components of the modern rationality of government.

The rationalities discussed above - police, reason of state, pastoral - and the practices disposed by each to shape a domain of government form the requisite fragments of the modern liberal rationality. In his lectures, Foucault was striving to reconcile a fundamental question: how does the modern liberal rationality of government manage populations? In so doing, Foucault looked to political rationalities of the past. In the late eighteenth century criticisms of the despotic disposition of the reason of state and the tyranny of the police resulted in providing the necessary conditions for the shift to a liberal rationality of government. In the western world the ideals of liberalism have always been associated with "wise restraint," "laissez-faire," and non-intrusion into the lives of individuals. It concerns a manner of intruding into the lives of populations while still maintaining a respect for 
individual liberty. It is premised on the idea that too much government impinges upon the liberty of the population. With the liberal rationality of government the domain to be governed shifts from the security of the state in relation to the risks posed by enemies, to the promotion of prosperity and happiness of the population. Knowledge is no longer accumulated for the purposes of strengthening the state, but to promote the well being of the population. There is a shift in the ends/means relationship. The population is no longer to be manipulated as the means to the security of the state but are considered to be ends in themselves.

While I am sympathetic to Foucault's work on governmentality as comprising an essential tool for discerning the $19^{\text {th }}$ century governance of the plain's aboriginals I am also, in some ways, critical. What is problematic is the attention Foucault paid to the discursive constitution of these regimes. In his search to problematize the contemporary form of liberal government he deliberated over, not the practical working out of the rationality of government, but rather the discourse contained in the writings of classical thinkers - the stoics, the sixteenth century church, the police, and many of the more modern thinkers on the subject of "right" government (Rousseau, LaPierre, Adam Smith). The problem is that Foucault, and the classical thinkers, developed their discourse on blank pages far removed from the textured reality of the colonial world. While the birth place of liberalism was constituted by a relatively homogeneous culture of native-born Europeans, the colonial setting (Canada, South Africa, Ireland, Australia), where the liberal activity of government was given ascendency constituted an environment of which neither classical thinkers, nor Foucault, were aware. Given this fact, should we brush off the insights offered by Foucault 
for being irrelevant to the study of colonial government? Hardly. While Foucault's analysis does not discuss the complexities encountered by government in the colonial world, his antitotalising discernment of governmentality proves valuable in this regard.

Political rationalities, given the discussion of the genealogy of the modern state, may be defined as the organization of practices as a means to sketch the objects of government members of a flock, the strength of the state, or a population - as a domain which renders it governable. While the ideology of liberalism emphasizes freedom and liberty for all, the cold reality of the colonial world portrays a quite different landscape. It is exclusionary. It denies liberty to some only to extend it to others. When considering a study of colonial governmentality the central question becomes: how is it possible to discern the rationality of governmen invented and disposed to govern the indigenous people. In what follows. I argue and demonstrate the need to understand colonial governmentality, on the one hand, as sharing liberal characteristics, while on the other, quite openly displaying anti-liberal tendencies. Unlike Europe, where the social and cultural disposition of the people did not require as many intrusions upon liberty, the aboriginal people of the Canadian plains were met at all life's choices with practices of government which endeavoured to structure their actions in relation to a prescribed mode of life. It is by grounding our analyses in the domain constituted to govern the aboriginals, the practices intrinsically generated to shape their actions, the activities of agents of government, and the ends they pursued, that it is possible to discern a colonial rationality of government as it relates to the $19^{\text {th }}$ century governance of aboriginals in Canada.

An analysis of a colonial rationality of government must not only be concerned with 
the rationality of governance, but also, must take into account a series of influences which conditioned its configuration. In coming to terms with the $19^{\text {th }}$ century liberal rationality of government I will observe the prior rationality of Hudson's Bay Company government, its effects on the mode of life of the aboriginals, on the subsistence base, and the effects of alcohol and disease on the aboriginals. Another important condition which influenced the way in which aboriginals are governed is freedom. Here I am not concerned with the unrestrained choice among actions, but rather that a choice does in fact exist. Freedom of choice among actions is the prerequisite of government. Without choice there would not be the need to govern. The aboriginal mode of life, in $19^{\text {th }}$ century Canada, was influenced by the conditions of life which confronted them, but they, nor the practices of government, in no way determined actions. Rather, aboriginal choice among actions was conditioned by the context of subsistence on the prairies, and the practices of government which endeavoured to structure them in relation to a prescribed mode of life.

\section{Organization}

In relation to what has already been stated, there are a number of intersecting methodological, substantive, and theoretical issues which I bring together in the pages that follow. These are debates which concern the study of post-colonial government generally, and specifically, the $19^{\text {th }}$ century governance of the aboriginals of the Canadian plains. It is my larger purpose here to provide the reader with an understanding of how the Canadian administrative state sought to govern the lives of the aboriginals in the late $19^{\text {th }}$ century. To this end, it is first necessary to come to an understanding of what form of government the liberal Canadian state replaced, and its effects on the aboriginals. This is the purpose of the 
first two chapters. They construct and situate the conditions of life of the aboriginals prior to confederation and the antecedent practice disposed to govern them within this rationality of government. The first chapter discusses the rationality of government of the HBC and demonstrates now the aboriginals took an active role in shaping the nature of this regime of government. In the second. I address how law and missionary practices began to intrude into the lives of the aboriginals. In the last chapters I address the $19^{\text {th }}$ century liberal rationality of the Canadian state. While this constitutes a definite break from the rationality of a fur trading Company, I endeavour to show the continuities between them, and how the conditions of existence which resulted from the prior mentality had consequences for the aboriginals and the content of liberal government. The third chapter addresses how the aboriginals were constituted as a domain of government through legal discourse and spatial division. In the following two chapters I discuss and trace the emergence of the practices of government which were disposed to structure the actions of the aboriginals in the direction of amalgamation with prescribed values. The final two chapters address the use of knowledge first, to give the practices of government their effect, and second, to provide those who are "at a distance" an angle of sight into the domain of government. 


\section{Chapter One}

\section{Liberalism, The Canadian State, and Govermentality: the Search for Principles}

In Foucault's (1991; 1988a; 1988b; 1988c; 1983; 1981a; 1981b) analysis of governmentality, scattered over few lectures and essays, he adopts a unique approach to the analysis of liberalism. While liberalism has most often been referred to as a political ideology which accentuates the optimization of individual liberty, and its protection from intrusion by the state, those who have followed Foucault's work (Hindess, 1997; Dean, 1996a: 1996b: 1994; Pavlich, 1994a; Rose; 1993; Rose and Miller. 1992) have rejected the normative discourse of liberalism and opted for a more critical interpretation of its activity of rule. Liberalism as an activity of rule, as often cited by classical and contemporary thinkers, reflects the natural order of things. But, we may ask, who participates in the privileges of this natural order? In order to discern the nature of aboriginal participation in this order. I will rely on two methodological principles derived from the governmentality literature. First. I will endeavour to refrain from articulating this study with the normative discourse of liberalism. And, secondly, I will try to understand the activity of $19^{\text {h }}$ century liberal rule in Canada and its rationality by considering not its ideology, but rather, the practices it intrinsically constructed to shape the domain of government whose parameters were the mode of life of the aboriginals. Before we come to understand the practical activity of 
government in $19^{\text {th }}$ century Canada, and its work upon the mode of life of the aboriginal people of the prairies, it is beneficial that we first situate the Canadian version of liberalism in terms of its development, extension. and proliferation.

One of the most evident circumstances to confront the student in search of a distinctly Canadian scholarship of liberalism is our comparative lack of literature. The individual who is searching to come to terms with the ideological foundation of this intrinsic governmental rationality must be content with, and satisfy their interrogation with, a collection of extracts from speeches and newspaper articles (cf. Forbes, 1985). In the debate which has gone on around the Western world concerning the fundamental values of freedom, of justice, and of what is essential concerning the human spirit, Canadian thinkers have taken little part (Underhill, 1960). In the last one hundred years Canadians have made great strides toward economic maturity and political autonomy, yet little contribution has been made to the discussion of the ideological issues which underlie this development. "Where are the classics in our political literature which embody our Canadian version of liberalism?" asks a leading Canadian critic (Underhill, 1960). But, if there is a lack of Canadian scholarship concerning the underlyıng principles of liberal government, how did Canada arrive at the present foundation of governmentality? The answer lies in the unique developmental history of Canadian politics and society. The underlying principle for unfolding the ideological foundation of $19^{\text {th }}$ century Canadian liberalism is that it is derivative. It is imported. It is colonial.

The stream of ideas which contributed to the formation of $19^{\text {th }}$ century Canadian liberalism was derived from the teachings and discourse of the English philosophers. 
Canadian liberals were always happiest and most effective when "applying to Canadian conditions the traditions of English constitutional development" (Underhill, 1960:132). These ideas provided the foundation upon which our version of liberalism emerged. However, it would not be sufficient to state that Canadian liberalism was merely an extension of its British heritage. Rather, it was shaped by two influences, one social and the other economic. On the one hand, since the 1830 's nativist liberal ideas have produced a unique twist to the British version through the distinctive agrarian mode of frontier life. This economic condition gave Canadian liberalism its conservative appearance. On the other hand, there was a social condition of influence. The first settlements in Upper Canada were constituted by United Empire Loyalists who had been driven out of the 13 colonies following the American revolution. House burnings, confiscation of belongings, suffering, these were what the early Canadians were reminded of when they thought of America, and their version of democracy. In 1812, the Americans launched a war of conquest against Upper Canada, thus making certain that those who looked to America for political inspiration had little influence on Canadian sentiment (Kelley, 1969). While Canada inherited the British liberal system of state and ideology, it was shaped by social and economic conditions of life intrinsic to the Canadian context (Smandych, 1995; Wise, 1974; Wise, 1965).

The founders of Canada were content to have a constitution similar in principle to that of England. They, nor any Canadian liberal thinkers, thought it desirable to spell out, to set in stone, the ideology of this foundation of government. Rather, the founders of this country have been more concerned with practical philosophy than their ideological antecedents. John A. MacDonald, the first Prime Minister of Canada, proclaimed the spirit 
of the nation, when he stated that he found it unjustified to "waste the time of the legislature and money of the people in fruitless discussions on abstract and theoretical questions of government." (Cited in Campbell, 1996). MacDonald and the initial members who made up the Canadian House of Commons were more concerned with the intrinsic exigencies of the country, such as its expansion and communication within it. They had other ends to meet and correct.

The Canadian liberal rationality of government was influenced by the ideology of the English stream, which was shaped by economic and social issues. However, while this made up the foundation of the practical activity of government, we are left to question, how did the Canadian state respond, take action against, and correct the problems it faced? Will ideology explain, and illuminate this? Hardly. In order to evaluate and understand the unique version of Canadian liberalism it is essential that we understand, and come to terms with the intrinsic problems and exigencies which it sought to correct and govern. Instead of viewing Canadian liberalism as an ideology, I argue that liberalism must be seen as the power and capacity of the state to act on and govern actions. In this way liberalism refers, not to ideology, nor to a normative framework, but rather to a political rationality of government which functions within a realm of exigencies and intrinsic problems encountered by the state who claims to embody its principles. What is left over from the interaction between political rationality and the intrinsic problems encountered by the state, is often quite different from the premises it is based on. While liberal ideological principles are the foundation upon which government is erected, it is only the backdrop against which the state governs its conditions.

In light of the above discussion we are able to envision the possibility of a 
Foucaultian governmentality approach concerning the governance of the plains aboriginal peoples. The first step in this process is to understand that the normative framework of liberalism is insufficient when discerning the practices of government which affected the lives of the aboriginal people. Instead we must look to its rationality. That is, the means through which it sought to realize the ends intrinsic to it. And secondly, that the liberal rationality of government cannot be deduced a priori, but must be viewed from, and understood in, the context of the domain it sets out to govern. To illuminate the liberal governmentality of the domain constructed around the parameters of the aboriginal mode of life, we must first address and understand the intrinsic exigencies which the Dominion of Canada was confronted with upon the cessation of land from the Hudson's Bay Company $(\mathrm{HBC})$. In order to do so, we must address on the one hand, the rationality of government by the HBC, and on the other, the aboriginal culture, and the HBC's effects on it.

\section{HBC rationality and the Mode of Life of the Aboriginal Peoples}

The conditions of life of the aboriginal peoples at the time of the cessation of land to the Dominion of Canada. and its response to these conditions, have been well articulated in the existing literature. However, what conditioned this situation? What gave the practices of government their permanence? The conditions of life which confronted the aboriginal peoples and the Canadian state in 1869-70 were not born out of abstract theoretical principles, but problematized out of the contextual reality of the Canadian west. To understand the practices disposed by the Dominion to shape the domain constituted around the aboriginal mode of life, and to come to terms with the reaction of the aboriginal peoples, it becomes essential to recount the emergence of these problems. Much too often historians 
have neglected the emergence of the conditions of life on the prairies which were the result of, and conditioned by, the rationality of the HBC. Before I move on to consider the treaties, the programme of government, its content, and resistance by the aboriginal people. we must first have a sound knowledge of the emergence of the problems which were responded to by the liberal rationality of the Canadian state, and the conditions of life in which a prescribed mode of life was intruded. In the remainder of this chapter and the next. I will be dealing with the relations between the political rationality of the $\mathrm{HBC}$ and the mode of life of the indigenous people of the prairies prior to 1870 .

In 1670 a Royal Charter was granted by the English Monarchy that bestowed to a fur trading company $(\mathrm{HBC})$ the exclusive right to extract the produce from, and govern, the area which now comprises most of what is now Western Canada. then referred to as Rupert's Land (Smandych and Sacca, 1996; Smandych and Linden, 1995). In the years that would follow, the $\mathrm{HBC}$ would initiate an intrinsic rationality of government which responded to the unique exigencies of the fur trade. The HBC sought to articulate a political rationality through which they would govern, not only the space of Rupert's Land, but a domain constructed around the parameters of the fur trade. The domain of the tur trade was the end governed by the Company. This end is circular. It resides in the security of the HBC itself. The rationality of government which embodied the HBC was one that sought, above all else, the security of its existence in relation to competition, settlement, and the harsh conditions of life in the Canadian North-West. These intrinsic concerns mediated against the accumulation of furs, and ultimately, profits. These problems were governed by the Company. However, to secure its interests, the $\mathrm{HBC}$ relied on the aboriginal mode of life as 
a means to this end. In order to be productive, the aboriginal mode of life, as the (aboriginal people were the) proletariat of the fur trade, had to be sheltered from alien intrusions in the form of missionaries and other philanthropists whose intent it was to shape their existence in ways which were contradictory to the ends of the Company. Alternatively, to produce more efficient hunters this mode of life had to be intruded upon by the introduction of European commodities such as guns and ammunition. In relation to the aboriginal mode of life. the rationality of government initiated by the $\mathrm{HBC}$ had to strike a careful balance between intrusion and non-intrusion.

In this we are able to envision the beginnings of the intrinsic $\mathrm{HBC}$ rationality of government. This rationality sought to shape and secure the knowledge of the Indigenous people, not for reasons residing in the population, but rather, as a product and function of its rationality. The ends of the company are not so much concerned with the aboriginal population - its present functioning, its troubles, and conditions of life - but only that it exists and functions in a "right" manner. The aboriginal people were a means to a desired end. What results from a mentality which seeks only the existence and preservation of itself is a domain of government whose parameters encompass only the amelioration of its own intrinsic probiems.

At the centre of what I have been discussing is the form of political rationality that the Company developed during their rule to govern a domain constituted around their own interests. The territorial space of Rupert's Land was governed according to rational principles which are intrinsic to the $\mathrm{HBC}$ and cannot be derived from abstract theoretical ideology. Government in this context, not only concerns itself with the maintenance of a territorial 
space, but also includes the mode of life of the aboriginal peoples as a means to realize the accumulation of profits. But the aboriginal peoples are more than a simple means to an end, they comprise an independent reality that has its own laws and mechanisms of reaction. In the next sections we will discuss the intermingling of this rationality with the aboriginal mode of life.

\section{Aboriginal mode of Life and Intrusions by the HBC}

When the aboriginal people entered into Treaty with the Dominion of Canada, they did so in the shadow of more than 200 years of cultural, political, and social infection and influence. Their mode of life was shaped and conditioned by the changing nature of the fur trade. These people comprised a culture of courage, determination, and enterprise which conditioned, or at least had a large part to play in the profit generating activity of the HBC. They were reflexive in adapting their culture to the exigencies of a niche in the fur trade which allowed them to exercise influence over their enemies and enjoy a life of profit (by selling at a surplus the trade items acquired). Here we find a very reflexive people who were able to shape their lives, and carve out a niche in the fur trade which they could call their own.

Some historians have started from the premise that the fur trade decimated the culture of the aboriginals. From this perspective the aboriginals were doomed prior to the emergence of the liberal Canadian government. This, in the end, proves limiting. It neglects many of the roles aboriginals played in the fur trade. It neglects the agency and subjectivity of the aboriginal people. Rather than starting from a perspective of a coercive practice of domination disposed by the HBC - which dooms the researcher from the start, since it does 
not allow them to expel this myth - I will loosen the grip of domination and discuss the elements of governance, choice, and subjectivity. From this perspective, I will be able to open up for analysis a whole range of factors which hitherto would have remained hidden in relation to that which envisions the aboriginal people as dominated by European values. The lives of the aboriginal people were not dominated, nor were they solely dependent on the fur trade (Rich, 1991), but rather their mode of life, was reflexively shaped in relation to the conditions it offered.

In what follows I will trace the lines of descent concerning how the aboriginal peoples mode of life was shaped by the intrusion of a fur trade domain of government. However, given the complexity of the contextual situation, I will not generalize the findings to the totality of the aboriginals who inhabited the space of the prairies, but confine them to the particular nations addressed.

\section{Traditional Political and Social Organization}

Prior to contact with Europeans, the aboriginal peoples of the prairies inhabited a complex social world comprising many behavioural contexts, which, when all were functioning as a social order, contributed to the security of the people in relation to the conditions of life encountered in the rugged wilderness of the northern plains. This contextual situation is imbedded in a philosophy of life which stressed the equality of all creatures and beings which share existence in the space inhabited by the aboriginal peoples. In the aboriginal mode of life all that which concerns their existence is enclosed in a space of knowledge consisting of a shared philosophy. That is, in aboriginal society all aspects of sociai, cultural economic and political existence are connected in what Sioui (1992) refers 
to as the "shared circle of life." Smandych and Lee (1995) have stated that the "function of spirituality in Amerindian life was all encompassing and provided the foundation for understanding."

Irving Hallowell (1965) an ethnologist who studied the Ojibway of Berens River in the early part of this century, commented that "one of the firmest links with the past is the persistence of Ojibway speech." According to Black (1967), one of the basic features of the Ojibway language, which is directly related to an understanding of the aboriginal philosophy of life, is that a grammatical distinction between animate and inanimate objects is not realized. That is, inanimate objects such as the sun, moon, and wind, are not distinguished in kind from animate entities. In addition, these beings are reified as inhabiting the same space of knowledge as the aboriginal peoples.

In addition to the reified fauna coexisting with the aboriginal peoples, there is also the existence of exceptionally "great" and "big" (Frogs, Turtles, Snakes) spiritual entities which are said to exist, but are rarely encountered and invoke exceptional fear. Hallowell (1965) relates a story of four Ojibway men who were:

Crossing Lake Winnipeg in a canoe and landed on an island where they expected to spend the night, one of these men discovered what he interpreted as tracks of a Great Frog. His companions agreed with him. All of these Indians became so fearful that, although night was approaching and they had a considerable distance to paddle, they decided to leave the island at once (p. 61).

In addition to the "great" and "big" class, there exists another class of animate beings designated as the Thunder Birds. As opposed to the Great Frogs they are encountered and known to all through the sounds and sights which they produce during the season when it 
rains. The sound which rumbles through the sky is due to their flapping wings, while the light which flashes during this time is due to their blinking eyes. These birds are heard and seen by the aboriginals from late in the spring season until just before the snow blankets the earth.

However, in addition to these entities, all species of wild animals and plants are believed to be under the control of "bosses" or "owners" (Hallowell, 1965). It was understood by the aboriginal peoples that only by permission of the "owners" that individual animals could be killed. Even though the aboriginal peoples possessed an expert knowledge of the natural world which was incorporated into their philosophy of life - by direct observation of the habitual movements of the animals of the forest and plains - and the skills necessary to down an animate being, it was not the killing of animals which constituted a valuable hunter. What made a good hunter was cognizance and respect of the "owners" of the downed animate being, which, if not properly treated, the owner would retaliate against the hunter by making his kind impossible for the hunter to overtake (Black, 1967). If one is to be a successtul hunter and provider, they are to fulfill their obligations to the "owners" of the animate being.

To the aboriginal peoples the "owners" of the animate beings to which one pays respect, the "great" and "big" animals of which one avoids, and the Thunder Birds which they hear in the sky are as much a part of the social, economic, spiritual, and political world as the concrete physical animals in the forests and on the plains. There are no distinctions made between the physical and metaphysical, but are rather interrelated in the philosophy of life of, or space of knowledge of the aboriginal peoples who came in contact with the HBC and 
the domain of the fur trade.

The philosophy of life of the aboriginal peoples was not homogenous, but was contingent upon their spatial location, - prairies, mountains, or forests - by their mode of procuring existence and their particular nation, however, the point of the preceding was to evidence the strong religious spirituality of the aboriginal people which was intimately linked to their social, economic, and political mode of existence and the basis of their society. It is into this context that the mentality of the fur trade intruded and later what the missionary sought to shape.

\section{Intrusions of the Rationality of the $\mathrm{HBC}$ and the Cree: fur trade entrepreneurs}

Throughout the more than 200 years of the fur trade, the Cree culture of the western plains went through a series of shifts resulting from the intrusion of the fur trade into their mode of life. The conditions of life which resulted had important implications for the Dominion of Canada upon the cessation of land from the HBC. In the beginning years of the $17^{\text {th }}$ century the Cree first experienced the introduction of European goods that comprised a motley assortment of dull knives, soiled cloth, and torn nets worn thin by extensive use (Milloy, 1990). In the last half of the century, commencing with the western drive of the fur trade and the opening of the Bayside posts of the HBC, the lives of the Cree would undergo a dramatic shift. How long prior to this had the Cree been introduced to European trade goods is unknown, nevertheless, their emergence on the prairies would have critical implications for the totality of the aboriginal people who occupied this space.

The introduction of European fur trading posts on Hudson Bay witnessed the emergence of a network of aboriginal persons who functioned as middle traders. The middle 
traders were responsible for extending the trade westward by taking European goods inland, and extracting furs for trade with the HBC. The Cree and Assiniboine nations traded with the HBC for various goods. One of the most important goods traded was the gun. By having access to this commodity they were able to exert influence over those who did not. and effectively shape the economic and political structure between the aboriginal nations of the prairies. In their role as middle traders, and with access to guns and ammunition, the Cree etched out a monopoly in the trade in furs. Through access to superior instruments of war the Cree were also able to control the approach to the posts thus ensuring that they were the ones who would trade with Company. In this configuration of trade, the middle traders greatly influenced and structured: first, the amount of furs to be sold to European and Canadian traders; second, their own conditions of life; and thirdly, and perhaps what is most important. the strength of their enemies.

This type of economic organization was not in keeping with the rationality of the Company. In order to extend their influence, the Company, in 1690-1, sent Henry Kelsey to the prairies to encourage other aboriginal nations to come to the Bay and trade (Milloy, 1990). But, as he penetrated further and further westward he found that the aboriginal nations were afraid to do so since the Cree, because of their access and monopoly of the gun, were jealously guarding their role as middle traders. In 1754 Anthony Henday stumbled upon the entrepreneurial spirit of the Cree (and Assiniboine) which extended throughout the continent. But to simply state that the Cree guarded their monopoly by blocking access to Hudson's Bay would deny the manner in which they maximized the benefits of their strategic geographic location. They were more than a military force which put blockades up to deter other nations 
from trading, more than suppliers of arms to their allies, but rather, were shrewd traders who benefited at both ends of the fur trade. That is not to say that the Cree were in some way tied to either the British or French traders, but rather used and manipulated this competition for trade to receive the greatest value for their labour (Rich, 1991). If they felt that the dealing was unfair, or the price of goods was excessive they would threaten to take their business to the competition (Isham, 1749). Once the Cree obtained the desired value for their goods. they would in turn trade these goods to other aboriginal nations who did not have access to the trade routes (Graham, 1969).

While this discussion may lead an individual to assume that the dynamics of the fur trade comprised a simple intrusion of European economic principles into the lives of the Cree, this is not so. The Cree actively shaped their mode of life around the trade in furs, but did not readily accept the European concept of property and the wanton accumulation of such. Rather. they shaped their lives to respond to fur trade demands in a manner which was intrinsic to their mode of life. Trade goods allowed them to structure the complex social, political. and economic world around them.

The early years of the fur trade shaped the traditional culture of the aboriginal peoples. The introduction and diffusion of European cultural artifacts, such as firearms, metal hatchets, and metal for arrows effectively altered political relations amongst the nations by putting the balance of power in the hands of those who controlled, or had access to, these commodities. Through their alliance with the Cree (Milloy, 1990) the Blackfoot nation was able to contrul a greater range of territory and access to subsistence which was previously unattainable. As well, those nations who were driven out of their traditional space had to 
fend for themselves, often in territories which they had not been accustomed to. Cameahwait, a leader of the Shishoni (or snake) nation testifies to this unbalancing effect of European trade goods:

If we had guns, instead of hiding ourselves in the mountains and living like bears on roots and berries we would then go down and live in the buffalo country in spite of our enemies whom we never fear when we meet on equal terms (Lewis and Clark. n.d.: 120).

Access to the gun and ammunition conditioned a realignment of political, economic and social interests of the nation in the western portions of North America.

\section{Shift in the Rationality of the Fur Trade - Intrinsic Principles of Government}

Throughout this early period of government, the HBC perpetually sought means to maximize their profits. They attempted to encourage aboriginals from the interior to come to trade with them at Hudson's Bay, as well as, using a series of other practices to encourage trade, however, no matter the practices put in place, profits remained relatively stable. This preponderance, among others, was brought to an issue in 1749 before a select committee of the House of Commons that heard testimony from 20 witnesses who had knowledge of the manner in which Company operated in Rupert's Land (Great Britain, House of Commons. 1749). Many intermingling concerns were addressed by the Committee, including criticisms of the Company's monopoly; if an agricultural colony could be established in the territory; and whether the trade in furs could be expanded. In relation to this last concern, two possible schemes were put forth. The first was in accordance with the principles laid down by the classical economists. The second took into account the intrinsic concerns and problems of a fur trade domain of government in Rupert's Land.

According to classical economists, if the Company was to give a "better price" to the 
aboriginal peoples for furs they would be able to accumulate more furs and thus increase their profits. "Tis a greater price would encourage the Indians to kill more" (Great Britain. House of Commons. 1749: 239). Robson, a stone mason, provided the Committee a similar opinion that if "the Standard of Trade was more advantageous to the Indians, a greater quantity of furs and pelts would be brought" (Great Britain, House of Commons, 1749: 220). This scheme, while consistent with the "natural" trade in England, was in opposition to both, the cultural complex of the aboriginal peoples, and the dynamics of the trade in the hinterland of the North. In 1769 Andrew Graham (1969) found that the aboriginal peoples would only trade for what they needed. The indigenous people could procure between seventy and one hundred beavers without effort, which satisfied all their wants before coming to trade again. Therefore, if the aboriginal people were given a "better price" for trading furs, they would need to trade less, not more. The dynamics of trade in the northern portions of the country too, mediated against the "rules of economy" set out by the classical economists. It was found that the French traders would intercept the Cree on their way to the Bay to trade. The French would trade with the Cree before they reached the HBC posts. These traders would get the lightest, and best furs, before the $\mathrm{HBC}$ had a chance to trade (Rich. 1991). Those in England failed to take into account the intrinsic problems and concerns of trading with a population who did not share the same sense of property, and failed to recognize, the intense competition which existed within the fur trade. To give a better price for goods sold is a sound tactic to induce a population to trade, however, it rifglects the intrinsic conditions of the fur trade and the mode of life of the aboriginal people.

How then could the HBC increase profits, given the fact that the French were 
intercepting furs coming to the Bay, and the aboriginal people "would kill no more Beasts than what is sufficient to purchase Commodities for the year" (Great Britain, House of Commons, 1749: Thompson, 233). The only manner in which to govern this domain was to develop a rationality to govern the fur trade which responded to the exigencies of it. In order to achieve a greater accumulation of furs. the $\mathrm{HBC}$ decided to cut out the middle trader by situatıng inland posts along the Saskatchewan River. This shift in the means to obtain a greater margin of profits responded to the problems encountered in trading with the aboriginal peoples. On the one hand, it enabled more nations to come to trade directly with the Company, while on the other, it curbed the number of furs which were lost to the competition.

However, with the shift in the means of government has another implication. The Cree, who were the essential link in the fur trade, were displaced by the inland forts. They then had a choice to make concerning their mode of life. They had two options to pursue, on the one hand they could continue to hunt the ever disappearing beaver (which the HBC was encouraging), or on the other, they could shape their mode of life in a way which was more consistent with the pursuit of the buffalo, which - in the late 1700's anyway - were plentiful on the plains. In the succeeding years, the Cree opted for the latter option. But this should not be seen as an irrational choice, or simply as a reaction to being squeezed out of their middle trader roles by the introduction of inland forts, but rather, the buffalo offered a reliable subsistence base. Duncan McGillivray, once indirectly implied that the mode of life of the Cree was not determined by the European fur traders, but conditioned by their own rational evaluation of the contextual situation: 
The inhabitants of the Plains are so advantageously situated that they could live very happily independent of our assistance. They are surrounded with innumerable herds of animals, whose flesh affords them excellent nourishment and whose skins defend them from the inclemency of the weather, and they have invented so many methods for the destruction of animals, that they stand in no need of ammunition to provide a sufficiency for these purposes (cited in Morton, 1929).

The Cree's lives were shaped by the ends pursued by the company. It must be stated however, that their mode of life and of gaining subsistence was not determined by this relationship. In the early years of the fur trade the Cree in their role as middle traders facilitated the HBC's pursuits of profit. But this role was proving to be an impediment to the pursuit of profits. To this end the company was perplexed. How was it possible to secure profits in the face of a mode of life which did not value the accumulation of personal property? The only manner to secure the end of governing the Companies profits was to respond to these intrinsic problems with inland forts, thus procuring a direct trade with the supply of furs. However, the Cree, chose not to pursue the beaver and other furs which was in the interest of the Company. Instead, they made a rational decision to pursue their own existence by following and subsisting upon the buffalo. This choice, as we will see. with the disappearance of the buffalo, and the disease which plagued the prairies had dramatic influences in the years around confederation. The Cree's life had been shaped and conditioned by the intrusion of European economic motivation in the fashion of the European fur trade, their life after confederation will be seen as shaped by another intrusion.

\section{Starvation/alcohol/disease}

In addition to intruding an economic rationality and the commodities which accompanied it, the fur trade intruded European vices, disease and excess which shaped the 
aboriginal culture in other ways. One of these intrusions was the use of alcohol as a commodity of trade. Competition between a Montreal based trade company, the Northwest Company, and the Hudson's Bay Company became intensified in the latter part of the $18^{\text {th }}$ century. In order to secure the ends of the respective companies, which required the aid of the aboriginal peoples, each company disposed a tactic which would have serious implications for these peoples. The struggle for control of the fur trade led to both, violent confrontation between traders - and also aboriginal people - but perhaps more importantly it led to the widespread distribution of alcohol as a practice disposed to obtain the loyalty of the Cree, Ojibway, Blackfoot, and other aboriginal fur traders. More than one HBC trader insisted that "they could get more done for a quart of brandy than for ten pounds worth of trade goods" (HBC, 1775-82). The introduction of alcohol, despite the prohibitive law of the HBC to eliminate it after the destructive/competitive era of the fur trade (1821), left a penetrating impression on the aboriginal people that would condition the problematizing effort of the Canadian state.

The fur trade, which intruded the practice of distributing alcohol for securing trade with the aboriginal inhabitants, also proved to be an efficient means for transmitting viruses, bacteria and diseases, such as, mumps, smallpox and measles. The introduction of diseases had serious implications for the economic and political composition of aboriginal culture. Some nations, such as the Assiniboine and Mandan, lost so many of their people to these destructive diseases that they were permanently weakened, and their role in both the fur trade, and politıcal position on the plains, was forever diminished (Miller, 1996b).

Wnile the intrusions of alcohol and disease had vital consequences for the shape of 
aboriginal society, perhaps it was the increased strain on the traditional resources of the prairies which had the greatest impact on the shape of their lives. The rationality of governing the fur trade domain where profits were the ultimate end, served to undermine the subsistence economy of the aboriginal peoples. Isbister (1857: 6), a former resident of Red River once stated that:

Owing to the numerous hunting ex..Jsions which the demands of the fur traded render necessary, and to the great slaughter of animals consequent thereon, the only present resources of the country have been gradually diminishing to such an extent, that the larger part of the native population can no longer find the means of supporting life from the produce of the chase, or the natural productions of the soil.

In the time before the intrusion of the European mentality of accumulation, the aboriginal people subsisted in harmony with the natural order of things (Binnema, 1996). However, when a mentality of government which seeks only the security of itself through the means of the aboriginal people, a certain shift in the culture emerges. The intrusion of a fur trade mentality into the mode of life of the aboriginal peoples, the expansion of it. and the commodities used to initiate and sustain it, as well as the resulting disease had important cultural. economic, political and social implications for the aboriginals. The native ability to carry on a traditional mode of life was undermined by the intrusions of vice, disease, commodities and mentality. When the fur traders of the $\mathrm{HBC}$ receded after the cessation of land to the Dominion of Canada, the scarcity which was the product of their intrinsic rationality of government and the intrusions into the lives of the aboriginal people did not cease to have implications for these peoples. Rather, the scarcity of game and introduction of alcohol and disease, which undermined the traditional culture of these peoples was part 
of the conditions which the Dominion problematized, and the aboriginal people sought to ameliorate.

The HBC attempted to articulate a specific form of governmental rationality which was intrinsic to their objectives of securing their interests in relation to competition, and the exigencies of the fur trade. With the cessation of land from the $\mathrm{HBC}$ to the Dominion of Canada. this form of political rationality suspends its influence over the aboriginal peoples, however the effects stemming from 200 years of economic government would be lasting. 


\section{Chapter Two}

\section{Security of Knowledge through Discourse and the Intrusion of Settlement: Liberal Antecedents}

At the centre of the preceding discussion was the political rationality that the HBC intrinsically developed to govern a domain of fur trade objectives. Simply, this rationality was expounded to govern profits. It was defined in relation to the intrinsic conditions of economy of a fur trade company operating in the specific locale of Rupert's Land. As such. the $\mathrm{HBC}$ constituted a domain of government whose parameters surrounded the exigencies of the fur trade. Government in this context included governing the mode of aboriginal life as a means to secure Company objectives. Aboriginal knowledge, contained within the indigenous behavioural context, was essential to the ends of the Company and thus in need of protection. Their mode of life, their existence, that of hunting the fur bearing animals of the forests and plains, was essential to the very existence of the fur trade Company.

The mode of life of the aboriginal people of the prairies, and the contents of that physical space, was to be preserved in the interests of securing the Company's profit. Sir George Simpson testified to this before the Select Committee of 1857 which was inquiring into criticism lodged against the Company:

Do you believe that a country can be settled which is retained for hunting ground? 
-I do not

Then the hunting ground is incompatible with the settlement of the country?

-Merely speaking from my own notion of the matter, without being a practical hunter; we find, as a matter of fact that the wild animals recede from the settlements (Great Britain, House of Commons, 1857: p.87).

In the first instance, the company intruded a rationality of government that sought the accumulation of profits. Secondly, they required the mode of life of the aboriginal peoples to obtain their objectives. Thirdly, in order for profit and accumulation be preserved, they needed to secure the interests of the company in relation to "foreign" intrusion of the kind which would negatively alter the profits of the company. Here I am referring to two things: settlement, and missionaries. This leads us into a discussion of the management of territorial space in the interests of securing the Company's constituted fur trade domain.

\section{Discourse and the Management of Space}

I conceive that the HBC are a company conducting their government in a manner consonant with their interests as a trading company ... I do not think that the interests of a trading company can ever be considered as compatible with the settlement of the province (Great Britain, House of Commons, 1857: W.H. Draper p.221).

The encroachment of settlers into the territorial space of Rupert's Land could not be reconciled within the interests of a fur trade company. That is, if the space in which the fur trade was conducted would be thrown open to settlement, it would have an adverse effect on the quantity of furs available, and thus the margin of profit enjoyed by the Company. Therefore, the whole of this space was to be jealously guarded by the HBC and reserved for the sole purpose of the accumulation of furs. The space of Rupert's land was one of the primary means to the desired end and was to be safeguarded from the intrusion by human 
settlers. except for those whose sole purpose was the facilitation of the ends of the Company. The geographical space of Rupert's Land comprised "a territory which is one third larger than all of Europe, covering a space sufficient for the establishment of kingdoms and empires" (Gladstone, 1857: 7). The vast amount of space the HBC controlled and governed was not opened to settlement, but rather, "treated as if intended by God and nature for no better purpose than the breeding of wild beasts and vermin. in order that a set of private adventurers might make the greatest possible profit out of their skins" (Gladstone, 1857: 8). However, there were no cement walls constructed around this space and no armed guards on the border to control entry and settlement into this space. How was this space governed?

To this end, the Company discursively constituted the geographical space which they governed as unfit for colonization. One prime example of this is Sir George Simpson's testimony before the select committee inquiring into the affairs of the HBC when he told the committee that Rupert's Land was unsuitable for cultivation. However, in his 1847 book, Journey Around the World he painted quite a different picture where he often compared the country side of Rupert's Land to that of England (vol.I pg.46). In one place he marvels, "nor are the banks less favourable to agriculture than the waters themselves to navigation. resembling, in some measure those of the Thames near Richmond" (vol. 1 p.53). But 16 years later, when Governor of the $\mathrm{HBC}$, he seems to have changed his mind. In reference to the question posed to him concerning the cultivation and colonization of the territory governed by the Company, he had no hesitation in expressing his opinion that no space of this territory was fit for settlers (Great Britain, House of Commons, 1857).

As a traveler, Simpson marveled at the splendor of the territorial space over which 
the Company governed, but as Commissioner, he could only find disdain. By constituting and perpetuating this discourse concerning the nature of Rupert's Land, the HBC was able to secure the space against settlement. For example. in 1858 the Canada's sent an expedition to Red River to see if it was possible to, first to reach it, and second, establish a "chain" of communicatio!. The expedition finally expelled the discourse perpetuated by the company, as is evidenced in the following:

Before Mr. Dawson's exploration, the rocky, broken structure of the country was thought to present an insuperable barrier to further extension except at an immense expenditure: but his examination led to the discovery of a good line (CSP vol. 7 no.31 1867: Mr. Folley).

A second way the Company managed and preserved a beneficial state of affairs was to charge excessively high prices for land. Again this had the effect of discouraging settlement. By discouraging settlement through these two means the HBC was able to guard and preserve the fur trade. However, in the opening years of the nineteenth century, this state of affairs would be intruded upon by a small group of Scottish settlers under the auspices of Lord Selkirk.

\section{Intrusions of Law and Religion}

The conditions of life confronting the aboriginal peoples at confederation were a direct result of the pursuit of the objectives of the $\mathrm{HBC}$. The resultant conditions of life were the fallout of the intrinsic economic organization of a fur trading Company. These conditions had implications for the mode of life of the aboriginal peoples, how they carried on their existence, the shape of their cultural, as well as, political and economic organization. The intrusion of European commodities, - including the use of alcohol as a means of barter - the 
effects of the decline of the subsistence base, and the ravages of disease all impacted the mode of life of the aboriginal peoples.

In addition to these conditions there existed two European intrusions which must be addressed before I discuss how the Canadian state governed the mode of aboriginal life: the intrusion of missionaries practices into the mode and philosophy of life of the aboriginal peoples; and the influence of European and Company law. The missionaries and law emerged in the latter stages of the fur trade with the introduction of settlement in the space marked out as Red River.

\section{The Red River Missions}

In 1811 , a Scottish colonizer by the name of Lord Selkirk, after much debate with HBC, collected together a group of settlers to establish the Red River colony at the junction of the Red and Assiniboine Rivers. The great majority of these settlers were Roman Catholic. which was reinforced by the presence of French Canadian fur traders and the Metis in the area (Huel, 1996). Since there was no Catholic priest among them, much to the outrage of the settlers, Selkirk invited Bishop Plessis to Red River in order that he may make provisions for bringing a priest to the settlement. In 1818 this request was filled. Two Catholic priests were sent to the colony with detailed instructions to "rescue the Indian population from barbarism" (Plesis, cited in Huel, 1996). Two years later the first Anglican missionary arrived at Red River.

A unique feature of the missionary activity in Rupert's Land was that it did not begin until 150 years after contact (Smandych and McGillivray, 1998). What was happening in the 1820 's which conditioned the intrusion of missionaries into the fur trade domain? As was 
witnessed above, the emergence of a settlement in the territory brought with it a concern for religious instruction. Another influence was Protestant evangelism in England, which also led to efforts to Christianize indigenous people in other parts of the world (Smandych and McGillivray, 1998). It was perhaps inevitable that missionaries would turn their attention to the aboriginals of Rupert's Land.

In 1820, John West, a Protestant missionary, was sent to Rupert's Land to serve as the Chaplain of the $\mathrm{HBC}$ and as a representative of the Church Missionary Society. Much to the dismay of the Company however, West commenced a programme of instructing the aboriginals in the ways of Christianity. The Company was opposed to such an endeavour, as it posed a threat to the security of the fur trade. For 150 years the HBC was able to conduct business in the region free from intrusions which would significantly alter the shape of the fur trade. The missionaries' activity of evangelizing the aboriginals initiated a divergent form of government in the space of Rupert's Land.

It is not my purpose, in this section, to provide the reader with an extensive chronology of missionary practices, but rather to make explicit the missionary intrusion of Truth. It is my larger purpose to delineate the conditions of existence of the aboriginal peoples at the time of confederation and how the HBC, missionaries, and law intervened in this process. In the future it may be beneficial to investigate further the practices and rationalities of the missionaries as they relate to the evangelization of the aboriginal nations of Rupert's Land. For now, I will look at the objectives of the missionaries, the practices intruded to achieve these ends, and their interaction with the conflicting rationalities of the HBC. 


\section{Rationality and practices of the Missionaries}

The mandate issued by Bishop Plessis - to rescue the Indian population from barbarism - is an important statement as it relates to the aboriginal peoples, in that: first. it is quite inconsistent with the objectives and rationality of the HBC; and second, it has continuity with the liberal rationality of government. In order to make this intelligible, I would like to link this statement with the observations made in the preceding section concerning the security of space. Above I discussed how the active construction of a space in a manner which was inconsistent with settlement led to the security of space. and the construction of an exclusive domain of government. However, not only the territorial space that was to be governed in relation to the preservation of the natural produce of the company, but too, the mode of life of the aboriginal peoples which was indispensable to the pursuit of profit. Here then, we are able to envision the objects of government by the Hudson`s Bay Company rationality. This object, and the domain in which it is exercised are two things, on the one hand territory, and on the other, and of no lesser importance, the knowledge of the aboriginal inhabitants. Both of these are means to the ultimate end, and that is profit. Space is the essential element of preservation, both, that designated for fur trading, and the space and contents of Aboriginal knowledge. Both are to be secured in order to govern the ends of the Company. The mode of aboriginal life, and the territory in which they carry on their existence, were designated and secured as a means to a desired end.

As evidenced in Plessis' instruction, the missionary project designates the aboriginal mode of life as their domain of government. The object of power for the missionary intrusion is not the physical territory but the second form of space guarded by the company - the mode 
of existence, or way of life of aboriginal peoples. It is in the domain of government constituted by the Company to extract valuable resources that the missionaries were to intrude their practices. The fact that the Company so jealously guarded this mode of life for their own benefit outraged many of the humanitarian liberals of the day, such as Gladstone in a pamphlet written in response to charges lodged against the Company: "more and worse still, it has kept the native races of man in a state of savage heathenism and ignorance in order that they might be the better hunters, and the more helpless victims to their exactions" (Gladstone, 1857: 8). Alexander Isbister, a former Metis resident of the Red River settlement who went to university in England and was a consultant for the Aborigines Protection Society, puts forth the idea that the aboriginal peoples conditions of life have not been ameliorated by the Company, but rather:

With a view of ... perpetuating the wandering precarious life of the hunter, on which they erroneously consider the existence of the fur trade to depend, they have permitted generation after generation to pass their lives in the darkest heathenism (Isbister, 1857: 5).

But what does this mean? I am not here making reference to the aboriginal peoples as 'heathens', but rather drawing attention to the moral calculation performed by the missionaries. I am not placing the European mode of life in opposition to that of the aboriginal, but merely demonstrating that the missionary intrusion into the lives of the aboriginal peoples refers, not to the security of the Company through the maintenance of the state of things, but that a conflicting rationality emerges, with the objectives residing in the population themselves. It can only be so for the missionaries. The mode of life of the aboriginal peoples, which was so valuable to the company, was regarded as material upon 
which the missionaries. and later liberal government. were to work. What is to be governed. or shaped, is not territory, but the aboriginal mode of life. It is this complex of relations of subsistence, habits, movement, spirituality, and ways of acting and carrying on an existence that made up the aboriginal mode of life and was to be governed. not as a means to an end, but the evangelization of the aboriginal peoples as an end in itself. The question remains to be answered: How did the missionaries intrude the message of Christianity into the mode of a'suriginal life?

It is of primary importance to consider what was to be governed, or shaped in a way conducive to the salvation of the aboriginal people. What is to be governed by the missionaries are the aboriginal peoples. However, it is not merely the people which are of concern. It is their mode of life. The missionaries sought to shape the relations of the aboriginal people with their traditional means of subsistence, their customs, habits, and ways of thinking and acting (Foucault, 1991) in relation to the salvation of their soul, or rather and perhaps what is more important, in association with the European mode of life. According to Bishop Tache: "the first nations would have to abandon their wandering ways if they were to become and remain solid Christians" (cited in Huel, 1996). The salvation of the souls of the aboriginal peoples was to be accomplished through the intermingling of conversion of the secuiar and spiritual philosophy of the aboriginals.

\section{Missionary Governance: Truth, Missions, and Practices}

In the early years of missionary activity in the Canadian North-West the missionaries sought to intrude the truth of European spirituality into the philosophy of life of the aborigunal peoples. Missionaries hoped that the Christian message would be so omnipotent 
and compelling that once it was heard by the indigenous people it would immediately, and without question, be accepted. The missionaries, who were accustomed to strategies of evangelizing the poor in Europe perceived that the knowledge of God's love, once released from their mouths, would bring about fundamental shifts in the soul of those who received the message (Huel, 1996). Early on the missionaries realized that the conversion of souls would be a difficult process and refined their techniques and strategies to this unique environment. The missions in Red River, and the surrounding territory, followed one of two basic strategies. The first consisted of conducting a mission by selecting a space and endeavouring to constitute a centre where aboriginal people could come to 'hear' the word of God, and send their children to school. The second comprised a manner of conducting religious activities - hymns, learning catechism, sermons - in hunting and trading camps durirg the fall and spring when the aboriginal peoples were gathered together in a specific locale.

To realize their goal of converting the aboriginal peoples, the missionaries would begin their evangelizing programme by providing an elementary explanation of the fundamental doctrines of their faith. In order to evangelize the aboriginal peoples in this way various strategies and tactics were disposed. One of these strategies was to develop a mission at a particular spot - designated by the Company - and recruit the aboriginal peoples to come to the mission and celebrate the word of God. John West, one of the first protestant missionaries in the Red River settlement, displayed this technique in his work. Missionaries destined for the Red River Settlement traveled from England aboard ships bound for York Factory on Hudson Bay. When West disembarked from his long and arduous journey he 
immediately took steps to locate children which he could bring to Red River in order that he may "instruct them in the ways of the Lord" (West, 1824). Throughout his journey to the settlement, West endeavoured to recruit aboriginal children for the school he intended to build. Finally, an individual complied with his request:

... it appeared to me that a wide and extensive field presented itself for cultivation in the instruction of the native children. With the aid of an interpreter, I spoke to an Indian named Withaweecapo about taking two of his boys to the Red River Colony with me to educate and maintain. He yielded to my request (West, n.d.).

Once in Red River. West continued his quest to acquire children. However, West was having problems keeping the children he had recruited from the surrounding villages at the school. Children would often go back to their villages after receiving food and clothing from the missions, or parents who felt that the children would be "the same as dead to them. if what they heard was true" would take them away (West, n.d.: 142).

Another strategy disposed by the missionaries to evangelize the aboriginals was to organize a regular mission when the aboriginal people gathered to hunt or trade. This was seen as a practical scheme due to the relative lengthy duration which the aboriginal people were in one place. It allowed the greatest amount of personal contact, surveillance, and effective instruction (Huel, 1996). The missions would consist of 2-3 weeks of evangelization twice a year, usually in the spring, when they came to trade their furs, and in the fall when they returned briefly to obtain supplies to maintain an existence over the long winter.

This aliowed the missionaries to perform surveillance on each and all of the native individuals who were coming to the Company post to trade. Missionaries would also use the 
aboriginals' schedule to gaze upon the population enabling them to procure knowledge of the present spiritual state of the aboriginals. For example. Father Lacombe, a Catholic missionary, would accompany the Cree during their fall buffalo hunt and utilize the different behavioural contexts as a technique to shape their soul. In the morning, when the women would gather in the middle of the camp, he would instruct them in the way of the Lord. when they returned to their duties, he would instruct the sick. After which he would gather the children and instruct them by teaching hymns and remedial doctrines contained within the catechism (Huel, 1996). At night when the men returned from the buffalo hunt, he would instruct them and discuss any religious matters which were put before them (Huel, 1996). With this technique the missionary was able to govern each and all by incorporating the behavioural context into their technique of government.

No matter the influence missionaries may have had on the soul of the native populations during their missions, all that was done had the potential of becoming undone when the aboriginals broke camp and headed out to their wintering groups. Winter hunting groups are smaller and more nomadic than those groups which would congregate for the fall hunt. or to gather supplies from the $\mathrm{HBC}$ post. The nature of the aboriginal winter hunting groups made it impossible for the missionary to provide the necessary supervision and instruction. The missionaries required, for their objectives to be reached, a settled population. By having a settled population the missionary could render visible the salvation of each and every member of his flock. However, when the objectives of the HBC interpenetrate with, and facilitate the traditional mode of existence of the aboriginal people, the objective of the missionaries to promote both secular and divine salvation is severely undermined. 


\section{Truth and Choice}

As the missionary project resolved the many difficulties associated with intruding the European and Christian truth, they refined their methods to structure the choices of the aboriginals. By disposing certain tactics - language, the image of the missionary self. food. clothes, behavioural contexts of aboriginals - the missionary was seeking to intrude upon the aboriginal peoples, not only a truth concerning their spiritual self, but too, a mode of life. In the above sections I discussed how the missionaries sought to intrude the truth of Christianity and its tenets into the lives of the aboriginal peoples. I also discussed how the relative failure of the missionary project was due to problems of the strategy employed which was also mediated by the ends of the HBC. However, in the final analysis, this is much too simplistic an interpretation since it does not consider how the aboriginal people who heard the message responded to the intrusion of this truth into their lives.

It may be that some aboriginal peoples accepted the truth prostylized by the missionaries, while others resisted it. Aboriginal reactions to the missionary truth included acceptance, resistance, or syncretism of the ideas. The missionaries were seeking to intrude a truth. By truth, I am not making a distinction between true and false, but rather, knowledge concerning a way of life that had attached to it practices for its realization. In order to impose the mode of life of Christianity, the missionaries exerted influence over a free people. However the conditions of life which existed on the prairies mediated this intrusion. For example. John Grant (1984) has suggested that aboriginal peoples responded positively to the message of Christianity because "the birds and animal spirit which they had looked for illumination were no longer readily found in their accustomed places or seemed already to 
have fled from them." Aboriginal peoples in different regions and at different times were subjected to difficult conditions of life, such as, disease and the inability to obtain material benefits, which in turn conditioned their responses to the message of Christianity. Or as James Axtell (1985) has put forth, "the adoption of Christianity ensured the ethnic survival of Indians because they successfully used it for their own purposes." Some of the aboriginal peoples would include some elements of Christianity in their culture to "fit their existing beliefs" (Long, 1987). Others would probe this mode of existence, but after investigating, would be heard to say "It is easier to hunt than to dig" or "A bow and arrow are lighter than a spade" (Ross, 1856: 221). Still others, like the Saulteaux, would refuse to listen to the message of Christianity "because they realized it would entail significant changes to their culture" (Huel, 1996:19).

The aburiginal people did not respond to the "truth" being intruded into their lives because it was more powerful than their religion, but because it somehow served a purpose. The fact that the aboriginals' response to missionary practices were not motivated by spiritual considerations outraged many of the missionaries who could not accept that there were numerous other reasons why the aboriginals embraced it. Deleuze and Guttari (1977) have put forth the idea that European society is not "exchangist," or that it does not value the exchange of belief systems from distinct cultures. It is rather an intrusive truth showing an intolerance for the values of the "other," whether it is another religion, or another culture. On the other hand, the aboriginal peoples were more inclusive in their values exhibiting a willingness to experiment and "include" other ideas.

In light of the diverse aboriginal reactions to the practices, strategies, and ends of the 
missionary intrusions, it is possible to envision that the aboriginal mode of life was shaped bv missionary efforts but "the Indians were neither unthinking opponents nor passive children" (Axtell, 1978). When the missionaries were seeking to intrude a divine and secular truth it was done so into the lives of a free people who conditioned their responses to the European mode of existence as a response to the message certainly, but perhaps more importantly, as a response to the conditions of life which were shaped by the mentality of the fur trade.

This becomes important when it is seen as foreshadowing the conditions existent on the prairies in the $1870 \mathrm{~s}$. The notaries of the treaties often expressed their concern. and willingness to shape their lives in accordance with a lifestyle similar to that proposed by the missionaries:

The beneficial measures you have proposed to us in the name of the government. we accept ... Our nomadic habits have unfitted us for their ancient calling and industry; however, we hope with patience and time that our children may get the benefit of honest labour, and enjoy the more secure means of existence than the precarious mode of living of a hunter of the wild (cited in Stanley, 1945: 229).

This is not to say that the intrusion of a prescribed mode of life was accepted without question by the aboriginals, rather, it shows how the practice of intruding a mode of existence was mediated by the conditions of prairie life. In this quotation, there is an interaction being worked out, between the traditional philosophy of aboriginal existence, the conditions of existence, and a regime of truth being projected by missionaries. It is more than prostylization and acceptance, but includes practices and strategies disposed to some end, which is mediated by the freedom of choice of the aboriginals and accounts for the 
conditions which confront them. It may be more wise to refer to this "interaction" as strategies informed by a "regime of truth" for the achievement of some final end. It is then. a "strategic interaction" where it is the objective of a person or a group of people to intrude upon, and ultimately shape the conduct of others in relation to a predefined end.

The missionary project introduces an important shift in the governance of aboriginal peoples. While the HBC endeavoured to secure the aboriginal mode of life in the interests of protits. the missionaries sought to shape it in relation to the conversion of their souls. In this shift there is a pivotal unsettling of the ends/means relationship which foreshadows the rationality of liberal government. Law, with the emergence of settlement in Rupert's Land. was another technique of government disposed to govern aboriginal peoples that came to be used alongside missionaries.

\section{Administering Company Law}

The rationality of $\mathrm{HBC}$ intrusions into the lives of aboriginals was primarily governed in the interests of the security of the ends of the company. As I have discussed previously, the rationality, or the mentality of the fur trade was intruded into, and shaped, the mode of aboriginal life. That is, the HBC constituted a domain for the insertion of various constructed practices to secure their objectives. To procure the greatest amount of furs through economic relations with aboriginal people the $\mathrm{HBC}$ disposed various practices such as, the intrusion of European commodities, the discursive constitution of knowledge concerning territorial space, and the intrusion of intrinsic economic principles. While all of these intrusions had effects on the philosophy of life of the aboriginal peoples. there is another practice to he considered. Here I am referring to the intrusion of both, intrinsic or 
private law of the $\mathrm{HBC}$ and the law of England.

The HBC, through their Charter, acquired many of the attributes of a sovereign state. The HBC Charter. granted by Charles the II, provided the company with the ability to enact laws which "were not repugnant with the laws of England." Along with this ability, the Company was also disposed to seize property and imprison British subjects (and the aboriginal people later on in the century) for the infringement of such laws without the sanction of any governing parliament. Oliver summarizes the law making powers granted to the Board of Governors of the HBC in the Charter of 1670 :

... The Governor and Company might assemble and make laws and ordinances for the good government of the Company and its colonies and forts, and for the advancement of trade. They might impose penalties and punishments, provided these were reasonable and not repugnant to the laws of England (1914, vol.1: 22).

But we may consider, what is the constitution of "good government." in the context of the fur trade domain. as an end to which laws may be "assembled"? Was it to ensure and secure the "amelioration" of the aboriginals' conditions of life? No, but if we consider what has been stated to this point, "good government" refers not to the welfare of the population. but to a state of affairs where all individuals (both Company employees and aboriginal people) without exception, are subject to, and facilitate the ends of government. The "good government" of the HBC then, refers to:

$\ldots$ an absolute and unqualified dominion over their bodies [the company's servants] and their souls - a dominion irresponsible to any legal authority - a depotism, whose severity no legislative control can mitigate, and no public opinion restrain. It knows but one limit, and obeys but one law, - "Put money in thy purse (Fitzpatrick, 1849).

If "gond government" refers to submission to the ends of the $\mathrm{HBC}$ - and the end is the profit 
making enterprise of the $\mathrm{HBC}$ - we may first consider; how did the private law making ability of the HBC serve as a practice to facilitate these ends? and secondly; how did these laws intrude into the lives of the aboriginal people? These questions will be the focus of the remainder of the chapter.

In the first years of $\mathrm{HBC}$ rule the laws created and disposed by the Company were aimed at governing the "siphoning of profits" by employees. Employees worked in relatively small groups isolated from friends and family; they were distant from the British legal system: and they were required to work effectively and efficiently in order to ensure profits for the corporate masters (Smandych and Linden, 1996). Of the many problems which can be envisioned in this environment, the foremost was that of "private trading". In fact in one of the first recorded meetings of the London Committee in 1672 the Company passed an order concerning private trading which stated that: "All persons to be imployed Shall enter into articles or otherwise oblige themselves not to trade in beaver upon forteiture of theyr goods \& wages" (Rich, 1951). In addition to disposing this intrinsic law, the Company, so as to ensure the loyalty of their employees and secure profit, required that employees swear an oath of loyalty to the Company. While practices disposed by the Company to ensure "good government" encountered many impediments - most importantly lack of surveillance which was not practical in the Canadian North West - the prospect of settlement and the increase in immigration around the southern border intensified this obstacle. In order to arrest the prospect of private traders intruding into the fur trade domain various practices were invented to secure the ends of government.

The first of these practices was included in the land deed which every settler was 
expected to sign and adhere to, which served to:

bind the purchaser of land not to infringe, either directly or indirectly, the exclusive rights, privileges, power of commerce, of or belonging, or anywise appertaining to, or held, used, or enjoyed by the Company; that he will not carry on or establish a trade or traffic in or relating to any kind of skins, furs, peltry, or dressed leather, in any part of North America (Isbister, 1857: appendix D).

This was the beginning of the practices created by the company to secure the ends of government in relation to the settlement of the Red River Colony. It seems evident that the subject of consideration of the governors was not "how to form a settlement upon the most solid and enlightened system" (Gladstone, 1857) but rather how to ensure "good government" in the face of it. One of the practices disposed by the Company to manage illegal trading was similar to that of governing their employees. Importers were required to sign an oath stating that their goods were not for use in illegal trade, and any refusal to do so would result in the forfeiture of their goods and that no more goods would be transported in Company ships (Ross, 1856; Great Britain, House of Commons, 1857). Another practice used was a form of surveillance of correspondence which would allow the Company to gather knowledge concerning the illicit trade (Bindon, 1981). Settlers were required to indicate on the outside of the mail the name of the sender, in addition, the letter was to be sealed in the presence of a Company employee, which implied their right to inspect the contents. Still another practice was to increase the tariff on American-made goods, which Alexander Ross (1856) stated that the "odium it created lives to this day."

While the tactics disposed by the Company to ensure "good government" intruded upon the settlers rights to "free and liberal trade" (Ross, 1856), they increasing came to 
intrude into the traditional philosophy of life of the aboriginals. In traditional aboriginal culture the giving of presents is a fundamental component of political and social dealings. Presents were provided in peace negotiations and social affairs (Mandelbaum, 1940). One of the items of traditional exchange took the form of furs. But the practice of presenting furs by aboriginal peoples was envisioned by the Company as an incursion on their profit generating mentality. John McLaughlin, a resident of Red River who had done some legal trading within the territory, testified before the Select Committee inquiring into charges lodged against the HBC. that:

the Indians are prevented even from making presents to one another; they cannot trade with each other: if the HBC are aware of it, they will take means to stop it. They even prevent presents from one Indian to another, and have gone so far as to try to bring missionary efforts to prevent them from even wearing furs (Great Britain, House of Commons, 1857).

Through this intrusion of the mentality of the fur trade, the Company's intrinsic law served to undermine the traditional structure of aboriginal culture and philosophy of life by directly governing and shaping one of the fundamental social and political practices inherent to their culture.

\section{The Intrusion of European Law}

In addition to the ability to "make laws and ordinances for the good government of the Company and its colonies and forts, and for the advancement of trade" the Company too disposed laws of England. Smandych and Linden (1995) state that the "most significant legislation that affected the direction taken by the development of Hudson's Bay Company law in the nineteenth century were the statutes enacted in 1803 and 1821." The purpose of the former was to make clear the rights of jurisdiction for crimes committed in the territory 
of Rupert's Land and the Indian territories while the latter was entitled "An Act for Regulating the Fur Trade" which was the result of the rival fur trade companies consolidating their interests. While these acts were essential to the introduction of formal law in the territory, their importance can only be considered alongside other conditions which had effected the shape of the Acts. These include the establishment of the Red River settlement. the creation of the Council of Assiniboia, the appointment of Adam Thom as the first legally trained court recorder of Rupert's Land, and legal developments which were occurring in the rest of Canada as well as the world (Smandych, 1997). While all of these conditions had effects on the shape of the law, here I am concerned with how European law intruded into the lives of aboriginal peoples.

The emergence of a formal structure of legal institutions at Red River commenced a new mechanics of law which directly shaped the dispute resolution tactics of the aboriginal peoples, yet it should not be viewed as the 'origin' of this type of intrusion. Prior to this. certain practices were utilized in order to govern relations of the HBC with both the aboriginal peoples and their employees in remote wilderness conditions. The practices disposed by the company operated as a system of private justice which included such measures as "beating Indians" for stealing goods from posts and blood for blood vengeance taken by the Company's servants on aboriginal people (Great Britain, House of Commons. 1749). Several historians have viewed this intrusion into the lives of aboriginal philosophy of life as having a long term historical impact on their customary law tradition and dispute resolution tecl:niques (Smandych and Linden, 1995: Brown, 1979: Brogden. 1990). Not until the emergence of a legal institution in Red River were they drawn into the formal legal 
system.

The first legally trained court recorder of Rupert's Land. Adam Thom, has been described by some historians as a racist (Knafla, 1986) and a Company judge who served to secure the interests of the Company through his position (Bindon. 1981). Important to understanding the mechanics disposed to draw aboriginal people into the European system of justice, is not whether or not Thom was a racist or a pawn of the company, but rather how it was that aboriginal peoples became "caught up" in the system and its effects on their culture. It seems evident that Thom considered the application of European law to aboriginal peoples as a measure for the requirement of "good government" when he stated in judgement following a case in 1845 :

Every community possesses the acknowledged right of avenging the wrongs, which its members may have sustained at the hands of any other community, either by public war or by private reappraisals. - a right. by-the-bye, which is expressly vested in the Hudson 's Bay Company by its Charter. Now such a right obviously comprises, what is far more consistent both with humanity and with justice, the lesser right of demanding, ... any Indian. who may have injured us even with the territory of his tribe (Thom, 1845: my emphasis).

In light of this requirement, Thom saw the intrusion of European law into the aboriginal customary law tradition as a legitimate practice. In the early years of the court many aboriginal people were required to stand trial for crimes of minor significance. However, a shift in this mentality occurred when an aboriginal person was tried and hung for the murder of two other aboriginals. In his narrative of the "Rise, Progress, and Present State" of Red River, Alexander Ross, the Sheriff of the settlement, describes the questioning of the aboriginal person:

He was pensive and mute, as if at a loss what to do or say for himself, and stood still till he was laid hold of; nor did he attempt to deny his guilt. On being questioned. he cooly 
answered, "The Sioux killed my brother, and wounded myself last year; from that moment I vowed revenge, that revenge I have now taken, and am satisfied" . . However justifiable the conduct of the Indian might be, according to his idea of things and the laws of his country. few acts more daring in its nature, or more insulting to the whites, had ever been committed in this quarter ... The fourth day after the murder was committed, he was tried in the regular way by a jury, found guilty and condemned to be hung (Ross, I 856: my emphasis).

This case marks an important shift in the intrusion of European law, not only because it was the first of the death penalty in Red River, but because it was the first time the "formal" English legal process was applied to a case which involved a serious crime committed by one aboriginal person on another (Smandych and Linden, 1995). From the above excerpt there is evidence of a confrontation between legal systems where one is subverted by the other. In the pre-contact aboriginal mode of life minor transgressions of the normative order were handled informally by the communal group through techniques of shaming and reintegration (Henderson, 1991; La Prairie, 1992; Braithwaite, 1991). Where a member of the social group is murdered, justice "was handled in the ancient ways ... murder was punished by the principle of an eye for an eye"(Gyles, 1869). The rationality of this practice is that through the aboriginal philosophy of life, it is believed, - essentially - "that if an individual is wrongfully murdered, their soul will not pass on to the next life, but will hang around and have no sense of peace until the transgression is avenged" (Pomeldi, 1986). Here then we are able to envision how the aboriginal person who murdered the Sioux "according to his idea of things and the laws of his country" was responding in a consistent manner to a truth, a truth concerning the approbation of "justice". More importantly we notice the collision of institutions of justice and the subversion of one by the intrusion of the other. 
Several points of note can be determined from this case as it relates to the increasing numbers of aboriginal peoples who were being "caught up" in the formal English system of justice. First. and perhaps what is most important, the case evidences the contending notions of truth concerning legitimate authority as held by both aboriginal peoples and the representatives of the justice system at Red River. Secondly, regardless of the merits of the individual case, the events signify the emergent intrusion of alien legal practices into the traditional dispute resolution tactics of aboriginal people which demonstrated that "they were amenable to the laws, and that crime, either by the whites or Indians, would not be tolerated within the colony" (Ross, 1856: 333).

The importance of this transaction, lies not in the case itself, but in the emerging rationality of inclusion which can be seen to commence a process that has had important effects on the present. This was not the "origin" of the Europe intrusion of law into the aboriginals' customary law tradition, rather, a system of private justice had been disposed by the Company and its servants prior to the emergence of the Red River settlement. The importance lies in the way private (and later state) justice was intruded into the philosophy of life of the aboriginal people and worked to undermine traditional aboriginal concepts of justice and customary law.

\section{Law and Missionaries: liberal antecedents}

I have taken a long, yet necessary, detour to come to this departure, which is, I believe, a precondition for discerning the nature of liberal rationality of government. The departure is characterized by a double movement, the rupture of the domain constituted by the HBC for the security of the fur trade, on the one hand, and on the other, the emergence 
of a liberal rationality of government. It is at this unique intersection that the problem of liberal government comes to pose questions of how to govern the aboriginal population.

But it is possible to ask, what concern did the HBC have for the indigenous peoples beyond being means to an obvious end? The population of aboriginal peoples of the prairies was not of primary concern to the HBC. What the HBC was concerned with was not their health. welfare, and present functioning and conditions of life, but rather the security of the mode of aboriginal life. Indeed, the Company had no knowledge of the numbers of aboriginal peoples who inhabited the territory (Great Britain. House of Commons. 1857: Ross, question 99-101; Simpson, question 983; Appendix no.l). The first appendix of the British Sessional Inquiry into complaints lodged against the Company presents a series of numbers concerning the population of the aboriginal peoples accumulated by the HBC. But, what do these numbers represent? What do they demonstrate? What becomes apparent is that the information obtained is gathered in reference to the number of aboriginal peoples who visited the various Company posts to trade. There are no distinguishing features and no names. no information concerning the mode of existence, nor the conditions of life of this population. Rather the information contained is, and can only be, envisioned as a device to ascertain the increase or decrease in the numbers of aboriginal peoples involved in the profit making endeavours of the Company. The aboriginal peoples are represented merely as means to an end and not as an end in themselves.

In the last years of $\mathrm{HBC}$ government there is the emergence of a second rationality which is quite inconsistent with the mentality of accumulating profits. Here I am referring to the emergence of missionary practices, and the development of a formal legal system and 
their intrusion into the aboriginal mode of life. The importance of these intrusions lies not in the relationship to the governance project disposed by the HBC, but in their continuity with the emergent regime of government. The missionary endeavour, and the inclusion of aboriginal peoples in the formal legal system, that followed in the wake of the settlement of the Red River colony commenced a complex process and a field of intervention by which a series of practices and tactics were disposed to undermine and shape the mode of aboriginal life, not in relation to the ends of the $\mathrm{HBC}$, but to some other end. I am not stating that this is the "origin" of this process, nor am I stating that the aboriginal people were passive victims of this intrusion, but rather I am drawing attention to the continuities and parallels that exist between law, missionary practices, and liberal government. I believe it is an important shift in the rationality of governance of aboriginal peoples generally, and specifically, a shift in the tactics, or practices disposed to shape, and undermine aboriginal culture. Whereas the end of the $\mathrm{HBC}$ is internal to itself and constructs and disposes intrinsic practices in the form of tactics to increase profits, in the emergent rationality the ends pursued reside in the population.

While some have argued that the incorporation of the aboriginal peoples in the formal European legal system, and the intrusion of missionary truth may have served an economic purpose for the HBC, I argue, that while arrested and intruded upon in some respects by the Company's interest, it evidences a fundamental shift in the manner in which aboriginal people were being governed. Within this emergent rationality, the Company is not the esseniial element in the equation, nor is profits, nor is the intrinsic instruments of government, what is essential becomes extrinsic to the ends of the Company. The key is that 
law, and the missionary practices, carved out a distinct form of rationality without reducing its function totally to the objectives of the dominant form of government.

However, as long as the HBC governed the territory of Rupert's Land and the exercise of power was intrinsic to company interests, the emergent rationality could not develop in a "specific and autonomous manner". Instead, the rationality of the fur trade acted as an "obstacle" to that realization. Gladstone, in a pamphlet written in protest of the Company's continued rule, states that:

the interests ... of law and justice - of civilization, Christianity and humanity, one and all of which have been ignored, during a period of nearly two hundred years, for an end utterly contemptible in itself, viz. the private gain of the 'merchant adventurers' aforesaid, that is to say, of holders of Hudson's Bay stock. (Gladstone, 1857: 8)

So long as the HBC retained a monopoly on the fur trade. and governed the territory of Rupert's Land, practices which centred on the population would remain subordinate to the interests of the Company. The objective pursued by the Company was a function of security and profit generating activities. In this state of things, governance of aboriginal people as an end in themselves is stifled by the economic rationality of government. It would not be until the emergence of the liberal Canadian state that these ends could be realized.

Perhaps, to some, all of this seems very remote. The reason for my insistence on coming to terms with the rationality of the $\mathrm{HBC}$ was to demonstrate how the intricacy of this mentality of government linked up with the mode of life of the aboriginal peoples and how, in the end, this had implications for the conditions of existence of these peoples. I wanted to illustrate the complexity of the conditions of life experienced by the aboriginal people at 
confederation. Much too often historians have neglected the emergence of these conditions of existence by commencing their analyses with the numbered Treaties. It is essential that before we move onto a consideration of the treaties and the programme of government of the Canadian State, their implications, and their contents, that there is a comprehensive understanding of the early emergence of the problems responded to, and the conditions of life in which a prescribed mode of existence was intruded. I have dealt with the relations between a political rationality at work within a fur trade company, and the mode of life of the indigenous people of the prairie provinces, and the implications each had for the other. It was not my intent to recount the history and origins of the $\mathrm{HBC}$, but rather to reveal the components that the project of governance by the Canadian state responded to (the disappearance of fur bearing animals. disease, alcohol), contrasted (concerns for space), and had continuity with (the emergent concern with population). 


\section{Chapter Three}

\section{The Emerging Canadian State: Liberal premises, Illiberal Tendencies}

All throughout the period extending from 1821 to the cessation of land to the Dominion of Canada there was interest in the Canada's in extending their sovereign territory to the West. Not only were there rumblings from the East, but too, from the territory settled inside the domain of the fur trade. Individuals in Red River complained that in an age where free trade and laissez faire capitalism is pervasive, they were not able to enjoy these privileges. Settlers in Red River also objected to the high price of goods - as a result of the monopoly of the Company (Ross, 1856). Whatever the conditions of the ultimate end of Company rule, and with it, their rationality of government, the implications of two hundred years of this mentality, and the conditions it produced, would weigh heavily for those who would secure management of this region, and perhaps more importantly, the aboriginal peoples.

\section{The Emerging Liberal Canadian Rationality}

The date December $1^{\text {st }} 1869$ marks a fundamental shift in the government of the aboriginal peoples of the prairie region of Canada. It is the day that the Dominion payed the HBC 300.000 British pounds for the lands they had occupied, conducted trade and executed a form of political rationality. A new rationality of government would now emerge, one 
which would endeavour to shape the mode of existence of the aboriginal people, not with a view of divine salvation, not one with circular intents, but rather, one which is constituted by numerous ends and multiform tactics which are employed to achieve these ends. There is a shift in both the ends to be achieved, and the manner of disposing practices to achieve these ends.

With the emergence of this rationality it is possible to witness a series of shifts in government from its former configuration. With the $\mathrm{HBC}$ we envisioned a rationality which sought to reflect back, and secure itself. That is, the practices disposed were aimed at nothing other than the accumulation of profits. While it may seem as if the HBC had a multitude of concerns, - space, profits, inland forts, a fragile resource base - these concerns must not be seen as independent of the end pursued, but rather, as implicit within the ultimate end. When the administrative apparatus of the Canadian state emerges in the West we envision a subtle but significant shift in the ends/means relationship. What were once means to an end now become ends in themselves. What once was the ultimate end passes into the background. What emerges is a new rationality of government concerned with a new manner of thinking about and acting upon, both the population and the territory. In the remainder of this work I will be endeavouring to decipher the implications of this shift for the aboriginal peoples of the prairies.

In the preceding chapters I have concerned myself with demonstrating how the HBC assembled a constitutive-discursive domain of government in which they intruded various tactics to secure the existence of the Company in relation to competition and settlement. Now, however, there emerges a somewhat paradoxical rationality, one that endeavours to 
open the space which the HBC discursively and defensively gated through subversive discourse and overt discouragement of settlement. With the emergence of a new liberal rationality of government, reflection now centres on rupturing the walls of this space. with throwing :open to settlement any portion of the land included in this area which may be susceptible of improvement and profitable occupation"(CSP vol 35 no. 22,1872 pg. 6 Morris). It was certain to those in Ottawa that "the old policy of exclusion of strangers from the Territory must shortly be at an end" ( CSP vol. 7 no.31 Return to an Address from the House of Commons, dated $18^{\text {th }}$ November, 1867 for Correspondence, Report of Proceedings and other documents, in Possession of the Government relative to the Hudson's Bay Territory. 1867-8. W.H. Lee). While this may have been an important end for the newly emergent liberal state, there were other ends to consider. Prior to the transference of land, order, morality, and the public good, were one and the same, tied to the despotic regime of government. In this environment the worst deprivations were committed. Alcohol trafficking and sale and other forms of crime went unchecked (Begg, 1894). However, with the transference of land from the HBC to the Dominion of Canada, a new liberal order. a new constitution of social relationships, institutions, and politics are to be intruded and reproduced. The introduction of this order of things was not based on submission to the tyranny of a Company, but rather based on the values of industry and liberty (for some). There exists a new regime of government that was endeavouring to break down the discursive walls of geographical space and intrude and secure a new order. However, there is also a population of aboriginal peoples "who have always been considered, if not as proprietors, at least as occupants of the soil" (CSP vol. 38 no. 8, 1875, Provencher) and who 
do not share these emergent values and mode of life.

The organization of aboriginal culture was based on a strong sense of group identity and a communal mode of procuring subsistence.' The basic unit of political and social structure of the northern plains aboriginal was based on the band (MacCloed, 1997). Bands were extended family groupings of from 50 to about 300 individuals. In any one band the number of individuals was directly conditioned by the availability of subsistence. In this mode of life the individual is motivated to procure subsistence in the interests of the larger group and qualities such as daring, skill, intelligence and courage were held in high esteem (Mandelbaum, 1940). While the values and organization of the aboriginal mode of life was highly valued in relation to the intrinsic rationality of the $\mathrm{HBC}$, in relation to the new shape of the country they constituted a "foreign element" which ran counter to the new order of things to be established. The emergent rationality of government would not tolerate "a day longer than is necessary a foreign element in its midst, for even should such an element be controlled as not to constitute a source of danger, it must assuredly for negative reasons, be one of weakness to the state" (PAC, Reed Papers, "Address", p. 30).

The traditional story of the entrance of Manitoba into confederation with the Dominion of Canada centres around a concern for space which is governed in relation to the erection of the Canadian Pacific railroad. But the national spirit ran much deeper than railways and immigration. Underlying these external concerns was the desire to constitute a distinct order of things which excluded the values and organization of aboriginal society (Brown, 1964). The aboriginal mode of life was not part of the new liberal order to be established on the prairies. The question then becomes, how was this "deviant" mode of life 
shaped in relation to the ends of the emergent rationality of government.

\section{Exclusion of the "other": Intrinsic Principles of Canadian liberalism}

It is the business of the speculative philosopher to mark the proper ends of government. It is the business of the politician, who is the philosopher in action, to find out proper means towards those ends, and to employ them with effect (Burke, 1770: p.29).

With confederation in 1867 the Dominion of Canada came to be made up of a group of European colonists who enjoyed the benefit of "free institutions" themselves, to engage in free trade and market competition and to be citizens of a state subject (for all intents and purposes) to no other state. This is the liberty they valued. The early Canadian liberal Sir Wilfred Laurier, in a lecture given in Montreal, stated that Canadian liberalism, when stripped to its bare essentials:

... and seen in its true colours, is the love of lawful and necessary liberty, of progressive freedom, which results from the natural conditions of progress and not from sudden shocks which dangerous spirits would wish to impart to it. Such are the characteristics of Canadian Liberalism (Laurier, 1887).

Freedom of progress and liberty from unnecessary intrusion into life are essential both, to the human condition and to the spirit of Canadian liberalism. At the same time, however, all too often Canada, and similar self declared liberal countries, refuses to concede the privileges of liberty in the same sense to "other" individuals and groups who carry on their mode of life in the same geographical and social space. Individuals and groups are excluded from partaking in the liberal spirit, they are denied access to that which is, according to Laurier (1887), essential to the "progress of the human spirit." If liberalism is exclusionary, it is also intrusive - striving to constitute and shape others in the likeness of itself. Liberalism. wherever it has reared its righteous head, is exclusionary. Here it shows itself to be narrow 
and one-sided and contains a contradiction which cannot be rectified by its principles. In such places - South Africa, Australia. Canada, Ireland - the antithesis of the liberal spirit emerges.

The Euro-Canadian members of the early Canadian community were smug idealists who cherished the British ideals of individuals and national liberty, even, at times, over extending its colonial heritage and principles (Underhill, 1960). When Alexander Mackenzie visited Britain in 1875 as Liberal premier, he found, quite to his disappointment, that few there shared the Dominions devotion to the spirit of liberalism and the Empire. "I have listened a lot" he once wrote home, "and I conclude that Canada is more British than Britain" (Thompson, 1960). This self-righteous adherence to the cherished principles of liberalism was done at the expense of, and jealously withheld from, certain segments of the population deemed unworthy of such entitlement.

It would seem plausible that the aboriginal mode of life, if the Canadian state followed the principles of liberalism, should continue to realize, enjoy, and be protected from intrusion upon their liberty. However, when the liberal rationality of government emerged in the prairies of Canada the aboriginal peoples and their mode of life was intruded upon by practices which sought to establish a normalized order of things. The rhetoric of liberalism obliges us to overlook the ways in which Dominion of Canada endeavoured to harmonize, constitute. and intrude upon the mode of life of the aboriginal peoples in relation to the incumbent order. When extended to the west, and when dealing with the aboriginal peoples, the principles of liberalism are no longer ones of progress and freedom, but rather, exclusion and intrusion. Liberal principles, such as the rule of law, were not utilized to create freedom 
from persecution, but rather were disposed as practices to govern a population which did not share the prescribed mode of life.

The justification for governing the aboriginal peoples of the emergent west was based on the principle of differentiation. On the one hand, we have witnessed the emergence of a liberal order whose principles are shared and enjoyed by the Euro-Canadian population, while on the other there is the mode of aboriginal life. It is this relationship of difference and opposition which is the condition and justification for exclusion of liberal privileges and the intrusion of practices of government into the lives of the aboriginal peoples. The status of difference illuminates the aboriginal culture as the domain of government. It is this difference which the emergent rationality of government sought to exclude and harmonize with the prescribed mode of life of the country.

\section{Problematizing the West: Treaties, Reserves and the Domain of Government}

To say that the aboriginal peoples were simply the victims of settlement and extension of a normalized and prescribed order would be to deny their role in shaping the policy constituted to govern their lives. While the ends of the emergent rationality of government sought to intrude upon a geographical space heretofore discursively and overtly closed, and. introduce a new mode of existence, the aboriginal peoples too had ends which they sought to establish in relation to these. In 1871 , Sweetgrass, a prominent leader of the Cree nation forwarded a message to lieutenant Governor Archibald which stated these concerns:

We heard our lands were sold and we did not like it; we don't want to sell our lands; it is our property and no one has a right to sell them. Our country is getting ruined of fur bearing animals, hitherto our sole support, and now we are poor and want help - we want you to pity us. We want cattle, tools, agricultural implements, and assistance . . . our country is no 
longer able to support us. Make provisions for us against years of starvation. We had great starvation the past winter, and the small pox took away many of our people ... We want you to stop the Americans from coming to trade on our lands, and giving firewater [alcohol] and ammunition and arms to our enemies the Blackfoot (Morris, 1880: 170-1).

The aboriginal concern was not to open a space for settlement, not to intrude a new rationality of government, but rather to secure the space which they inhabited and to ameliorate the conditions of life which were conditioned by the rationality of the fur trade.

This concern for space was made clear to the Canadian authorities when the Saulteaux from the territory around present day Kenora stopped Governor Archibald on his way to Red River and when Yellow Quill's band turned back settlers who tried to go west of Portage la Prairie before any arrangements were made with them for the use of their land (Morris, 1880). The aboriginals' spatial concerns were made clear in 1858 to a special expedition charged with "the Exploration of the Country between Lake Superior and the Red River Settlement" when they were greeted by a band of Saulteaux who wished to "ascertain the reasons why a group of white-men wished to pass through this part of their country" (JLAC, vol.21 Appendix. 3: Dawson). It required the expedition several hours of consultation with Band leaders for them to cede to their travelling across their territory. The experience led the geographer George Gladman to conclude that the lands through which the "exploring party has had to pass, being Indian property, the necessity of making some arrangements with the tribes to which they belong becomes immediately apparent, in order that measures may be devised to prevent difficulties and collisions" (JLAC, vol.21 Appendix. 3). By refusing Euro-Canadians to settle in the territories of Manitoba and the North-west, the aboriginal peoples forced the Dominion of Canada to constitute a policy to deal with their 
concerns (Public Archives of Canada. Record Group 10 vol. 3576. file 3781; vol. 3636 file $6694-1)^{2}$

The emergence of a new rationality of government denotes a new concern for space. a concern to open up the territory which had for so long been governed and gated by the HBC. The aboriginal peoples recognized this would have discriminate implications for their mode of being. In response to the concerns and actions of the aboriginal peoples, the Dominion of Canada negotiated a series of seven Treaties between 1873 and 1876 which surrendered aboriginal title to the land. While the Canadian state intended only to concede spaces of land, and cash annuities. the aboriginal peoples sought that which would help to solidify their future. The Saulteaux of Treaty 3 rejected this initial offer from the state in 1871 and again in 1872 . It was not until in 1873 that the state ceded to their demand for animals, horses. wagons, and farming implements which then became standard articles of the treaties (RG 10, vol. 3571 file 124-2; vol. 3603 file 2036).

With confederation and the opening of the space of the West two distinct cultural groups with clearly perceived interests who, as a functions of their dissimilar ends, entered into association with one another. On the one hand. the Canadian state was concerned with a "national plan" which would see the "development and settlement of the vast regions between Ontario and the Pacific Ocean" and the intrusion of a prescribed mode of life, while on the other, the aboriginal peoples were concerned with their traditional space and conditions of existence. It is these two clearly defined concerns, each with an investment in their future existence, which would shape future relations.

\section{The Creation of a Space and Domain of Intrusions}


An important provision of the treaties was setting aside land as reserves for the different Bands at the increased proportion of one square mile, or 640 acres per family of five (CSP vol. 35 no. 22, 1872, pg. 14). Governor Archibald explains that the Dominion:

will lay aside for you lots of land, to be used by you and your children forever. She will not allow the white man to intrude upon these lots. She will make rule to keep them for you. (Cited in Begg, 1894).

While the treaties ultimately functioned to cede the aboriginal title to the land, perhaps the capacity of the treaties and the creation of reserved lots of land was more than opening a closed space. more than the cessation of a territory. Perhaps it was for the closing of space. of the constitution of a domain of government, one designed to divide and constitute the aboriginal mode of life in relation to the intrusive prescribed mode of European life. The mode of life of the aboriginai peoples, and their concern for space ultimately rationalized their exclusion from the privileges of liberalism and the intrusion of practices of government to harmonize their actions. Hayter Reed, of the Department of Indian Affairs, states that the aboriginal peoples:

must be imbued with the white man's spirit and impregnated with his ideas. The end in view in the policy adopted for the treatment of our wards is to lead them, step by step to provide for their own requirements, through their industry ... which will fit them for enfranchisement, and the enjoyment of all the privileges, as well as the responsibility of citizenship (CSP vol.53, no.12, 1890 pg. 165).

Once the Dominion of Canada obtained title to the western portion of the country they were able to open this portion of the country for settlement. However, the extension of citizenship and participation in the emergent order of things excluded the aboriginal peoples. If they were to participate in this order their values and mode of life would have to be harmonized 
in relation to it.

The relationship of difference is here ordered and othered once and for all. On the one side. the aboriginal mode of life is othered. By this I am referring to the process of setting boundaries between the aboriginal mode of life and that of the emergent and prescribed EuroCanadian one that is valued and placed in opposition to the "other" (Salvatore, 1996). While on the other side, and implicit in it, is the ordering of aboriginal culture. That is, the process of normalizing and harmonizing the mode of life of the aboriginal peoples with the newly emergent order of things. This process - of othering/ordering - does not originate with the emergence of the Canadian state in the west. but rather, with the early settlement of the territorial space, with the intrusion of missionary practices and the drawing of the aboriginal peoples into a foreign "justice system." However, where a rationality of government is extended and inscribed to perpetuate its own ends, these practices and ends will not flourish, but are seen as secondary to the interests of sovereignty. When attached to a rationality of government which seeks to establish and intrude a mode of life, the process of othering/ordering becomes not only pertinent, but fundamental to the ends of the emergent Dominion.

The aboriginal mode of life was not valued in relation to the emergent Euro-Canadian one and thus was to be shaped, moulded, and "imbued with the white man's spirit" (CSP vol.53 no.12 1890 pg.165 Reed). The emergent liberal order is marked in opposition to the aboriginal mode of life. It is a difference which is to be divided out and excluded from privileges enjoyed by the included. It becomes a status of exclusion which marks those who share its values and mode of life as a domain, a domain of intrusions to govern and shape 
their mode of life. This status is othered, and the new mode of life made functional. through the demarcation of the aboriginal mode of life as a domain of government to be shaped, harmonized and ordered in relation to the prescribed mode of Euro-Canadian life. To render the othered status of the aboriginal mode of life functional, government disposed two practices to mark this material and divide it as a domain of government. The process of marking and dividing the othered status of the aboriginal peoples was initiated by the signing of the treaties, however, in addition government sought to both, physically divide the aboriginal mode of life through reserves, and legally through status.

\section{Marking the Domain of Government: Tangible Boundaries}

While settlement on reserves, was in no way compulsory, these spaces designated a space of government where the demarcation of aboriginal peoples as other could be at once ordered. However, this is not to say that the aboriginal peoples refused to settle on, or determine the site of their reserves, but rather within a few months of the signing of the Treaties they had already begun the process (RG 10 vol. 3625 , file 5489 Christie to Laird, Oct. 7,1875 ). Some bands formally requested the Dominion surveyors to mark out their space (RG 10 vol. 3626 file 5894; vol. 3635 file 6647). Clearly some of the aboriginal bands were ready to commence a new life on their reserves. While the reserve provided the aboriginal peoples with a space to enter into a new mode of existence, it also served another important function. It set out the boundaries between the aboriginal mode of life and the emergent one in a tangible way. By setting out plots of land for the exclusive use by the aboriginal peoples, the Dominion of Canada effectively divided their mode of life from the emergent order and constituted it as a domain of government. 
The practice of dividing the aboriginal mode of life from the prescribed order of things emerged with the programme of amalgamating the aboriginals in the east. While the situation in the east was not identical to that of the west, ${ }^{3}$ the programme of physically dividing out the aboriginal mode of life was initiated here and sheds iight on the introduction of the practice.

Prior to the 1820 's, and the emergence of the practice of physical division, the aboriginals were military allies who received presents in exchange for their services. Much like the aboriginal peoples in the fur trade domain, the indigenous mode of life was valued in relation to an end. In the latter part of the $1810^{\prime}$ s the aboriginal peoples were no longer required in this service and debate was initiated in England concerning the efticacy of continuing the system of presents (JLAC, 1844-5). At the same time discussion also centred around the possibility of settling the aboriginals on reserves. In the 1820 's the military personnel in charge of Indian affairs reached a decision - which was supported by the colonial governors in Upper and Lower Canada and given approval by the Imperial authorities in 1829 - to settle the aboriginals on reserves (JLAC, 1844-5). It was with this decision that the emergence of the reserve system can be envisioned.

Prior to this decision, the Royal Proclamation of 1763 protected the aboriginal mode of life from intrusion of European encroachment on their traditional hunting grounds. The aboriginal peoples were granted the right to self government which assured them the right to determine their own fate, and to govern "such Parts of our dominions and Territories as, not having been ceded to or purchased by Us, are reserved to them, or any of them. as their Hunting Grounds (Royal Proclamation, 1763) and that they "should not be molested or 
disturbed" until they sold "their lands to the crown" (Royal Proclamation, 1763). Despite this proclamation and the urging of the "Select Committee of the House of Commons on the Aborigines of the British Settlements" that "whatever may be the legislative system of any colony, we therefore advise, that, as far as possible, the Aborigines be withdrawn from its control," (Great Britain. House of Commons, 1837) there came a time where the aboriginals corporate rights to the land, timber, fish and game and protection from "villains, poachers, alcohol peddlers" and their amalgamation with the Europeans had to be considered.

The most efficient manner of protecting the Indians against these evils was to divide them from the Euro-Canadian population and settle them on isolated reserves. By settling them on isolated reserves where contact with the Europeans would be minimal, the aboriginals would be protected from the worst deprivations of the culture, however, it would do little for their amalgamation with the Euro-Canadian population. In the years that followed, there were many ambitious attempts and experiments conducted to devise a programme to govern and shape the souls of the aboriginal people. One of these experiments was conducted on Manitoulin Island and consisted of elaborate provisions for schoolteachers. missionaries, artisans, and trade schools (ЛAC. 1858). It was thought that by dividing and training the aboriginal peoples they would quickly embrace the culture. In short Manitoulin Island became a fully administered domain of government. It was found, much like the missionaries did in Red River, that in the absence of the personnel the governed would revert back to their old ways.

In 1858 it was left to a "special commission" to inquire, "first - as to the best means of securing the future progress and civilization of the Indian Tribes in Canada" and "second - 
as to the best mode of managing the Indian property as to secure its full benefit to the Indians without impeding the settlement of the country"(JLAC,1858, part I). The conclusions reached by the commissioners led to the basic programme of settling the aboriginal peoples on reserves of land and encouraging them to take up some form of industry - which mostly meant farming - until that time which they could prove themselves worthy of the removal of the legal distinction between them and "other Canadians" +

\section{Marking the Domain of government: Legal Definitions}

The Dominion of Canada's relations with the aboriginal people witnessed a transformation from the liberty of self government incorporated in the Royal Proclamation of 1763 into a people whose mode of life was marked as a domain of government (Clark, 1990). Up until this point I have made mention of the "othering" of the aboriginal peoples only in relation to setting tangible boundaries between the aboriginal mode of life and the emergent one. An essential element in the process of othering a people concerns the question of membership. That is, in order to govern a population, and constitute it as a domain of government, it becomes qualitatively necessary to define the material upon which to work. However, the definition of this material, and the inclusion or exclusion from that population is what Derek Smith (1993) terms an "inauthentic ethnic category". That is, one whose definition was not derived from the cultural members, but rather from criteria generated entirely from an administrative origin. The definition of the aboriginal person, and the material which was to be worked on and harmonized, is embedded in Canada's constitutional documents (British North America Act, 1867) as well as, in later Acts directly aimed at consolidating the administration of Indian Affairs (Indian Act. 1876). If the reserve was to 
be the space where the programme of government was to be realized, the legally defined mode of life of the aboriginal peoples was to be the domain into which this was to be intruded.

An interesting feature of the definition of the aboriginal person is the determination of group association. In the discourse of these legal documents, a group of Indians is always referred to as a "band", which is distinguished by [bands of Indians] "who are interested in a reserve of lands in common, of which the legal title is in the Crown (Indian Act 1876). The administrative constitution of the aboriginal person rests upon additional criteria that applies directly to the individual. The individual's membership is tied to the patrilineal system of descent, where an individual was only considered included in this category if their father embodied this legal distinction (Indian Act, 1876). Those included in this category are subject to certain restrictions on their personal liberties, such as, the inability of those included to own property and dispose of it as desired. The boundaries of this status can be liquidated by enfranchisement where the aboriginal person must prove that they are free from debt, of good moral character and after a probationary period of three years receives a "patent for their land within the reserve" and all the "rights accompanying it" (Scott, 1914).

The aboriginal person can cease to be included in the legally constituted category of aboriginal peoples. How can this be? The individuals biology has not some how been ruptured. If the person can cease to become a member of the included, what is it that constitutes this legal category? It must be the mode of life, the culture and values shared by the included group. It is this material, the mode of life, that becomes othered and constituted as the domain into which are intruded practices of government aimed at enfranchising and 
amalgamating the aboriginals.

The question of the status, and legal definition of the aboriginal person was, according to Dickieson. an Indian agent in the West, an important one to decide:

The question of who is or who is not an Indian is a difficult one to decide. . the question then arises - where shall the line be drawn to decide who is or who is not an Indian? I considered the policy of the government was to elevate the Indian in the scale of humanity not to degrade the White to the position of the savage (CSP vol. 40, no. 11, 1877: xxxiv).

In these comments the division between the different modes of life becomes obvious. There is a boundary between a prescribed mode of life and one which was discursively and legally constituted as deviant. It is in relation to this constituted status that the aboriginal peoples are to be governed. The legal definition of the aboriginal peoples effectively rendered visible and marked the material upon which practices of government were to work. It is not a biological characteristic which was to be "elevated," but is the mode of life, the culture, and values of a divergent domain.

The status of othered demarks a governmental domain of intrusion. The ultimate end is the creation of an individual who is not "othered", but embodies the prescribed mode of life. Here then, the status of the aboriginal peoples is to be known and governed. not as a category in and of itself, but in relation to a normalized mode of life. It refers, and is defined, in relation to an outside which is both legally and spatially constituted. The outside constitutes a normalized mode of life which is embodied in the Euro-Canadian order of things. This becomes a category of inclusion and exclusion where the othered is at once differentiated and ultimately marked as a domain of intrusion.

\section{Dividing Practices and the ends of government}


Through the reservation system and the legal definition of aboriginals the dominion of Canada effectively set both physical and discursive boundaries between the mode of life of the aboriginal peoples and that of the emergent normalized one. The end of this division was to specify the material which was to be shaped. moulded and ultimately eradicated through enfranchisement. By setting the aboriginal mode of life apart both spatially and discursively, government defined, delineated, and constituted a domain of government where practice could be disposed to structure the actions of the demarcated.

The aboriginal peoples were defined as individuals and in relation to their group membership. Above, I discussed how the band was the basic political, social and economic unit of the northern plains aboriginals, now however, the definition of the band shifts. The band, with the signing of the Treaties and the emergent rationality of government, becomes an administrative unit which is attached to a geographical space. While the choice of the band as an administrative unit did not have to do with grafting an emergent mode of life onto the old, it did have to do with the creation of an instrument of government which was made practical through the partitioning of space and the discourse and technology of governance. Dividing the aboriginal peoples, not only from the Euro-Canadian population. but also amongst themselves, and by settling them on physically defined spaces, it constituted an "othered" domain which becomes governable. What one is able to say and observe about the total of the aboriginal peoples may be qualitatively different from whatever may be said about a single band contained within this administrative unit (Smith, 1985). Through the division of the aboriginal peoples, both by legal discourse and spatially, the Dominion was able to open the West for settlement, isolate the deviant mode of life as a domain of 
government, and through this, constitute them as an administrative unit of government where they could be shaped, normalized, and ultimately enfranchised.

\section{Liberal Rationality, Illiberal Tendencies, and Domains of Government}

In this chapter I endeavoured to demonstrate how, by addressing questions of political rationality, the practical questions of governing a domain becomes tied. not to external discourse, but to the intrinsic exigencies of the aboriginal mode of life. In this we are able to witness the implications of the emergence of a liberal rationality of government. With the emergence of a liberal rationality of government, it is not profits which are to be governed. but rather the aboriginal mode of life. However, it was not only the population that was the end of government, but too, the extension of space. And intruded into this emergent space was to be a new mode life. To achieve these intrinsic ends of government the aboriginal mode of life was divided out of the included population through legal and spatial means and constituted as a domain of government.

The discourse of liberalism stresses freedom and non-intrusion into individuals' lives where differences, among individuals, (religion, wealth, social position) are declared irrelevant to their qualifications for inclusion among those who enjoy liberties offered of the "natural human spirit" (Hoernle, 1969). The principles of liberalism were not born of the cultural contingencies and contact of the emergent frontier, but rather on blank pages of philosophers such as Rousseau, Mill, Bentham, and Montesquieu. In their theories, attention was centred on the consideration that all class based inequalities between humans were unnatural. All differences among humans, when considering the totality of humanity become irrelevant. The formula of liberalism asks the state to consider human units as though each 
were as like any other, "as one atom of a given element is like any other atom of that element" (Hoernle, 1969: 124). In the theoretical ramblings of the "great classical thinkers" this ideology was to apply to all individuals everywhere, no matter culture nor structural position in the societal regime.

Ideology, as Deleuze and Guttari have stated (1977), "explains nothing." However, this is only partly true. Liberalism is an ideology which is scattered throughout the note books of history. Rather than relying on ideology, the best "approach to a theory of liberalism" and its practices "is by way of the concept of man's [sic] power to do" (Hoernle, 1969: 109). In this, liberalism refers to a political rationality of government which functions within a realm of exigencies and intrinsic problems encountered by the state claiming to embody its principles. The wake of the interaction between political rationality and the intrinsic problems encountered by the state is often quite different from the premises upon which it is based.

The frontier of Canada, with all of its exigencies, was a context which these classical thinkers on liberty do not seem to have been aware of, and the Dominion of Canada not concerned with. The aboriginal mode of life was a barrier to the further settlement of the country. The aboriginal mode of life was an intrinsic concern that had to be dealt with before these ends could be realized. A defining aspect of this association was the relationship of difference which existed between a prescribed, and aboriginal mode of life. There was a boundary placed between the intermingling modes of life. A boundary that was defined, divided out, and through this constituted as a domain of government which sought to harnnonize this divergence. A fundamental aspect of this definition, and domain, was the 
manipulation of the traditional organization of aboriginal society - the band - as an administrative unit. Simply, those who embodied the aboriginal mode of life were to be excluded from the liberal privileges enjoyed by Euro-Canadians until that time which they could prove themselves worthy. Until that time, as we will see in the following chapters, their mode of life would be subjected to intrusion of government which sought to harmonize it.

The Canadian state, who so jealously cherished and extended liberal principles to the new Dominion, were lovers of liberty only when it concerned themselves. The "rights of humans" are the rights of those who embodied the prescribed mode of life while the divergent are divided out and excluded until that time when their mode of life is in harmony with the prescribed one. In short, when confronted by difference, the Canadian state was quick to abandon the fundamental principles of liberalism.

In this chapter I have sought to explain how the aboriginal peoples of the west became "othered," and how this status was both spatially and legally defined. When confronted with the intrinsic difficulty of a difference in a mode of life, the Canadian state did not fall back on the tenets of liberalism, but constituted it as a domain of government. In what follows I will endeavour to delineate how this othered difference was subjected to practices of government which sought to harmonize it. 


\section{Chapter Four}

\section{Intrusion of a Mode of Life: Subjection of the Normal}

The intrinsic concerns of the (Canadian) liberal rationality of government, when immersed in the West, centred around the opening of space for settlement, and the intrusion and establishment of a prescribed mode of life. These intrinsic concerns have three implications for the traditional aboriginal mode of life: first. that it was, in relation to it. differentiated and othered; second, that this mode of life was to be divided out and constituted as a domain of government; and third that certain intrusive practices were devised to govern and shape it in this direction. Above I established how the aboriginal mode of life became the parameters around which a domain of intrusive practices of government were to be intruded. The third implication is what the remainder of this work will consider.

The marking of the aboriginal mode of life as a liberal domain of government highlights the alienating quality of the emergent rationality of government. The rejection. exclusion, and further intrusion of a mode of life which is consistent with a national vision constitutes and marks, not only the aboriginal mode of life, but constitutes the new shape of the country. In dividing out the aboriginal mode of life, the Dominion effectively constituted itself. Had the aboriginal mode of life no insights to offer the emergent Dominion of Canada? And is it altogether just to treat the Indian in the way we are doing? Is it altogether fair to 
deprive them of their nationality, to laugh at their old laws and customs and traditions. to force upon them our own laws and customs as though there could be no two questions as to their superiority in every way, and that they must, of course, be just as suitable and applicable to the Indian as they are to ourselves. Is there nothing - nothing whatever - in the past history of this ancient people to merit our esteem, or to call forth our praise? Were their laws in the past all mere childishness (Fairplay, 1891)?

The answer to the preceding question, highlighted by an individual writing under the pseudonym "Fairplay," simply, according to those who had visions of the new constitution of the country, became no. Rather, this mode of life became subjected to practices of government which sought to shape and conduct it in relation to this vision. By excluding the aboriginal mode of life from privilege, and subjecting it to practices of division and intrusion, the Dominion of Canada endeavoured to first, constitute it in relation to the introduction of a prescribed mode of life; and secondly, constitute the nature and order of the Dominion. The division and differentiation of this mode of life is not merely a repressive practice. but is much more, it is creative, it is social, cultural, calculating and political.

\section{Inducing Change: Practices of Government}

The reserves and treaties served to mark and divide out a legally constituted category of individuals and groups as a special community of probationary citizens and a domain of government intrusion. The definition and division induced its effects so long as the individual aboriginal person continued to follow and engage in the constituted mode of life. The process of marking the aboriginal mode of life as "other" has a dual function: on the one hand, it privileges and constitutes one mode of life over another; and on the other it marks the deviant material as a domain of government. Its main function, however, is to make visible the gap between the two. In marking this division as a domain of intrusion and 
making it functional through spatial division, government was confronted with a problem of how to induce the prescribed change.

The answer to this problematic of government was not a simple one. In the space between the mode of existence of the Euro-Canadians and that of the traditional aboriginal one, many factors intermingled, one being the conditions of existence in the prairie region. The rationality of the fur trade had intruded a mentality which sought the accumulation of furs, however, this had certain important effects on the fragile resource base upon which the aboriginal peoples depended. Given this factor, government was left to consider "what measures can be taken to prepare the Indians for the time not far distant when the buffalo will be a thing of the past" (CSP vol. 40, no. 11, 1877, Laird: xii).' The solution to the problem, for individuals such as J.A. MacDonald, came down to:

a choice between two evils. We cannot allow them to starve, and we cannot make them into white men [sic]. All we can do is endeavour to induce them to abandon their nomadic habits, and settle down and cultivate the soil (Canada, Debates, House of Commons, April 23, 1880: 1693).

But what does this mean? I don't think that MacDonald is opposing the Euro-Canadian mode of life to the starvation of the aboriginal peoples, but rather showing that the concerns of government have more to do with shaping the mode of life of the aboriginal peoples in relation to the euro-Canadian one. To shape the domain of the aboriginal mode of life requires the training of this material in relation to both, the conditions of existence of the aboriginal peoples and the gap which exists between the differentiated modes of life. What governing this domain has to do with is a complex of relations concerning an "othered" category of people, their mode of life, the conditions of existence, and the intrusion of 
practices of government to shape it in conformity with the "new position of the country" (CSP vol38 no.8 1875 pg.14, Provencher).

The strategy of government to intrude a mode of life was initiated by a system of differentiation. The end of this strategy is to, on the one hand, induce the aboriginals "to abandon their nomadic habits" while on the other, to "cultivate the soil."(Canada. Debates, House of Commons, April, 23, 1880:1693, MacDonald). The means of bringing these objectives into being was through a complex set of practices disposed by agents of government to induce, to train, and to shape the aboriginal mode of life. Notice here that I am not concerned with a system of "coercive tutelage" (Dyck, 1991) of government, nor the "destruction of the tribal organization" (Carter, 1990) but with the practices of government which sought to structure the possible field of actions of the aboriginal peoples.

\section{Practices of Government: a Coercive Apparatus?}

A common discourse among historians who have commented on the subject of the administration of Indian affairs in the west, is the view that 1885 , and the aftermath of the North-West Rebellion, marks a coercive shift in governing aboriginal peoples. The tendency has been to view this event as the origin of a rigorous policy of destroying the tribal structure. Often this view is granted legitimacy by pointing to a memo by Hayter Reed (RG 10, vol. 3710 , file, 19,550$)$ as providing the impetus to this change in philosophy. If the North-West uprising of 1885 marks the origin of a coercive policy of government, then we must view the prior intrusions on the part of government - the intrusive practices of division, of missionary, and law - as merely being arranged around and excluding the mode of aboriginal life. Instead, there is evidence to suggest that the "assault on the tribal structure" had, since the 
commissioners of 1858 investigated the affairs of administering the aboriginal peoples, been of paramount concern. They concluded that, "another point of vital importance to be kept steadily in view, is the gradual destruction of the tribal organization." (JLAC vol. 21 appendix 21,1858$)$. It was also a concern for the first Lieutenant Governor of Manitoba. when he questioned the efficacy of the policy of government: "I may say, I have serious doubts as to the wisdom of the Canadian policy in perpetuating the tribal structure among the Indians, and likewise to the practice of granting reservations in large blocks of land" (CSP vol. 42 , no. 71879 , pg. 65 , Morris).

All throughout the period leading up to the events of 1885 , the political structure of aboriginal social organization was considered an end and concern of government policy (Debates H of C, May 5, 1880, Mills, pg.1994; Dawson. pg.1996). In the previous chapter of this work I have endeavoured to demonstrate how the practices of missionaries and the instrument of law shaped the mode of life of the aboriginal peoples. Prior to this, it was the mentality of the fur trade that was intruded into their mode of existence and had great implications for the shape of aboriginal social life. Where can we mark the origin of this policy? Simply, we cannot. Rather, and what I have sought to establish, is how the aboriginal mode of existence, - including the tribal structure - became marked, divided out, and intruded upon by practices of government at a historical point in time. What is important to consider, is not the tribal structure, nor the customs, and not the politics of the aboriginal peoples viewed in isolation, but rather as comprising a mode of life which was differentiated, othered and constituted as an intrusive domain of government. Through a policy of differentiation, and the sunstitution of the aboriginal mode of life as the parameters around which 
government intruded, it was the objective of government, through agriculture and settlement to "lead" the aboriginals "to a mode of life more in conformity with the new position of the country" (CSP, vol. 7. 1875; pg. 56, Provencher). While this policy may not be construed as "destructive," it was neither a benevolent policy which enabled the aboriginals to carry on a mode of existence heretofore undisturbed. The terms destruction, and benevolent do not capture the essence of the policy of government, rather, government must be seen and viewed in relation to the end of structuring aboriginal actions in a prescribed direction.

How then did those who governed the domain of the aboriginal mode of life endeavour to structure the choice of actions in a direction which would "attach them to agriculture" and "settle them on reserves." According to Agent Markle of the Department of Indian Affairs:

It must however be remembered that our great desire is to educate and to persuade the Indians to do what is right because every step made by such method is valuable, where as apparent restrainment, to which in reality is the result of coercion, can only be of value so long as the restraining force is in operation (Markle to Birtle, May 12, 1887, RG 10 vol. 3598 file 1361 ).

It was no use to coerce the aboriginal peoples to stay on the reserve and farm. for as soon as the coercive apparatus was removed any perceptible gains would be lost. Instead, when governing the aboriginal mode of life it was necessary to structure their actions through practices of government which were to intrude and shape it. That is, "no one can at once force an Indian to take hold of the plough and keep stead at work" (Dewdney, CSP vol. 43, no. 11, 1880: 100). To govern the actions of the aboriginal peoples. to settle them on reserves, to induce them to commence an agriculture mode of life, required that government devise certain practices to govern the choice of actions of those who constituted the domain 
of government. It may be better to think of this in terms of conducting as opposed to coercive domination, or destruction. To conduct signifies the action of leading, and guiding the possibility of actions and putting in order the possible outcomes of government (Foucault, 1983). To govern a domain, to shape its mode of life, is to govern the choice of actions. It is to "lead' or 'induce" the aboriginal peoples to shape their mode of life in relation to the Euro-Canadian one.

Implied in this conception of government is an element of freedom which cannot be included when the defining discourse is coercion and domination. In this way, resistance is not merely something to be added in at the end of a chapter, but is a fundamental part of the government project. It is implied. It is a requisite for the practices of government. Thought of in this way, government is action upon the actions of the aboriginal peoples. But does this mean that those who chose to engage in agriculture were consenting while those bands who refused to take up this mode of life were resisting and had to be coerced? In my opinion the nature of the project to govern aboriginal peoples cannot be captured using this dichotomy. Rather. what is pertinent in this consideration, is an understanding of the conditions of life which confronted the aboriginal mode of life, the ends of government, and agency of the indigenous peoples.

If given the unrestrained choice among modes of life, one could assume that the aboriginal peoples would choose to continue in their traditional one. In the treaties there was a stipulation that:

you will still be free to hunt over much of the land included in the Treaty ... you will be free to hunt over them, and make all the use of them which you have in the past ... the Queen, though she may think it good for you to adopt civilized habits, has no idea of compelling you to do so. This she leaves up to your choice and you need not live like white 
men [sic] unless you can be persuaded to do so with your own free will (CSP vol. 35 no. 22 1872: 16. my emphasis).

The fact that this mode of life existed and was offered as an alternative was not a precondition for its acceptance, rather, the choice to engage in agriculture or to "live like white men [sic]" must be seen as tied to the practices of power which governed the choices of the aboriginal people. However, practices of government, on their own, would not be sufficient to induce the aboriginal peoples to take on the prescribed mode of life. Rather, these practices were mediated by and through the conditions of existence on the prairies. Consider the following example of the Commissioner of Indian Affairs Dewdney's comments when on an inspection of Crowfoots band at Blackfoot Crossing:

On arriving there. I found about 1300 Indians in a very destitute condition, and many on the verge of starvation. Young men who were known to be stout and hearty fellows some months ago were quite emaciated and so weak they could hardly work (Dewdney to Dennis. RG. 10 vol. 3696 file 15266 ).

Given the conditions of existence of Crowfoot's band, it is not difficult to image how government sought to intrude a new mode of life and how (some) aboriginals welcomed it. The conditions of life on the prairies were such that the traditional means of subsistence would no longer support them in the manner they had in the past (Hagarty to Laird, RG 10 vol. 3695, file 14924). In addition, abuses of alcohol perpetuated by American whiskey traders and disease added further to these conditions. These conditions in and of themselves, for many bands, was sufficient cause to settle on their reserves and commence agriculture. However, on the other hand, the practices of government were also mediated by these conditions of life. In order to achieve the ends of governing this domain - settlement on reserves, and the undertaking of agriculture, and ultimately the amalgamation with Euro- 
Canadian society - certain practices of government, which linked up with the conditions of life on the prairies, were disposed to structure the actions and govern the choices of the aboriginal peoples.

\section{Inducing Change: the Reserve and Agriculture}

One thing is clear from reading the reports, files and correspondence of the Department of Indian Affairs, and the Debates in the house of commons, and that is; the Dominion of Canada did not have a coherent policy for dealing with the aboriginal peoples of the west when the territory was first ceded to them. This would have critical implications for the relation between government and the aboriginal peoples.

In the years which directly followed the signing of the treaties many of the bands were not only willing to commence agriculture, but demanded that the government survey the lands where this new mode of life would be carried out. However, the surveys did not commence until 1875. and when they did, it was only with those bands who expressed a desire to commence this mode of life immediately, or for those Bands whose reserve was where the railway or telegraph line was to be laid (RG 10, vol. 3625 , file. 5489 , Christie to Laird, October, 1875). To complicate matters even more, during this same year, there were no actions by government to issue the necessary materials for the aboriginal peoples to farm. There was no issue of seed nor implements, and only one band received cows or oxen for the purpose of farming ( $R G 10$, vol. 3642, file 7581, McKay, 1876). But this was no fault of the aboriginal peoples, for in 1875 some of the bands who were ready to begin a farming mode of life demanded that agricultural implements be furnished them (RG 10 vol. 3622 . file 5007 , Morris to Laird, July, 1875). In not supplying the required implements, cattle, and not 
surveying the land the Dominion of Canada effectively undermined the aboriginal peoples efforts to commence a farming mode of life. In addition, and to further arrest the development of the aboriginal peoples toward agriculture, was the fact that the aboriginals did not possess the necessary knowledge for farming. Consider the following words of Yellow Quill: "The Canadians have chased away the moose, the Buffalo and all our wild game; and nothing now remains but the land. We would like to get a living from it, but we have neither the means nor skills to do so" (RG 10, vol. 3695, file 14924, Hagarty to Laird, August, 13,1875$)$. Other agents in the field, too, witnessed the need for providing some form of instruction in the new mode of life (RG 10, vol. 3609. file 3229, Dickieson to Laird, January, 1875). The end of this policy of non-intervention by the Dominion resulted in mass starvation. and in one case in 1878 about seventy-five aboriginal peoples were found near Qu'Appelle unable to travel since their dogs and horses had been consumed (Carter. 1990).

This result is no surprise however, when the discourse contained in the reports, correspondence, and organization of the department of Indian Affairs is considered. In the period between the cessation of land from the $\mathrm{HBC}$ and 1876 (or the conclusion of the final treaty) the concern reflected by the discourse of the DIA reports was the opening of the space of the prairies for settlement. The Department of Indian affairs during this time was organized in such a way that would facilitate the signing of the treaties, but not the instruction, nor the aid in assisting the aboriginal peoples in adopting this new mode of life. In a memorandum to the Minister of the Interior Howe, Lieutenant Governor Morris expressed his dissatisfaction with the manner in which these affairs were carried out. The conduct of Indian affairs in Manitoba and the North-West Territories: 
...naturally divides itself into two branches, the carrying out the existing Treaties, and the entering into new Treaties. First with regard to the carrying out of existing Treaties, I regard the system adopted as eminently unsatisfactory. The work is placed under an officer, the Indian Agent, with one assistant (RG 10, vol.3605, file 2946, Jan.24 1874).

According to Morris the lack of officials to conduct aboriginal affairs was quite unsatisfactory, and to remedy this situation "I [Morris] would separate entirely the duties of carrying out the existing Treaties, and the making of new ones"(RG 10, vol. 3605, file 2946, Jan. 24, 1874, Morris). However, it would not be until two years later that this policy would be implemented.

A number of intervening factors limited the potential success of the intrusion and commencement of this programme. On the one hand, those who were to govern this domain were ill-prepared for the demands of governing this domain, both. in terms of organization and in terms of the granting of Treaty promises. While on the other hand, and as a result, the Dominion of Canada was ill prepared for the expense of this endeavour. As a result of not aiding the aboriginal peoples in commencing a new mode of life, combined with the conditions of existence facing the aboriginal peoples, their want of food, and the disease which plague the prairies, the state incurred a great expense in feeding or "rationing" and administering the aboriginal peoples. The expense was not in keeping with concerns that the Dominion had for economy. Mr. Blake in a debate in the house of Commons, stated:

You are expending about $\$ 500000$ annually upon the Indians, and $\$ 300000$ for the Mounted Police, the principle cause of which was to overhaul the Indians peaceably. You are approximating to the expenditure of $\$ 1000000$ a year for the management of the Indians of the North-West. (Canada, House of Commons, Debates, April 231880 Blake. pg.1692).

The result of the policy of feeding the aboriginal peoples was that the state was "training the 
Indians to look to us for aid"(Canada, House of Commons, Debates, April 23, 1880, Blake, pg. 1692) and encouraging "idleness" (Canada, House of Commons, Debates. April, 23, Mills. pg.. 1691). This system of governing the aboriginal peoples was a great expense to the Dominion, as well, it "had a tendency to put the Indians in a worse, instead of better position" because they "are led to look to the community for their support" (Canada, House of Commons, Debates, April, 23, Mills, pg. 1691). Until a shift in government took shape, the policy initiated to induce a change in the mode of aboriginal life was ineffective. Looking to the state for relief was not training the aboriginal peoples to support themselves within the parameters of the Canadian economy. Reliance on the state for survival was widening. instead of narrowing, the gap of differentiation.

To train the aboriginal peoples, to govern their actions, reduce the cost of administration. and narrow the gap of differentiation required a shift in the organization and conduct of Indian Affairs. A shift which would enable government to structure the actions of the aboriginals in the direction which would allow them, "to gain their own livelihood and not to depend for it on the tax payers of Canada"(RG 10 vol.3743 file 29488-2 Dewdney to Vankoughnet, 1886). To govern the aboriginal mode of life a 'new' policy was invented where provisions would be made only "for the men who worked" (CSP vol.44 1881 pg.82 Farm Instructor Rae). This policy, initiated in 1879-80, "enabled the Government to relieve hunger and sickness" (RG 10 vol. 3743 file 29488-2 Dewdney to Vankoughnet, 1886) of the aboriginal peoples, while at the same time it functioned to "induce the Indians to adopt the habits and labors" of the Euro-Canadian mode of life.

The conditions of life of the aboriginal peoples, the concern for economy, and the end 
of the programme - settlement on reserves and engaging in agriculture - linked together to comprise an organization of government which sought to structure the actions of the aboriginal peoples of the prairies in relation to the prescribed mode of life. The desire to shape this mode of life was conditioned by the belief that "so long as his [sic] nomadic habits are encouraged so long will the authorities have to provide for him without any adequate return being had from the land" (CSP vol. 47 no.4 1887, Dewdney, pg. 102). The nomadic habit specifically. and the mode of life generally, of the aboriginal peoples was the domain of concern. It was a domain which was to be structured by actions of government. 


\section{Chapter Five}

\section{Governing the Choice of Actions: Law; Consumption; and Individualization}

Practices of government, which are invented and disposed by agents of government, must be seen as tied to the ends of government. In the previous chapter we saw how the ends of government were comprised of settling aboriginals on reserves and the adoption of an agricuitural mode of life. These two ends, however, should not be viewed as distanced from the amalgamation of the aboriginals with the Euro-Canadian mode of life, but rather, as directiy tied to it. The purpose of this chapter is to delineate how government, through the use of practices, structured aboriginal actions in the direction of amalgamation with a "prescribed" order. I will be focussing my attention on how practices of government structured the choices of aboriginals. The first section undertakes an analysis of the mechanics of the practices of government. Here I provide the reader with a brief introduction to the mechanics of practices. In the remainder of the chapter I discuss the cluster of practices which were disposed by agents of government. The second section focusses attention on the use of law as a practice of govemment. However, law in itself is not sufficient to induce the requisite transformation. Therefore, in the final sections I discuss the numerous practices of government, which in addition to law, functioned to structure the 
Ḧogeveen, An intrusne ana Correctrve Government

choices of the aboriginals in relation to the "prescribed" order.

\section{The Mechanics of Government Practices}

Whiie practices of government are intrinsicaily iinked to the domain which is their end, there are other essentiai components of this machinery. For exampie, when indian Agent Clarke states that: "Every able bodied indian was required to prove to the satisfaction of the Farming Instructor, that he [sic] was engaged in some of these occupations before receiving reiief for him and his family" (CSP vol.44 $1881 \mathrm{pg} .101$ ), there is evidence that practices of government impiy much more than a iink to a domain of government.

First, practices of government are tied to, and link up with the conditions of existence which faced the aboriginals. Where else, except in reference to this domain of government, could the practice of withholding provisions of food be disposed to govern actions. In this way, practices are not viewed or interpreted as being universai, nor functionai in any other domain. Practices specificaily, and government generaily, are linked intrinsicaily to the exigencies of the popuiation which is to be acted on. Simply put, practices to govern actions are invented and given prominence among oniy the popuiation which is their end.

Second, there is an attachment of vaiue to actions. That is, if an aboriginal person is busy farming and settied on the reserve, their actions are deemed desirable, normal, and thus deserving of rewards in the form of rations. However, if there are actions which are encouraged, there must be an inverse. If an individual is engaged in "other" occupations, ones that are consistent with their traditional mode of life and thus in opposition to the prescribed one, their actions would be observed negatively.

Third, practices of government presuppose an element of freedom and agency of the 
governed. Implied in the practices of government is a free and active subject, one who requires intervention to shape their actions. Freedom is the materiai which is being worked on. it is the mode of life of the aboriginai people. It is the deviant materiai. To engage in traditionai actions is resistance. If the aboriginal peoples were not resisting the intrusions of a prescribed mode of life, there would be no need for practices of government. Freeciom is impiied and a requisite part of practices of government instead of viewing the mechanics of government and the actions of aboriginal peopies as dichotomized between "coercive assimilation“ (Miiler, $\mathrm{i} 9 \hat{9} 9 \mathrm{i}$ ), and unrestrained resistance and treedom, it is more beneñciai to presuppose freedom of actions as the material which is to be structured.

Lastly, there exists an agent of government who "sees" and "ciassifies" actions. This implies a form of surveiliance and a knowiedge which is indispensabie to the government of aboriginais.

Through this doubie system of classification and visuai observation of actions it is now possibie to envision how the mechanics of government practices endeavour to structure the actions of the traditionai aboriginai mode of iife. Here then we are abie to discern how it was that agents of government conducted the aboriginal choice between traditionai and prescribed actions and habits. The mechanics of governing the iives of the aboriginai peopies is tied to a system of "training" which is based on the iogic of vision, classification, and gratification and punishment that is iinked to the conditions of existence, and the objectives of government.

These points ( which i have outined above) are absolutely crucial to an understanding of the practices of government, or rather, the mechanics by whicn government sought to 
structure the actions of the aboriginal in relation to a "prescribed" mode of life. it is necessary to avoid a teieoiogicai anaiysis in which the characterization of governmentai practices are estabiished in reiation to "events"- the North-Ẅest Rebeiiion of $\mathrm{i} 885$ - which oniy partiaiiy represents the interactions between government and aboriginais. To reiy on the fiow of "evenis" from confederation to recount a story of government would be io deny the importance of subtie shifts in poilicy and the more mundane forms of government and resistance. in the remainder of this chapter İ seek to make inteiiigibie the practices under examination on their own terms. This type of approach eschews the "event" as provocation for snifts, breaks, and ruptures in practices of government.

Before moving to an anaiysis of the mechanics of government iet us consider one exampie of how practices of government endeavour to structure the choices of aboriginais. in the Treaties there was an agreement made that certain farming impiements wouid be granted ( which are outiined in Chapter three) " with a view of inducing the incians to adopt the habiis and labors of civiiization" (CSP voi. 35 no. 22, i872, pg.29 iviorris). when taken by itseif and in a different context, providing agricuiturai impiements to individuais does not govern choice. However, when tied to the uitimate end of government - the amaigamation of the aboriginais with the prescribed order - and situated within the context of the conditions of existence on the prairies, the practice of granting/withnoiding agriculturai impiements takes on a meaningfui role in shaping aboriginai actions. Practices of government become functionai oniy when there is vaiue and rewardis/punishments attached to actions. Consider for example the foilowing statement made by Commissioner of indian Âffairs Dewdiney: 
it would be a great inducement to our indians to settie down and become independent if a piough were given to those families who satisfied the Agent that by their industry they couid become so (CSP voi.45 no.6. i882. pg.4i).

In this instance the constituted positive choice of action is encouraged through rewarding those individuais whose actions are ciassified by an Agent as desirabie, normai, and consistent with the ends of government. The practice of granting/withhoiding farming implements implies that there exists an individuai who is capable of choice among avaiiabie actions. it is this choice which the practices of government seek to ciassify and structure in the direction of amaigamation with Euro-Canadian actions.

Practices of government are "corrective". They seek to structure the actions of the aboriginais in a derinite and normai direction. There is then, a mechanics of government which arranges actions in reiation to that which is considered normal - an independent and settied mode of life - and that which is considered deviant - the traditionai mode of aboriginai iife. Corresponding to this is a system of gratification/punishments (Foucauit, 1977: 180 ) which seeks to structure the choice of possibie actions of the iatter in conformity with the former.

\section{Law as 'a' Practice of government}

Perhaps the most obvious exampie of the use of the punishmentgratification principie for correcting actions and intruaing a prescribed mode ố iife within a iiberai rationaiity of government is the practice of disposing laws to this end. in iiberal political discourse law is often equated with order. Some authors have specuiated that law constituted the driving force behind the institution and "making" of order in the West (Loo, i 994 ). it wiii become ciear in what foliows that the approach which merges the power of law with a 
constituted order, and the arrangement of institutions which it presupposes, must be chailenged to appreciate the ruii significance of the practices of government. This is not to say that iaw is unimportant to this end, but rather, that order is constituted by more than a simpie invoking of formal iaw. Rather, formal state law comprises oniy one of a cluster of practices which confronted and governed the aboriginals choice of actions. The remainder of this section considers the role of law in the government of plains aboriginais after 1870 .

\section{NWMP and Government}

When the Dominion of Canada acquired the territories formerly occupied and governed by the $\mathrm{HBC}$ they took immediate steps to institute law in the territory. However, without "a civil force to enforce them [laws] they are not worth the paper they are written on" (RG I0, file 3278, vol.3609 McDougal to Smith 1874 ). In the face of the intrusion of Euro-Canadian settiers into the west, there was the risk of "a rupture with the natives, not unlike that experienced to the South" (RG 10, file 3278, vol.3609 McDougai to Smith 1874). In relation to these concerns - the constitution of an order of things, the enforcement of laws, and the security of settiers - Prime Minister Macdonald's solution was the organization of a mounted police force for the "preservation of law and order in the North-West Territories" and consisted of introducing (in the beginning) "120 men and 50 horses" (Annuai Report, NWMP, 1874, pg.27) into the territory. The extension of the Euro-Canadian law to the North-West Territories after 1874 was established through, and organized under, an act which created the North West Mounted police (NWMP) as the governors of this process (Dominion Statute 36 Vic., Cap. 35).

The conditions of existence of aboriginal peoples induced them to choose between 
one of two courses of action. Either settle on reserves and take up agriculture or endure the hardships conditioned by the mentality of the fur trade and search for food over large expanses of territory. These conditions structured their choice of actions. The individuals who chose the former course of actions did not take up agriculture because of its superiority over their traditional mode of life. Instead, this choice was conditioned by their experiences encountered in the harsh environment of the resource depleted west. The latter choice of actions was structured by the practices of government such as law.

To envision the role of law, it is essential to consider what actions it governed. In a recent study, Macleod and Rollason (1997) endeavoured to quantify the aboriginai involvement in the Canadian criminal justice system. Contrary to contemporary Canadian society, they found with only one exception, the Euro-Canadian population was overiy represented in the cases of criminal activity which came before the criminal courts in the North-West territories between 1878-1885. These were the more traditional crimes, such as theft, assault, and "mischief". The one exception was in relation to a category which the authors called "livestock" theft. This crime, comprised of horse stealing and cattle killing, constituted $11 \%$ of the total of crimes brought to the attention to the NWMP. In this category of offences, aboriginal peoples made up the majority of the individuals charged.

When coming to terms with these findings it must be done so in the light of, the conditions of existence, the traditionai cuitural values, and the ends of government. For example, in one case two Stony aboriginal peoples were arrested for cattle killing, however, this was not a wanton act of cruelty, but rather a means of staying alive in the face of a blizzard. The two "Stonies ... came down from their reserve to hunt along the mountains 
and were caught in a heavy snow storm and almost starved" (CSP vol.47 no.4 1884 pg.79). Even given these conditions the NWMP"-arrested and punished [them] for their crime" (CSP vol. 47 no. 4,1884 pg. 79 ). Arrest and prosecution for this crime must be seen as having the effect of structuring the future choice of actions. In this way, law has the effect of working on the actions of the individuals arrested, but also, other aboriginals who wish to avoid the punishments associated with the negatively vaiued action of cattle killing. I am not here stating that killing livestock was part of a cultural determination which required work, but rather, aboriginal attitudes toward this action were influenced by practicai considerations. The decline of fur bearing animals, and the efforts by the Dominion to exercise economy conditioned this response by the aboriginal peoples.

In addition, part of the programme of intruding a mode of life were the efforts by agents of government to teach aboriginal peoples to raise livestock (partly to offset costs of "rationing")(CSP vol.45 no.6 1882, pg. 88, McCoil). However, in many cases, the aboriginai peoples viewed the greatest utility of these animals as a ready sources of subsistence. In one case, "the cattie were in a corral when a young man. . . shot 3 head" (CSP vol.44 no. $1418 \overline{8}$ ). Dewdiney, pg.86). The agent in charge quickly summoned the NWMP who then promptiy arrested the guilty party. Through the "plucky manner in which the arrests were made, and the prompt action of the authorities, the guilty parties received a lesson they will not soon forget. Since this occurred the Indians have worked well and behaved much better" (CSP vol.44 no. 14 1881, Dewdney, pg. 86). Through arrest and the practice of law the aboriginal actions of cattle killing came to be criminalized.

Until the 1870's the act of stealing horses was held in high esteem in aboriginal 
culture (Milloy, 1990). It was a matter of prestige to procure enemy horses without sustaining injury or death. To do so was to demonstrate courage. A successful attempt would eievate the status of individual among the members of the band (RG 10 , vol. 3668 , file 10644, Reed to Dewdney, 1884). Conversely, the Dominion of Canada deemed this action as criminal, as theft. To intrude this belief, this value, into the culture of the aboriginal peoples, or to "correct" this action, meant that government action was necessary. To deal with aboriginai horse thieves, Irvine tells us (Annual Report, NWMP, 1883, pg. 18)

The Indians so sent to the Mannituba Penilentiary were tried on the charge [or horse then]. Many other arrests on similar charges were made duning the surnmer. in all cases convictions followed. The sentences inflicted varied from two to five years imprisonment with hard labour. Such punishment has unquestionably been accompanied with the most beneficial results, proving, that the Canadian government was determined to use its utmost endeavours towards stamping out pernicious and criminal activities.

Law was disposed to govern, to shape, and correct the action of horse stealing. It was also used to shape other actions, such as the cultural practice of taking more than one wife:

it will be noticed . . . sixty-six indians have two, and eieven, three wives each; but since they are as amenable to the law as other subjects of the Queen. there is no valid reason for perpetuating polygamy by encouraging its continuance (CSP vol. 45 no.ó i $882 \mathrm{pg} .88$ iicCoili).

Other traditional aboriginal actions and habits were governed by the law. One of these was leaving the reserve. If the aboriginal person left the reserve they were subject to the provisions contained in the Vagrancy act. In order to be charged under this act, all an aboriginal person had to do was be seen in the vicinity of a town or city. in one case the mounted police explained the provision of the act, which stated "that no body of men [sic] would be allowed to remain idly about the country, and that unless the wishes of the 
government were acceded to, I should be forced to make arrests." (Annual Report of the NWMP, 1883 pg. 16 Irvine).

Other laws sought to undermine traditional ceremonies such as the potiach and sun dance ( Fetipas, 1991 ). To undermine these traditional gatherings, the agents of government disposed law to prevent the aboriginal peopies from leaving their reserves. Hayter Reed, the assistant Commissioner of Indian Affairs, stated that:

.. It behoves us iv do all in un powei io preveril ảnese gatherings if pussibie, and as a meuns to this enci, it would be weỉ, if the silghtest prelexi ofifers to arrest some of bite ring ieaders before the indians have assembied, inte iaws may have io be siruined a liatie to meet a particuiar case (my emphasis; Reed to Dewainey, i884 RG i0 voi. 3668 file lốt4).

This quote iiluminates two important points. On the one hand, and much more obvious, the traditional ceremonies and gatherings of the aboriginal people were seen as divergent actions that were to be harmonized. On the other hand, but not distinct from the first, is that law was disposed as a practice of government as a means to this end. This iast point is essentiai. Aboriginal peopie were arrested for actions which were consistent with their traditionai mode of life and practical experience, given the condicions of existence on the prairies.

Law was not oniy an end in itseif, to be intruded to undermine the customary law tradition of the aboriginals. No, this is hardiy the case. In many of the reports by the NWMP guilty parties of aboriginal peoples were left by the police to be deait with in their community. However, this is not to say that the traditional dispute settiement processes of the aboriginal peoples were to be maintained as a viable institution in the west ( $R \bar{G} 10$, vol. 346 ifle 3610 , Mckay to Hardisty 1875 ), but rather, that the intrusion of Euro-Canadian law was concerned with another end. Law, even if it had to be "strained" (RG 10, vol. 3668 file 
10644, Dewdiney, 1884) codified traditional actions as divergent and in need of correction. By codifying and sanctioning actions such as horse stealing, cattie killing, polygamy, and the gathering of aboriginal peoples for ceremonial purposes, the law functioned to conduct and shape their actions in relation to an end. This end, it must be seen, was the amaigamation of the aboriginais with the Euro-Canadians.

Law codifies and ciassiñes actions which are defined in opposition to the new order of things. Law corrects through punishment and negarive sanctions. However, it cannot be accounted for in terms of the assimilation of vaiues, but rather, and oniy, among the new ciuster of power relations which are bruughi to beal on the mocie of lifie of the aboriginal peopies with the shifn in the rationaiity of government. it is but one of the practices that sought to work on the actions of the aboriginai peopies. Law, on its own, couid not be disposed as a practice to intrude a new mode of life. Instead, a whole range of other practices were also disposed to structure the choice of actions of aboriginai peopies.

\section{Governing througin Consumption}

To have order impiies not only law but an arrangement of institutions consistent with the Euro-Canadian mode of life. While law, and a force to govern it, may have been sufficient to maintain and establish an order of things with the prior rationality of government, it is not a sufficient condition for the realization of it in the emergent one. This is not to say that law is an unimportant practice for the governance and convergence of order, but that it is merely one of a ciuster of practices disposed by those who govern to ensure a right arrangement of "things". A liberal order does not find its end in itself, nor does it find its end in law, but implies a plurality of ends and a cluster of practices to realize 
these ends. What becomes of interest then, is not law, per se, but the manner in which government works on, arranges, and structures the mode of life of the aboriginal people.

The iack of a sufficient subsistence base was a necessary pre-condition for government's attempt to struclure the actions of the aboriginal peopies. In this state of things, aboriginal peoples had a choice, to continue to hunt for food, or to commence a farming mode of iife. However, as we saw in the discussion of law, the former actions were not consistent with the prescribed order. These actions, because they were classified as negative vaiue in reiation to the "new position of the country" were to be worked on and structured in relation to the ends of government.

The conditions of existence on the prairies following the signing of the Treaties had important impiications for both, the aboriginal mode of life, and the practices of government to shape it. While the ideology of liberaiism goes against the granting of charity, the controi of foud consumption for the prairie aboriginal peopies was deemed necessary to both keep the aboriginal peoples from starving, and maintain them on reserves. Denying the aboriginal peoples food meant they would look for it eisewhere which in turn meant that the practical availability of settiers cattie would be an attractive aiternative (Satzewich, 1996). It was aiso thought that if the Dominion did not provide sume form of subsistence for the aboriginal peoples they would they would "cummil depredations amungst the settlers" (RG 10, voi. 372i, file 23666, Macloed to Vankoughnet).

The initial system of providing food for the aboriginai peoples saw the Dominion administer rations' to a selected Chief for them to distribute to the members of the band. However, this plan was deemed unsuccessful due to "complaints of unfair allutments" (RG 
10, voi. 3625 , file 5495 , Morris to Laird). in response to this. Agent Mackay endeavoured to introduce a system by which an agent of government would work at "ascertaining the number of famiiies and . . divide the provisions themseives among the heads of families" (RG i0, vol. 3625, file 5495, Mackay to Laird). While this system mediated against unfair allotments of rations, it functioned to "heip those who refuse to heip themseives" ( $R \bar{G}$ iU. voi. 3598, file $\mathrm{i} 36 \mathrm{I}$, Markie to Birtie). Through this system the agents of government were encouraging the aboriginal peoples to continue with their mode of life. in 1879 , the system of the "distribution of rations without rhyme or reason" was conciuded iRG i0, vol. jóve, file 3380 . Wadsworth to Denny). In place of this, there was a shift in policy where agents would be directiy responsible for the amount of rations distributed ( $R G 10$ voi. 3576 , file 309a, Dewdnev to Vankoughnet). T.P. Wadsworth. an Indian Agent, acquaints us with the system he referred to as "rationing Indians":

I do not confine myseif to give each Indian l pound of beef and $1 / 2$ pound of tlour per day precisely, but look upon the regulation ration as an average, or rather the maximum that may be given. Families that do little or no work. I give less than the amount. and so am able to give parties that work for themselves, or do work on errands for me a littie more. in thar way I am abie to get. a great deal more value for the amount of rations (RG IÚ. vol. 3605 . file 2950).

With Wadsworth's words we are able to envision how it was that agents of government rewarded those actions which are deemed normal or positive while at the same time corrected actions deemed undesirable. Value is attached to the classification of actions. In this way the idle, or those individuals who embody the negative pole of actions are encouraged to work in the 'right' manner through the desire to be rewarded, to receive relief and gratification in the same way as the diligent. The agents of government are not merely prohibiting traditional actions, but encouraging the adoption of more convergent way of life. 
Classification of actions was formalized through various means (reports, surveillance), however, the most immediate was surveillance by the agent who resided directly with the band. In an effort to reduce the cost of governing aboriginal peoples the Dominion of Canada endeavoured to make Indian agents accountable for the amount of rations they provided. They were to provide Ottawa with "lists" of individuais who were "eligible" to receive rations. To be eligible the aboriginal person was required to be engaged in acceptable actions. Through these lists, the Department of Indian Affairs would determine the amount of rations required to feed the eligibie individuais. However, if an aboriginai person, or group, decided to abandon these positive actions "their names would be struck off the list for rations“ (RG 10 vol. 3610 file 3434, Pocklington to Dewdiney, 1882). Through means of classification, agents of government, were able to effectively govern and structure the possibie fieid of action of the aboriginal people by governing consumption.

To govern the aboriginals was to classify and correct, reward and train their actions. However, to end our discussion on practices of government at this point wouid be premature. That is, given what $\mathrm{I}$ have been discussing in relation to classification and correction of actions, practices of government aliude to three related components: first, resistance by the aboriginal peopies; second, the classification of actions lends itself to further classification, selection and, as a resuit, medsures to correct these actions; and finally, to govern, to correct, and to classify actions implies an intrusive surveiilance of the population through agents of government.

\section{Yellow Calf - Overt Resistence}

Implied in government is a free and active subject. Resistance to intrusions upon 
their actions is an everyday occurrence, it is implied. It is the material which is to be worked on. If the aboriginal people were not resisting and not active there would be no need for the invention and intrusion of practices of government. However, there are times when these actions of government agents prompt a response which goes beyond everyday resistance. An example of this is the "the Yellow Calf incident".

In 1884 the farm instructor, for Cow-ne-ness band, Afr. Keith, was sitting at home when Yeilow Caif and 25 armed men entered requesting an interview with him. According to Keith, Yellow Calf, in an intimidating manner, told him that "uniess I would give all his men present flour and Bacone [sic] to take home with them, enough to last them some few weeks, they would burst open the Storehouse and heip themseives" (RG I0, file iúl 181 vol. 3660 , Keith to Dewdney, 1884). However, Keith informed the men that the instructions he received from "Mr. Assistant Indian Commissioner Reed would not ailow me giving his young men rations" (RG 10, vol. 3666, file 10181, Keith to Dewdney, 1884). What happened next, according to Keith, was that while he was trying to defend the stores, the men knocked him down and "stole right before" his eyes.

What accounted for this act of resistance by Yeilow Caif and his followers? According to Keith, the immediate reason for this raid was a cut in the amount of rations given to the members of the band (RG 10, vol. 3666, file 10181, Keith to Dewdiney, June 1884). Hayter Reed, the Assistant Indian Commissioner, agreed. Just a few days before this incident he had gone on an inspection of the band and found that "with two or three exceptions, Yellow Calf s band should not draw rations, as they were better circumstanced than any of the rest" (RG 10 vol 3666 file 10181 Reed to Dewdney, 1884). it was not 
"starvation which caused the band to commit the overt act" of resistance (RG i0 vol 3666 file 10181 Reed to Dewdney, 1884) since this bands condition had been observed and classified in a positive light, but rather, the practices of government to "train the Indians to work for what they receive." (RG 10, vol 3576 file 309a, Dewdney to Vankoughnet, July 29 1884). What Yellow Calf and his followers were resisting, was not the conditions of existence, but rather, the government practice of withholding rations from those who refused to labour in the "right" manner.

The "Yellow Caif" incident is one of the most glaring examples of resistance by the aboriginal peopies to the actions of government. While this is an obvious example of resistance, as is the North-West rebellion, there were acts of resistance which occurred more regulariy. It is these actions that the agents of government sought to manage. These were the conditions, the experiences, and the actions which were to be acted on, shaped and corrected. What resistance, or agency, amounted to was the engagement in tradition ways. The majority of these actions were labelled as deviant, and anomalies which were to be contained, governed and shaped. The traditional aboriginal mode of life was the domain in to which these practices were intruded, however, to shape the mode of life, to correct deviant actions, required the invention of practices of government. The denial of rations to the deviant was a powerful tactic enabling agents of government to structure the actions of the aboriginal peoples in relation to the values of settiement and agricuiture. Dewdney once stated that the system of administering rations was the "only discipline at command to compel Indians to work against their inclinations"(CSP vol.50 no.6 $1887 \mathrm{pg} .108$ ). Working against their inclinations implies a manner of training and correcting a mode of life, to work 
on actions, however, it also implies its compliment: resistance. Refusing to work in positive or constructive ways, in the desired manner of government, were ways the aboriginal peoples could resist, or act against the actions of government. Leaving the reserve was another.

\section{Governing Through Division and Classification}

The reserve, the plots of land set aside for the exclusive use of the aboriginal peoples, was the space upon which the aboriginal mode of life was to be shaped in relation to the values of the prescribed order. It was the space where the aboriginal people were to commence their new mode of life. Taking on this new mode of life required that they spend their time in this space and not wandering iooking for food. The nomadic traditional mode of life was seen as threatening to settlement, and the work which was being done to structure their mode of life. The reserve did not have stone walls and steel bars to "hold" the aburiginal peoples on this space of land. To govern this traditional action of wandering in search of food required the use of practices to shape and mould it.

In the above section we discussed how law was used as a practice to curtail this action by charging, and picking up aboriginal peoples under the Vagrancy act. Through this practice of government, the aboriginal choice between searching for subsistence in a wide "open" space and settiing down on reserves and engaging in agriculture was being structured. This must also be seen as mediated by the deciine of the fur bearing animals. That is, if the aboriginal person chose to search for subsistence outside the space of the reserve they would have to be sure they would obtain food since the granting of ration provisions did not extend beyond the outline of the reserve. If they were abie to find some 
deer, rabbit, or perhaps even a bear, they would have to evade the vision of the NWMP who may pick them up for Vagrancy. However, in addition to these practices a whole series of other practices of government, some silent, some more over, were invented to this end. They were disposed to close the open space of the reserve.

In stating that the reserve was a closed space of government, I am witnessing, not the enclosure, but the practices disposed to contain the aboriginais in this space. Confining the aboriginals to a fixed space served to, on the one hand, structure actions, and other, render the aboriginal mode of life visible. I am not stating that the reserve is the essential core of governing choice. Nor am I opposing, or stating that the reserve functions as either, "Indian homelands or devices for assimilation" (Tobias, 1977), but rather that the reserve is a space where practices of government seek to structure the choices of the aboriginal peoples. As a space of government, the reserve divides the aboriginal peoples, it marks them spatially as a domain of government, and provides a place were the new mode of life can begin. On the other hand, the practices of government seek to shape the mode of life of the aboriginals to maintain an existence on this space in the "right" manner. The reserve is a technique for amalgamation, not because it exists and is closed, but rather because it divides the aboriginals as a domain of government that permits classification of actions and allows government to dispose practices which structure the possible choice of actions. It is then, not the reserve which becomes the object of interest, but the practices disposed to structure the actions of the aboriginals and the conditions of existence which mediated it.

The aboriginal peoples left their reserves for many reasons; to visit family, to search for subsistence, to engage in traditional ceremonies (RG 10, vol 3728 file 25940 Galt to 
Dewdney, 1880 ), to meet and discuss treatment by the Dominion, or to obtain rations at large forts. Whatever the reason for leaving the reserve, there was no doubt that this action was threatening to both the settlers of the region and to the work done by the Department in structuring their actions. In i 881 , Vankoughnet, stated that when the "Indians leave [their reserves] in large numbers they are committing depredations which results in retarding the settlement of the country“ (RG 10 vol. 375 I file 30249, Vankoughnet to Macpherson, 1881; RG I0 vol. 3721 file 23666, Macioed to Vankoughnet, Dec. 12,1880). In leaving the reserve the aboriginal peopies were not only 'bothering' settlers (many reports unfounded) but their "progress" was artested. Agent Pockington, once stated that;

These Indians have not made much progress during the month, working only by fits and starts: the great drawback is they are too near Caigary, and are constantily going to and fro. some of them bringing their Lodges and camping, $i$ told them time afier lime if they didi not remain on the Reserves their names would be struck off the list for rations. (Agent Pocklington to Dewdney, 1882 volume 3610 file 3434 ; my emphasis).

To be struck off the list for rations was, given the conditions of existence, a powerful encouragement to remain on the space of the reserve. According to Reverend Thomas Sedgewick, a Presbyterian Minister, "this policy of the Government seems to be a wise une, and is justified by its results. The Indians while kept from starvation are given every encouragement to industry". The mode of life of the aboriginal peoples, their culture, their actions of nomadic hunting, of ceremonies, is governed through its classification and subjection to practices which endeavour to shape a new mode of life. The practice of governing aboriginal consumption is based on a dual system of classification which endeavours to structure the choices among actions, both traditional and emergent. By 
discouraging the former through the denial of food, the choice of the latter is then encouraged.

However, much to the dismay the agents of government, the aboriginal people found that if they camped around the larger forts (HBC and NWMP) they would be fed and allowed to carry on their traditional mode of existence. In contrast, when on the reserves the aboriginals were expected to work for what they received. At the forts, however, they would receive provisions without having to engage in agriculture. It must be seen that this is not begging or being lazy, but a manner of resisting the attempts to structure their actions. It was a third choice - along with commencing an agricultural mode of life, or hunting - among available actions to be considered. When confronted by the practice of rationing, and the conditions of existence, obtaining subsistence from the forts certainly must have been attractive.

At Fort Walsh, in the spring of $188 \mathrm{i}$, there was, according to Commissioner of Indian Affairs Dewdney, "a large camp composed of all the idle Indians in the country being fed at large expense." (RG 10, voi. 309a, Dewdney to Vankoughnet). This situation was deemed "detrimental to the policy of the Government, inasmuch as retaining this post offers an inducement to the Indians of the north to abandon their reserves and move towards" the Fort (Annual Report of the NWMP. 1881 pg. 13). In order to govern this choice, the NWMP and the DIA thought it wise to transport the aboriginal peoples "with police wagons from Fort Walsh to their reservations“ (Annual Report of the NWMP, pg. 22)“ further north. In a few months the aboriginal peoples returned to the fort. In response, the NWMP decided to abandon Fort Walsh. In the future the NWMP Headquarters would be smaller and located 
at a distance from the reserve (Annual Report of the NWMP, 1880, pg. 36 Walker) so that the aboriginal peoples would not be inclined to abandon their reserves. In so doing the NWMP and DIA removed this choice of actions from the aboriginal peoples.

Another more obtrusive action by government to maintain the aboriginal peoples on their reservation was the encouragement of individuality in maintaining and building up property, stock, and houses. In short, government was encouraging individual responsibility at a fixed location. The reasons for encouragement in these endeavours was. "that they would be obliged to settle down and give up their wandering habits." (CSP vol.44 no. 14 1881 pg.98 MacCloed). This practice of encouraging individual pursuits may seem irrelevant. However, this must be viewed in relation to the larger strategy of government. Havter Reed, then the Commissioner of Indian Affairs, states that this practice of encouragement helped to foster:

... a sense of pride in their independence which prosperity is engendering among the farming Indians causes them to be much more independent than in the days when communist ideas prevailed in sharing their subsistence with their impecunious neighbors, which has its effect in compeiling the reluctant to put themselves in the hands of the Government to be trained ... (CSP vol. 53 no. 121890 pg. 161)

By encouraging the aboriginal peoples to take up agriculture for the benefit of themselves it serves to undermine the communal structure of the aboriginal mode of life. But, it is more than this. If those who choose not to engage in agriculture and hunt instead find that the hunt is not productive, they will not have the option of falling back on the band and its members for assistance as they had done in the past. The end of the programme of government - the convergence of aboriginal and European modes of life - is promoted 
through the concept of individual responsibility. The effect that this has is that government now seeks to make the individual responsibie for their own weifare and well being which is directly opposed to the traditional communal values. in its course, this practice of government functions to govern the choice of those who prefer to hunt by making them responsible for their own welfare. When considered in relation to the conditions of existence, the system of rations and the practice of laws disposed there is a great incentive for the aboriginal person to settle down on the reserve and commence an agricultural mode of life.

A key element in transforming the mode of aboriginal life was the subdivision of reserves into individual lots. When fully surveyed, land certificates were granted to individuals by the Department, which heiped to develop a "spirit of individual responsibility" (Dewdney, vol.50 no.6 $1887 \mathrm{pg} .108$ ).: While the hay and wood found on the reserve were still held in common, the cattle and other general kinds of stock once owned by the Dominion and lent out to the aboriginals, was granted to them as individual proprietors. This system of granting certificates - not to be confused with ownership - and stock had, according to Commissioner Dewdney (CSP voi. 54, no. 18, 1890):

... given the owners that sense of possessory rights which is so essentiai to the formation of those seif-interested motives which attach individuals to localities and render them unwililing to leave them for any light cause ... and the labour expended by him [sic] on his holding in building and fencing and cultivating has a similar effect to bind him to the locality.

From this excerpt of Dewdney's annual report we are able to witness the rationality of this practice. In addition to correcting the actions of those who continue to hunt, the encouragement of individual responsibility invites aboriginals to take up residence and farm 
the land. The subdivision of reservations into individual plots of land is an important practice of government for the harmonization of the aboriginal mode of life in that it creates individuals who are responsible for their own well being. Aboriginal peopie who were not reliant on government rations were showing a propensity towards convergence with the prescribed order. In the traditional mode of life the individual relied on the communal group for their cultural and subsistence requirements. By fostering individual responsibiitity govermment was undermining the traditional communal structure of aboriginal life.

While these actions of government sought to bind the aboriginal person to the space of the reserve, the practice of encouraging aboriginals to build fixed residences also assisted in this end. The traditionai residence of the aboriginal people was less permanent which reflected their nomadic mode of life. On the other hand, a house is a fixed residence with a fixed and permanent locality. To abandon the traditional residence for a house encouraged the aboriginal peoples to remain on the reserve and take up the settied lifestyle of agriculture.

The practice of fostering a sense individuality corrected the actions of the aboriginal mode of life in an almost silem manner. However, the practice of issuing passes was a much more overt tactic to maintain the aboriginal peoples on the space of the reserve. Commentaturs on this practice of government have debated three points of concern: their origin; their legality; and their effectiveness (Carter, 1985). While these are interesting and informative points, the practice of granting passes to aboriginal peoples sheds light on something more important.

In the aftermath of the 1885 North-West rebellion Hayter Reed, the assistant 
commissioner of Indian Affairs, penned a lengthy memorandum entitled "reiative to the future management of Indians" (RG 10, vol. 3710, file, 19,550-3, Aug, 14, 1885). In this memo Reed put forth 15 suggestions which would ensure that another uprising such as the one just experienced would not occur in the future. Among the recommendations was a section dealing with the issuance of passes. The pass system would require an individual who desired to leave the reserve to obtain written permission from the agent in charge of their reserve. The party would also be obligated to provide the agent with information relative to their destination and the duration of their leave. Through this practice, it was thought, the aboriginal peoples would be confined to the space of the reserve. If an aboriginal person was found away from the space of the reserve without a pass they would be taken into custody by the police and returned.

Almost from their inception, many historians have commented, the "system was ineffectual ... in practice passes were now granted on demand for every conceivable purpose“ (Miller, 1991). While this practice may have proven ineffectual in controlling movements, it illuminates something further, which is, perhaps, more important. Prior to the issuing of passes an aboriginal person could leave the reserve without informing the agent of their destination or the duration of their leave. With the change in policy, even though passes were granted "for every conceivable purpose", the agent had knowledge of the whereabouts of the individual. The function of the passes was not only a question of how to constrain the actions of the aboriginal peoples, but more importantly, to have knowledge of their location. The effectiveness of the passes lies not in the constraining force of government, but rather in the surveillance they granted agents of government. 
To conduct and govern the choice of actions of the aboriginal peoples required that the agents of government have knowledge of the actions and location of the aboriginai peopies. To classify actions, those deserving of rations or those subject to the laws, requires that agents of government have an intensive and all encompassing knowledge and surveillance of the population. Having the abiilty to obtain this knowiedge and perform the requisite surveillance required settling the aboriginal peoples in a space where they could be rendered visible. Recall that prior to the intrusion of the practices of liberal government, the aboriginal peoples were a nomadic people who wandered the open space of the prairies, woudlands, and mountains in search of subsistence. This mude of life, huwever, did not lend itseif to either the intrusion of a "new" mode of life, nor the observation of actions. To obtain these ends required the settlement of the aboriginal peoples in a space where observation could be made practical and the invention and intrusion of practice to structure the nomadic habits rendered functional.

\section{Strucluring Actions: Governing the choice of Pussible Actions}

In this chapter I sought to iliuminate the practices of government which structured the actions of the aboriginai peoples. Implied in this conception of government is aboriginal resistance and agency. Agency, resistance, and subjectivity of aboriginal peoples is not distinct from, nor separate from practices of government. Here then, resistance is mundane. Although it is overlooked by historians it is essential to the practices of government. The North-West rebellion has been cited as a definitive point in aboriginal resistance, the assertion of agency, and subjectivity. However, the most remarkable aspect of the rebellion is that aboriginal participation was so limited (Stunechild and Waiser, 1997; Dyck, 1991). 
Does this mean that those who did not participate were rendered docile by the practices of government? This view can hardly be given credence when we interrogate the practices of government. What were their ends? How did they function? As we were able to envision above, the practices of government endeavoured to govern the choices of the aboriginal peopies in relation to their traditional mode of life. The fact that these practices exist attests to the agency and resistance of the aboriginal peopie. The practices of government are intrinsic to the domain they set out to govern and few, if any, find their origin in the rebellion. Rather, it is this mode of life which conditions the emergence of practices of govertument. Resistance is not unly implied in the practices of govertument, it is what gives them their immediacy.

Another important consideration is that practices of government are disposed. That is, practices are not cuercively imposed into the mode of life of the aboriginal peuples but rather used as a technique of intrusion fo siruciure actions. They seti io siructure the actions of the aboriginals in a definite direction. The practices discussed in this section - of law, rations, settlement, individuality - were not ends in themselves to be imposed, but rather means to the re-shaping and convergence of the aboriginal mode of life. In and of themselves they are not sufficient conditions to struciure the traditional actions. Huwever, when viewed in telational furm they complise a system of government which seeks to work on, and intrude a new mode of life into every aspect of the aboriginal mode of existence. in this chapter I discussed a series of practices initiated to govern the choice of actions, however, this is not, by any means, the totaiity or a final tally of all the minutiate of tactics disposed by agents to intrude this new mode of existence. 


\section{Chapter Six}

\section{Knowledge, the Requisite of Government: Agents, Police and Reports}

Prior to the Treaties and the surveys of the reserves the prairies comprised an open space in which the aboriginals movements were surveilled by no one. They had the freedom of travel, of hunting, living communally, and enjoying traditional ceremonies. Only the availability of subsistence, familial affiliation, and the traditional politics of indigenous society governed their actions. With the emergence of a practical rationality of liberal governance a transfiguration of this space occurred. The signing of the treaties and the survey of reserves constituted this space into two distinct modes of life. One was based on the exclusion from enjoyment of liberal privileges and rights that required practices of government to harmonize; the other was based on, and embodied. the new position of the nation. Space became related to, on the one hand, privilege, freedom, and the Euro-Canadian population, while on the other, it was related to a legally and spatially constituted domain of government.

In order to make this domain practical, in terms of structuring the choice of available aboriginal actions, government required that it was not only manageable, but visible. Since aboriginal culture is diverse comprising many different cultural traditions, languages, and modes of subsistence, governing this domain in its totality, without division and classification, would be impractical. If the aboriginal peoples were known as an 
undifferentiated cultural mass of people, the accumulation of knowledge, and the vision required could not be rendered practical. That is, what is said to be observable about the total of the aboriginal peoples may be qualitatively different from whatever may be said about a single band. What government required was a unit of administration and a filter through which aboriginal society could be observed. In a preceding section I alluded to how the band became the filter through which the aboriginal population was observed and rendered knowable. This may seem paradoxical given the ends of government. There exists a tension between the desire to construct a unit of government and the desire to employ indigenous categories and societal organization. However, given the expansive nature of the country and the diversity of social and cultural groups, the unit of the band seems logical given the desire to classify, correct, and harmonize aboriginal culture. The desire to "colonize" the band as an administrative unit did not have to do with grafting an emergent mode of life onto the traditional, but had to do with partitioning the domain of government into an administrative unit.

The settlement of the aboriginal peoples on reserves now takes on a different meaning. While it cannot be divorced from the programme of amalgamation, neither can it be separated from the vision and knowledge required to govern this domain. In an expansive space comprised of diverse cultural values and modes of subsistence the band becomes a strainer, sorting the diversity of the aboriginal peoples and allowing the differences between and among them to be known. It allows government to react to these differences. With the band as the instrument of government, as its administrative unit, and the settlement of aboriginals on their reserves, the social, and geographical space of the prairies becomes 
mapable, observable, and thus governable.

The division of the aboriginal peoples, by legal discourse, and by practices of settlement, enabled agents of government to constitute the band as the administrative unit of government. But there is another division, another classification to be made. Through the organization of government, with the band as its unit of administration. the aboriginal peoples were not only divided amongst themselves but also within itself. With the band as the unit of government. not only does its exigencies, habits, and present functioning become known, but too, the individuals contained within this unit. Again, what an agent of government could say concerning the band they would not necessarily be entitled to say about the individuals within it. Government is concerned not only the whole but each individual that constitutes it.

Through the means of division, and further division, the aboriginal population becomes subject to an infinite series of classifications which seek to correct, shape, and converge their mode of life. The whole of the aboriginal population was divided along band lines, the bands were divided from each other, and the individuals amongst themselves. By division and classification, bands and individuals were rendered visible. It is visibility that offers the ability to bring into play the cluster of power relations which are based on, and find their rationality in, classification. The practices of government, the classifications which were required, were generated through two types of knowledge accumulation: by the physical surveillance by agents - including NWMP, DIA agents, and home farm instructors, missionaries - and through reports and records.

\section{Physical Surveillance by Agents of Government}


One striking feature of the administration of Indian affairs in the years 1870-90 is the shifts in the location, number, and functions of the agents of government. Locating agents directly on reserves is perhaps the most obvious example. Even prior to this, however, there were a series of shifts which successively located agents closer to the proximity of the domain of government. In addition, the NWMP contributed to both the accumulation of knowledge concerning the aboriginal people, and their surveillance.

In the years following the cessation of land from the $\mathrm{HBC}$ the predominant concern, both for the Dominion of Canada and the DIA was the negotiation of Treaties and opening the space of the West. The annual reports, correspondence, and the number of agents of the Department reflect this end. With the exception of agents Perry and Dawson, DIA agents were employed in the negotiation of Treaties. The initial organization of the DIA, in the West, was based on an Order in Council of the $16^{\text {th }}$ June 1873 which "authorized and established a Board of Commissioners for the North West" (RG 10, vol. 3625, file 5506, Laird Memorandum Dec. 7, 1875). Under this organization of the DIA the responsibilities of agents were divided along two lines, the entering into new treaties, and the carrying out of the conditions of the existing ones (RG 10, vol.3605, file 2946, L.G. Morris to the Minister of the Interior Howe Jan, 24. 1874). Since these ends were combined and not governed separately neither, according to Morris the first Lieutenant-Governor of Manitoba, could be effectively carried out (RG 10, vol.3605, file 2946, L.G. Morris to the Minister of the Interior Howe Jan, 24. 1874). From its introduction, this system "continued in an Imperfect state and was in fact practically inoperative" (RG 10, vol. 3625, file 5506. Laird Memorandum Dec. 7, 1875). 
Almost from its inception. the organization of the DIA, which was based on the system of Agency's. was deemed a failure. No perceptible changes were seen in the actions of the aboriginals. and the population was complaining extensively about the treatment they received at the hands of the Department. In addition, as of 1874, few of the treaty agreements had been carried out. and the reserves had not been surveyed as promised. Experience had informed the Department that a shift in the mode of life of the aboriginal peoples could only be realized through the appointment of local agents to govern their affairs. However, at this time the role of the Indian agent did not find its end in the surveillance of the population, but rather in the opening of space. Agents did not reside near the reserves, nor did they visit them on a regular basis except for the payment of Treaty money (perhaps with the exception of Agents Perry and Dawson).

There were three problems with this approach. First, by paying annuities with a single agent meeting with several bands, it necessitated large gatherings of the aboriginals. These peoples would often have to travel long distances to obtain their monies (RG 10, vol.3605, file 2946, L.G. Morris to the Minister of the Interior Howe Jan. 24. 1874). Morris, the first Lieutenant Governor of Manitoba, stated that this was counterproductive since most of the money was expended in the travel to and from the payments leaving the aboriginals with nothing (RG 10, vol.3605, file 2946, L.G. Morris to the Minister of the Interior Howe Jan. 24. 1874). Secondly, when the aboriginal peoples gathered for such an event it was necessary to feed them. This was costly since, (and not in keeping with the thinking of government) they were to grant provisions, not only while at the payments, but too, for the travel back to their reserves. And finally, while the payment ceremonies may have lasted for several days 
(or even weeks) there was insufficient exposure to the aboriginal peoples to obtain even the most general of observations concerning their progress, and conditions. These conditions were in themselves enough to encourage the shift to a new machinery of government. In addition, however, the administration of aboriginal affairs was becoming "every day more important and more complicated" as a result of the increase in the settlement of the country and the fact that the aboriginal peoples were now "entering in a way of progress that requires constant supervision" (RG 10 vol 3634 file 6540, Provencher to Laird, Sept. 12 1876). The necessary supervision could only be accomplished through the medium of a local agent who would be living among, or in the vicinity of, the aboriginal peoples (CSP vol.38 no. 81875 Provencher, pg. 15).

Despite the problems with this approach to governing the aboriginal mode of life, and Lieutenant Governor Morris' memorandum of 1874 complaining of the "inefficiencies of the present organization" and the Commissioner of Indian affairs constant appeals for the appointment of local agents (CSP vol. 38 no. 81875 pg.15; CSP vol.39 no.9 1876 pg.33; Provencher to Laird, Sept.12, 1876 RG 10, vol 3634 file 6540) it was not until 1876 that this shift was finally debated, and not until 1877 that a perceptible change is evidenced in the organization of the machinery of government. Under the new organization, the agent would be in a position to provide "immediate information on every question" (Provencher to Laird, Sept.12, 1876, RG 10, vol 3634, file 6540), and the "necessity of large gatherings of the Indians to receive the payments will be avoided," as well, "much expense to the government and inconvenience to the Indians" would also be avoided (RG 10 vol.3625 file 5495, Morris to Laird). 
The 1877 report for the DIA evidences a shift in the nature and extent of their concerns. Whereas in previous years the primary concern reflected in the reports and correspondence of the Department was the opening of the space of the west. in 1867-8 there is a subtle shift in the management of Indian Affairs, which Provencher refers to as "the new era of Indian administration" (CSP vol 41 no.10 $1878 \mathrm{pg} .40$ ). The ends of the Department now shifted to governing the aboriginal mode of life, classifying actions, and developing a more complete knowledge of the aboriginal peoples. This end also corresponds with the introduction of local agents.

With the new era of Indian administration more agents were appointed and instructed to reside at a "central location" to the bands which were under their charge. That is, as one agent was instructed.

I beg to be allowed to propose moreover that the appointment of Mr. MacPherson should be confined in a permanent way and that he should be instructed to establish his office, north of Lake of the Woods at Assabaskasing, where from he could attend to the affairs of the Indians of Lake of the Woods, Rat Portage and Islington (Provencher to Laird. RG 10, vol 3634 file 6540).

In this way, agents were now able to provide information on the conditions of life of the aboriginal peoples under their charge. In addition, if the bands under supervision required assistance, or had a complaint, the agent could address it without the aboriginal peoples leaving their reserves (Provencher to Laird RG 10, vol. 3613, file 4062, 1875).

Before long the "new era of administration" was experiencing problems. Even though agents were closer to the reserves, closer to the population under their charge, the space over which the agent was to govern was far too expansive for the agent to have any real effect. In correspondence Dewdney informs Vankougnet, that the "distance between the reserves is 
altogether too great, for the Agent at the latter place [Blackfoot Crossing] to have successful supervision over them in their work" (RG 10. vol. 3716, file 22173, 1885). In some places the distance between the reserves under an agents charge was over 100 miles. which is far too extensive for a single agent to have any considerable influence over (Dewdney to Vankoughnet, RG 10. vol.3635 file 6567). Again, a shift in the machinery of government was required.

The "centralized" approach to transforming the aboriginal mode of life was more efficient than the prior machinery. It was, however, also coming under scrutiny from agents in the field who were finding their duties overwhelming. To mediate this condition two changes were made. The first saw the appointment of more agents. By having an agent appointed directly over the aboriginals, the DIA was able to perform constant surveillance over their actions. enabling a more efficient and exacting classification and correction of actions. Secondly, the larger agencies, those where large distances separated the bands. were divided and an agent placed over each division (Vankoughnet to Dewdney, RG 10, vol. 3664, file 9834,1883 ). This shift in government was not immediately extended to incorporate all of the prairie agencies, but following aboriginal participation in the North-West Rebellion of 1885 the increase in agents, and the division of larger agencies was advanced to incorporate the whole of the Manitoba and North-West Superintendencies. Agents were now appointed directly over bands of aboriginal people which allowed them more time to devote to correcting aboriginal actions, as Hayter Reed, the Commissioner of Indian Affairs explains:

The good results from the sub-division of larger agencies becomes yearly more apparent. In 1886 it had to be remarked of these Indians that they were probably the least advanced 
in civilization, of any Indians in the Territories. Now, under the energetic management of an agent who can devote his whole time to them, a most pleasing transformation has taken place (Reed, CSP vol 52 no. 161889 pg. (28).

The role of the agent is to conduct the actions of the aboriginal people towards, what Hayter Reed refers to, as civilization. They are to structure their actions towards convergence with the Euro-Canadians. Under the previous organizations of the machinery of government this end was severely frustrated by the distance between the agents lines of site and its object. Under this new arrangement, government becomes more immediate. It is now a matter of a constant surveillance where each and all become known, seen, and governed in relation to this end.

The encroachment of agents closer to the reserves is one of the most essential conditions of governing the mode of aboriginal life. Each shift in the machinery of government brought more agents closer to the reserve, closer to the population. where knowledge and surveillance could be at once accumulated and acted upon. Whereas, with the initial organization of the Department the aboriginal peoples could remain 'hidden' for a year at a time, with the last, their actions are rendered almost perpetually visible and thus subjected to classification and correction. The "atomization" (Tobias, 1977) of Indian affairs exacts a form of surveillance which allows the agent to acquire an intimate knowledge of their actions, behaviours, and habits. This granted them the ability to differentiate, classify and act on the actions of the aboriginal peoples through the practices of government. The functions and responsibilities of the agents of the department too. shifted with this encroachment. In the initial organization, agents were responsible for the "carrying out of existing Treaties and the entering into new ones". In the last shift, the agents duties became 
more concerned with the government of aboriginal actions. In a letter of instruction to a new agent, Dewdney advised him that the governance of aboriginal peoples cannot be written in stone and that some things must be left to the good judgement of the person holding this responsibility, but there were some things which was expected of them:

... you must be ever watchful of their conduct, informing yourself as to the movements of every Indian; visitors to reserves from other bands should be known and their presence enquired into. It has been the desire of the authorities to obtain a return in labour for the large food and clothing supplies from time to time being issued to Indians. . If you can judge properly when to give and when to withhold, you have overcome the greatest share of these difficulties. An agent has to be guarded against a too liberal issue on the one hand, which, as a rule, lends to laziness and independence of the wishes of the officials on the part of the Indians. and a too scanty ration on the other which would cause many to wander away to other reserves in the hope of obtaining provisions under easier circumstances (Dewdney to Wright. RG 10, vol. 3721 , file 23818 , November 1885).

The role of the agent is to structure aboriginal actions towards the end of the programme of government. That is. towards amalgamation with the Euro-Canadian population. In the excerpt cited directly above, we evidence how this transformation is made material. The agent of government combines the practices of government - here the use of rations - with the watchfulness necessary to induce a change in the shape of actions of the population. The surveillance of the agent is a corrective one. It makes possible the classification and the shaping of the traditional actions of the aboriginal mode of life.

The surveillance of the aboriginal peoples, with the successive shifts in the machinery of government, became more and more exacting, rigorous, and localized. The former mode of observing aboriginal actions was periodic and could not have the effects of inducing change. However, with the presence of local agents residing over the bands this would change. In the following years the machinery of government was transformed into a more 
regular, more intense. and frequent surveillance which provided the ability to make the practices of government functional. When combined with the practices to structure the aboriginal choice of (non)movements, surveillance allows agents of government to procure knowledge of the present functioning, state, and actions, not only of the torality of the band under consideration, but allows the agent to differentiate between the level of development and actions of the individuals who make up the unit of administration.

\section{Surveillance and the NWMP}

Surveillance of the aboriginal peoples could not be solely the function of DIA agents. The gaze of the agents could only extend so far. In an immense expanse of country, such as the prairies, the gaze of the Indian Agent could not possibly govern and see all. Instead, the geometry of surveillance was executed more efficiently and exactly by linking up with a mobile patrol of a mounted police force. In this manner, observation of aboriginal actions would become overlapping. When left exclusively to the site of the agents of the DIA, surveillance would be localized and relinquish the space outside the reserve. The NWMP filled the breach in the vision of the Indian agents.

There are many overlaps with the machinery of the DIA and that of the police. First. whenever a crisis erupted in carrying out their duties, the force responded with an increase in the number of officers. In their first years in the territories the numbers of mounted police officers was 120. In response to the lawlessness of the prairies (Annual Report of the NWMP,1881, Crozier, pg.10), and the number of aboriginals leaving their reserves (Annual Report of the NWMP, 1882, pg. 11, Van Home) the numbers of mounted police went from 300 to 500 in 1882 and then to 1000 after the North-West rebellion. The number increased 
until 1893. Secondly, the NWMP, as time went on, moved their outposts closer to the reserves where "the Indians were in a very unsettled state." (Annual Report of the NWMP.1883, pg. 8 Irvine).

The NWMP outposts were the primary technique disposed to govern the actions of those individuals who defied the law. For example, in 1883 an outpost was established at Fort Pitt because "reports which had reached His Honour, to the effect that the Indians on reserves in that vicinity were likely to give serious trouble" (Annual Report of the NWMP, 1883, pg.8, Irvine). By locating the outpost closer to the reserve the NWMP could assist the Indian agent in "keeping a constant watch on" those individuals who were causing problems (Annual Report of the NWMP,1879, pg. 23 Walker). In addition, NWMP outposts were established to prevent cattle killing, horse stealing, and smuggling. Prior to the North-West Rebellion there were approximately 60 outposts strategically situated among and around the country for the purposes of surveillance of deviant and unlawful aboriginal (and settler) behaviour. The outposts were based on a system of mobile satellite camps which enabled the officers in the field to accumulate and disseminate information concerning the actions of aboriginals, the number of aboriginals who have left their respective reserves. and the amount of crime they observed in the country. The presence of these detachments in and ai ound the country, according to Irvine had "a most salutary effect in preventing crime generally" (Annual Report of the NWMP,1883, pg. 10). Constant supervision of spaces of discontent, "backed by the threat of penitentiary sentences had worked wonders" (Turner, 1975). That is, surveillance when combined with the effects of the law as a practice of government functioned to shape the actions of those deemed deviant. 
Outposts, along with agents stationed on reserves, allowed for an effective instrument of government for observation of those aboriginal peoples who were settled, but even this geometry of site could not begin to capture the totality of movements, actions, and habits of the whole of the aboriginal peoples. In 1886, in an attempt to render their gaze more regular and exacting, the NWMP instituted a system of patrols. Patrols consisted of an officer and five non-commissioned officers who would transverse the country for the purposes of gathering information and to "make manifest to Indians that a watchful police supervision was maintained over their actions." (Annual Report of the NWMP, 1887,pg.25 Neale). The patrols and the vision they exacted had the real effect of maintaining the aboriginals on the reserves. In and of itself, vision does not exert a correcting influence, but when linked with the practices of government - the Vagrancy act, law, passes - it produces effects for the objects of its gaze. The system of patrolling the prairies "tended to keep the Indians on their reserves" and the use of law "put a stop to the passage of parties of Indians on horse-stealing expeditions" (Annual Report of the NWMP,1887, pg. 45 Neale). Patrols and outposts maintained by the NWMP linked up with the correcting vision of Indian agents to increase the angles of visibility of the aboriginal peoples.

The patrols, while successful in shedding light on aboriginal actions, had some short comings. When we consider the extent of a patrol, in one place it was a "distance of 292 miles" (Annual Report of the NWMP, 1887 pg. 45 Neale), it is not hard to imagine how many crimes and negative actions escaped the vision of the police. The second problem with this type of patrolling was that it was "systematic". Any aboriginal person, or criminal, who desired to escape detection by the police had only to wait until the patrols had completed 
their inspection and were off to the next site. To fill in the breach in their surveillance, the NWMP devised two tactics. The first comprised the implementation of two "flying patrols" for each division. The flying patrol was differentiated from the systematic variety in that it was random and had no fixed route to follow (Annual Report of NWMP, i890, Herchmer). The second tactic was employment of "full blooded Indians as scouts" (Annual Report of the NWMP, 1887 pg. 8 Herchmer). Scouts were attached to the systematic patrols as trailers. They would follow the inspections of the localities by the police and endeavour to ascertain whether, in the absence of the police, any individuals left the reserve or were committing any other "crimes".

\section{Geometry and Light: Surveillance of Aboriginal Actions}

The mechanics of the organization of the NWMP mirrors that of the DIA in many ways. While the agents of the DIA increased and moved their location closer to the reserve so as to exact a greater surveillance over the actions of the aboriginal peoples, too, the NWMP increased their numbers and moved their outposts closer to the site of problems. However. there is one important distinction between the two, and that is, the police were a mobile unit who could cover a massive amount of space very quickly. This was a very important consideration for the surveillance and conduct of aboriginal actions. At first, observation of their actions was arbitrary and irregular owing to the small number of police and agents in the field. The probability of being seen and caught was highly unlikely. However, as time went on, as the agents of government gained experience in dealing with the territory and the aboriginal peoples, the system of observation became more intensified and localized. The old system, where the aboriginal peoples could remain hidden from the 
correcting gaze of these agents, was transformed into a system which was regular and enabled the practices of government to classify and structure the choices of the aboriginal peoples.

When the successive movements of the agents of government are considered it brings to mind the ways in which spotlights highlight a stage. When there is no light, when the stage is engulfed in darkness no observations can be made concerning its characteristics nor its design. However, when a solitary beam of light is shawn down on it, the stage becomes seen. While this may illuminate a portion of the stage, many objects still remain hidden and unknown. When a second light is added at a slightly different angle, more objects become recognizable. Then a third and a fourth are added, and the whole of the stage is visible. All of the characteristics can be seen. While the first beam of light was able to illuminate a portion of the stage, it requires more light and different angles to make out the stage. Too. with the observation of the aboriginal peoples. Light and geometry dominate the observation of aboriginal actions. The DIA is able to illuminate and govern the characteristics and habits which they are able to directly observe, however there are more angles to be considered. The NWMP are able to see other angles through the use of patrols and outposts. If there was no light, there could be no correction and no governing of actions. The different angles upon which the agents of government illuminate the actions of the aboriginal peoples allow them to endeavour to correct the different actions which come to their attention. The linking up of the NWMP and the DIA - as well as other agents of government - combined to render visible the actions and habits of the aboriginal peoples. Regular observation was the precondition which allowed the agents of government to use practices to conduct the actions 
of the aboriginal mode of life.

In much of the discourse surrounding the DIA's reaction to the North-West rebellion of 1885 there is a tendency to mark it as the turning point in the supervision and tutelage of the aboriginal mode of life. But if we mark this as a distinctive shift in the management of aboriginal affairs there is a tendency to neglected the prior shifts in this machinery which conditioned it. That is, the appointment of agents to reside directly over the aboriginals was not a new policy, nor an original formulation derived from the events of 1885 , but was part of a dynamic process towards a more localized and efficient supervision of the affairs of the aboriginals. It was a response to the conditions of the supervision of a large population. Whenever there was a crises in the administration of Indian affairs, the response of the DIA and the police to mediate it was to increase the number of agents and move them closer to the reserves. The shifts in the machinery of government are then, not a rupture with the past. but rather part of a process which created a more efficient and more knowledgeable government.

The increase in agents and their closer proximity to the aboriginal peoples granted Indian Agents and police the ability to observe, know, and govern the actions of this population. At the same time the exacting influence of observation and classification also serves to place the aboriginal population, bands and individuals in a whole field of knowledge which is said to represent their objective reality, including their progress, present state, and a whole series of other facts that could be recorded and transmitted to a central location for further comparison and classification. The use of these devices to govern aboriginal actions "at a distance" will be explored in the next chapter. 
Knowledge, the Requisite of Government 


\title{
Chapter Seven
}

\section{Accumulating Knowledge: Statistics Reports and Correspondence}

\author{
"I have to do more writing than I care for."
}

Locating agents of government in close proximity to reserves provided local agents with the ability to know, govern and structure the actions of the aboriginal people. But in addition to this function of government the agent who resided over the local Band. through their observations, provided those who were at a distance from the domain an angle of sight into it. The DIA relied on a technology of writing which was said to represent the aboriginal people, their objective reality, and their progress as a series of facts. Writing codifies the distant situation. It represents, classifies and renders the domain of government visible by transforming the people into farts, statistics, and statements which represent the experiences and observations of the agents who reside within and around the domain. Writing, and numbering codifies and represents a reality which, when standardized, becomes an essential tool of government for deciphering and amending policy and actions. The local agents were essential, not only for acting in the local context of the reserve and the band, but in granting those agents in Ottawa an angle of surveillance through which to have knowledge of. and otherwise participate in, the government of this domain.

The treaties, surveys, and the practices of government to settle the diverse bands, divided the aboriginal peoples amongst themselves for the purposes of government. Once the 
aboriginal population is broken down into distinct units they become more efficiently governed. However, when this population has been broken down into groups of individuals through these means, statistics and standardized information puts it back together again for the purposes of further government. The rationality of the writing technology of government is that it is said to represent an objective reality as a series of facts. When facts are combined in a standardized manner to include the totality of the population, anomalies and differences can be evidenced and thus actions can be taken to rectify them. The whole of the population can be compared. Through statistics and writing, individual Band progress can be compared, their progress noted, and the differences acted on. Individuals too can be identified as belonging to that class who requires work on their actions. Writing and statistics classify and render observable a domain which is "at a distance" from the "centre" of government.

\section{Diffused Agents and Central Inspection of "Facts"}

Like the bands of aboriginal persons and their reserves, the agents of the DIA were scattered around the space of the prairies. They were diffused. They governed and resided over diverse cultural groups. To make their observations and classifications functional, information had to be collected, amalgamated, and standardized. To standardize observations required the use of a codified instrument which could represent the population "at a glance" (JLAC. 1858, Report of the Special Commissioners). But the standardized measurement of the factual reality had to be, in some way, observed and debated. This was the task of those who were at a distance and relied on these measures. When I speak of the "centre," I am referring to that which arises and is created to assemble the observations of local agents who capture and classify the reality which is represented. In reference to the DIA, the centre is 
comprised of the "inside service". Individuals located at central headquarters amalgamate, and are responsible for, the information collected by the local agents. or the "outside service". The field agents make observations concerning the factual reality and transport these to the centre for amalgamation and debate. However, this is not to say that the DIA had always had a strong central authority.

In 1858 Special Commissioners were appointed to inquire into the condition and affairs of the aboriginal peoples in the Canada's. They found that one of the greatest obstacles to be overcome in penning their report was the absence of accumulated data. However. this was not due to a deficiency in the amount of collected data, for the colonial and provincial governors had extensive information concerning this population. The inefficiency of the prior system stemmed from the lack of a central data base in which writing could be collected, stored, and disposed in the governing of the aboriginal people. Prior to this report, Indian affairs was conducted on a piece-meal, or rather disjointed basis. In addition to. and as a product of, the lack of a central decision making authority, the conduct of Indian Affairs did not have a coherent scheme by which to govern. While the commissioners did not explicitly assess the merits of this system of administration, their report reflects a general dissatisfaction, even disdain, for this type of incoherent and fractured organization. One of the commissioners concluded: "Much of the delay in the preparation of the Report has arisen from the paucity of the information accessible at the commencement of our investigation, a deficiency which we have had to supply from our own inquiries." (JLAC, 1858, Report of the Special Commissioners).

In order to establish a coherent department, one which operated with consistency, the 
machinery of its organization had to be one with a strong centre. In this way information and knowledge could be collected and debated, and the department could act as a harmonious body with a coherent programme to conduct the affairs of its "clients" (JLAC, 1858, Report of the Special Commissioners). Overall the commissioners favoured the creation of a strong central administrative agency. However, this organization was not implemented until the coloniai authorities in Canada assumed control over Indian Affairs in 1860. But it was not until 1876, and the first Indian Act, that the administration of Indian affairs developed a "coherent" body of legislation. Since 1876 the DIA has maintained its central manner of governing.

The importance of a central governing authority was not lost on the NWMP. When surveying the space of the prairies for a suitable location for their headquarters, the requirements of a desirable location was: "a country amenable to agriculture, lots of timber for building and fuel and good water" (Annual Report of the NWMP, 1880 pg. 8). However, the most essential requirement was that: "that the point selected be a central one, where information from other portions of the North-West Territories can be readily imparted to the commanding officer, and where all the various Indian tribes could best be controlled from (Annual Report of the NWMP, 1881:22; my emphasis). By centralizing authority the DIA and NWMP were able to accumulate massive amounts of knowledge from their agents which allowed them to evaluate, know, and conduct the affairs of the aboriginal peoples in a harmonious and consistent manner.

The manner in which the aboriginal bands and individuals become visualized and known by the centre is by reports, correspondence, and statistics. The relations of the 
aboriginals with government are inscribed in this technology of government. The process of debate and classification depends upon the site of an individual in one place which is transferred to a central location where problems in one administrative unit can be compared, made known, and constituted in relation to the whole of the population and a solution devised (Rose and Miller, 1992). We have already witnessed this in the successive shifts in the location of agents. Other examples include the shifts in policies intruding a settled and agricultural mode of life, rations, and law. The examples are many. Shifts in Indian Affairs policy should not be seen as the result of a blind government at the centre deciding that it may be beneficial to reduce the rations and use it as a practice to induce the aboriginal peoples to work for what they receive. Rather, central inspection of records, which represent and assemble facts about the distant context, revealed that too much government money was being spent on rations without much change in the shape of the life of the aboriginal peoples. A relation is here being made. The mode of life of the aboriginal peoples is viewed in relation to the change desired, which is viewed in relation to the amount of government funds spent to provide for the aboriginal peoples, which is viewed in relation to the various problems facing them. The solution to this problem was illuminated in reports of government expenditures, "progress" of the aboriginal peoples, and their conditions of existence. Each is a problem. Each is evidenced in reports. Each requires a solution. The problem of one, is the problem of the other, which is a problem in relation to the end of government. All of this was debated (Canada, House of Commons, Debates, April, 23 and May 5 1880) and a solution deciphered. The solution was the policy of having the aboriginal peoples "work for food" which resolved the problems illuminated by the reports. In the above section I 
endeavoured to demonstrate how this policy worked itself out, the point here is. how the centre of government debated a series of problems evidenced in reports from the local situation and formulated a solution.

Central observation of the aboriginal peoples relies on surveillance by local agents of government. These agents transcribe observations into codified form which are then transferred to a central location to be debated. classified and acted upon. By amalgamating statistics and writing, the centre is able to know and come to understand a local reality which is at a distance from itself. However, the problems illuminated in reports need not be as large as the one described above but may concern few individuals which require a solution. For example, it was found that on some of the reserves cultivation of the ground was not possible due to the poorness of the soil. To resolve this problem the agents of government (prompted by the aboriginal penple) decided to grant the affected bands cattle and swine. Reports. correspondence, and statistics inscribe a local situation which renders it observable and knowable at a central location.

The process of writing and recording allows for evaluation and revision of the programme and strategy of governing. If the "progress" of the aboriginal peoples is alegligible from the last time data was collected, a new strategy will have to be initiated. However, if only some of the bands progress has been arrested. then measures will only have to be instituted in those places. Too, individuals progress can be noted, and practices disposed to rectify the situation. Through central inspection of records the problems facing individuals and bands can be noted and solutions devised. The aboriginal people, their mode of life. individuals, and bands, through this process of knowledge accumulation. were 
subjected to an infinite series of classifications, distinctions, and comparisons which allowed those in the "inside service" to decipher the "problems" facing individuals and groups in such a way that enabled them to link each to its resolution. The aboriginal people were broken down into administrative units by bands, the centre and the outside field agents further broke down their actions and progress. only to put it back together for means of comparison and debate.

\section{Rationality, types, content, evolution of Reports}

The process, organization and dissemination of knowledge arranged along the angles of sight of local agents is an essential chapter in the governance of the aboriginal mode of life. The governing of a population is connected to the vital factual representation of the objective reality. In recent years, historians have begun to evidence how this type of knowledge is central to the governance of populations. They have begun to show how the accumulation of knowledge through reports, statistics and other technologies of writing have rendered populations visible (Smith, 1985; Smith, D, 1993). In this section of the present work, I will be endeavouring to show how official categories of government - the band and individuals - became caught up in this technology of writing. In addition. the shifting nature and function of reports and records will be considered. The centrality of knowledge in the government of the aboriginal peoples can be evidenced by considering the actions of the Dominion prior to the cessation of land from the $\mathrm{HBC}$, and the report by the Commissioners of 1858 to investigate Indian Affairs in the Canada's.

As has been stated above the HBC, in their endeavour to govern the accumulation of profits did not accumulate statistics or vast amounts of knowledge concerning the aboriginal 
people, nor their mode of life. They did, however, collect those statistics which concerned their own end. That is. employees of the Company collected, or rather, counted. the number of aboriginal peoples who came to trade at the posts. In these statistics there was no individualization. nor classifications, nor divisions upon which to draw conclusions concerning the aboriginals (Great Britain, House of Commons, 1857. Appendix 1). The only conclusions which could be made using this data concerned the nature of the fur trade, but even these could not be made with any certainty. If the numbers of aboriginal peoples who came to trade increased it could mean that game was plentiful, or a variety of other things. Other than a work entitled A Voyage Around the World by Sir George Simpson, John Ross testified at the Select committee inquiring into complaints lodged against the HBC that the Canadian government had no knowledge on the number, extent or conditions of life of the aboriginal peoples (Great Britain, House of Commons, 1857: John Ross, questions 99-101). When the rationality of government finds its end within itself, knowledge of the kind required to shape and conduct the lives of a population was not a requisite condition for its existence. However, when there is a shift in this rationality, a shift in the ends of government from one which is intrinsic to itself to one with a series of ends, knowledge of the various domains becomes essential. With a (il)liberal rationality, population and its exigencies become the essential conditions of government, and knowledge and surveillance becomes a means to know it.

In 1857 , a Select Committee was appointed to consider the testimony from a series of witnesses on the administration of government by the HBC. A series of themes become evident when reading the testimony presented before the Committee, many of which have 
been discussed previously - treatment of missionaries, barriers erected by the Company to inhibit settlement. how government by a fur trade company inhibited liberal government (to name a few). For our purposes in this section, the most important theme presented was that even though the Dominion of Canada was interested in acquiring the territory, they were not certain, first, of the nature and extent of the aboriginal population (Great Britain, House of Commons, 1857: John Ross, qu. 99-101), and secondly, whether they could govern the vast space of the prairies under the present condition of things. When asked whether "Canada could conveniently or efficiently govern and manage the whole of the vast territory to the east of the Rocky Mountains" (Great Britain, House of Commons, 1857: qu. 4062) W.H Draper stated that:

If you say at this moment, I shall be obliged to answer in the negative, because at the present moment our communications are not opened: we have not yet established the prospect of opening them; and to undertake to govern a country which we do not know that we can get at, would be an unwise step. That is why I premise that we should desire to survey and explore before we do anything else.

According to Draper, to govern this territory would require a line of sight into it. However, as a result of the discourse of the Company, the authorities in the Canada's were not sure that they would be able to open a line of communication, let alone reach it. Following a question, posed in front of the Select Committee inquiring into complaints lodged against the HBC, concerning Canada's interest in Rupert's Land, Draper stated that "if they [the Canada's] found they could not communicate . . they would not desire to take the country" (Great Britain, House of Commons, 1857). The ability to have knowledge of, and insight into, both the space of the prairies and the state of affairs of the population is a necessary condition of government. If these could not be realized, government of the space and population would 
not be feasible.

To govern at a distance required provisions for communications. In the same year instructions were given to S. J. Dawson to depart on an expedition to make a thorough examination of the tract of country between Lake Superior and Red River. The reason for such an expedition was for the purposes of "determining the best route for opening a facile communication through British territory, from that Lake to the Red River Settlements, and ultimately to the great tracts of cultivable land beyond them" (JLAC, vol. 21, Appendix, 3). While the members of this expedition were also concerned with soil samples, amount of arable land, and other articles of general concern. they were ultimately endeavouring to discern whether a route of communication was conceivable. While some of the members of the expedition were expecting to find impenetrable territory. H.Y. Hind found that the territory, was "so much apposed to the impressions which generally prevail respecting this country"(JLAC, vol. 21, Appendix, 3). The expedition was, despite resistance from the aboriginal peoples to their presence and survey of the territory, able to establish the "chain of our Canadian internal communications" (JLAC, vol. 21, Appendix. 3, Dawson) which would provide the Dominion of Canada the ability to govern at a distance.

With this chain of communication, knowledge of the local reality could be represented and transmitted to the centre. Knowledge then, is what is important here. It is knowledge of an objective reality which is at a distance that could be represented as a series of facts. These facts for the most part were transcribed in the form of correspondence. monthly, and annual reports. These serve the purpose of providing those at the centre with a snapshot of the objective reality which is governed. While these snapshots provide the 
centre with an angle of vision, they have been employed by historians and sociologists to "reconstruct" the past. Use of these records of the past attests to their utility, not as sources of academic fodder to regurgitate the past as experienced by the agents of government, but rather, as visions of a "factual reality." Historians have generally regarded the records of the DIA as rich sources of historic insight. In almost every case where a researcher is endeavouring to come to terms with the past, the reports of the DIA and NWMP are cited as references to this past reality. We can look to these reports and envision the things the aboriginal peoples were doing and witness the changes that were taking place in their mode of life. Reports measure a reality and construct for the researcher the annual and periodic vision of the past. This vision lends itself well to the traditional version of history. It allows the researcher to reconstruct a reality - albeit from a biassed point of reference. But, what, we must ask ourselves, was the purpose of these reports?

In the remainder of this chapter, I have taken a different perspective. I am not using the records to make claims of truth, but rather turning the records and reports laid down by the DIA and NWMP back on themselves and considering them in relation to a comprehensive convergence between the accumulation of knowledge and the resulting programme of government. Through this the records and reports are "no longer a monument for future memory, but a document for possible use" (Foucault, 1977: 191).

The Table...

While a "chain of communication" and annual reports are requisite conditions for governing a population and acquiring knowledge, it is not that which makes government functional. In 1858 Special Commissioners were appointed to inquire into the government 
and conditions of life of the aboriginal people in what is now Ontario and Quebec. One of the conclusions reached by these individuals was that despite "all these years and in spite of the industry and ability displayed in collecting information and drawing up reports, [we] are still groping in the dark" (ЛAC. 1858, Report of the Special Commissioners). The conduct of Indian Affairs was blind due to the fact that, first, as was discussed above. no coherent central body of policy to govern this domain and accumulate knowledge; second, there was no codified table or form to measure the factual reality and make "central inspection of the records feasible" (JLAC, 1858, Report of the Special Commissioners). That is, even if a central authority was established, without a systematic manner of presenting the data, the centre would still not be granted an angle of vision. There could be no comparisons, no conclusions drawn, there would only be a mass of information without coherence. Data, and knowledge, to be functional must be presented in tabular form to make governing possible. When presented without rhyme or reason few conclusions can be drawn. However, when presented as objective facts of a represented reality in a codified and standard manner, insights and comparisons can be easily made. The special commissioners recommended that in order to render the knowledge accumulated by agents functional for the purposes of government, it must be presented in a manner "as would shew the situation of everyone at one view, instead of the research ... now necessary under the present system" (JLAC. 1858. Report of the Special Commissioners). In this way, bands and individuals could be easily viewed, their progress noted, and any alterations in the conduct of Indian Affairs effected. The ohisctive reality of the aboriginal people as represented as a series of facts concerning their progress, development, and present functioning is the angle through which 
central authority views and comes to know it. These facts provide the link between a reality and the centre. There is then a relation between documentation, observation and actuality. The actuality becomes 'texted' where properties of governing are inherent and built into the text. Central authority depends on the represented objective reality to conduct its affairs and that of the aboriginal people. However, the way that these facts are presented, the manner in which they are organized is tethered by the relations of governing. The objective reality of the aboriginal peoples had to be observed and rendered into a series of texted facts which would reveal the intricacies of it. In this way, the manner in which facts are presented is as important, if not more so, than the content they embody.

There is whole body of information which had to, in some way, measure the objective reality of the aboriginal people, their advancement, their development, their progress, and the gaps and differentiations between them. However, in the west. the tabular representation of the aboriginal peoples was not realized until the Annual Report of 1876. when, as Joseph Howe explains:

An attempt [was] made to exhibit in this Report in comprehensive and compendious form, statistical information on all matters relating to the Indians. The return in question shews the number, material progress and state of education, of nearly every Indian Band. The information on each of these heads is more complete than any which has been heretofore furnished, and has been procured in such a shape as to admit of being easily tabulated and presented in a convenient form for purposes of reference (CSP vol. 39 n.9 1876 pg.iii).

It is through a statistical representation of reality of the domain of government that it becomes observed and rendered knowable, it is not the presence of statistics that provided this function. Statistics without a manner of presentation and comparison are not functional. Rather, to measure the objective reality, to make comparisons, and classifications, required 
that "their [aboriginal] advancement in civilization be accurately determined at a glance in reference to the tabular statements" (CSP, vol. 45 no. 6 1882. McColl, pg. 87). The observed reality of the aboriginal peoples then, was to be presented and observed in tabular form. In this way, the exigencies of the aboriginal people could be represented, viewed, and classified in an efficient manner. The table of facts aligned the aboriginal progress "towards civilization" in columns which made the situation of bands and individuals comparable, and thus governable. The table pulls together diverse strands of information for the purposes of classification and governing.

In the above excerpt, Howe states that this is the first time this type of data has been presented. This in and of itself is significant. The date 1876 marks the emergence of the centralized approach of Indian Affairs and the "new era of administration". The manoeuvre which situates the agents of government closer to the reserves, towards the bands, also situates the aboriginal people within a "network of writing" and serves to textualize them as a series of facts on a table. The move closer to the administrative unit of governmeni facilitates both, a system of surveillance which allows these agents to structure the choices of the aboriginal people, and documentary accumulation.

The move to a closer proximity of the reserve opened up two correlative mechanisms of government. On the one hand, agents are granted an angle of sight into the actions, behaviours, and habits of the particular band over which they reside. On the other, this same angle of sight allows for the observation of the band for purposes of central inspection. The agent, who resides and conducts the Band, also renders these actions into an objective reality. Actions, behaviours, habits, are all observable. They become the objects which are rendered 
into facts. These facts can then be rendered into numerical fashion and situated on the table. The table then allows for the descriptions of a bands progress in terms of observable and objective "facts". By arranging these facts in a table by columns and rows, allows the centralized authority to measure gaps, to describe individual achievement, or lack thereof. The arrangement of facts allows for the easy of comparison where a band. or an individual can be situated within a distribution of the totality of the population. These facts fix an observable reality, whether it be the actions of the individual or the group to which they belong, in relation to a given end. It is through tabulation and comparison that progress can be marked and made objective.

\section{... rows and columns of "progress"}

Fundamental to envisioning the function of tabular statements as angles of site into the reality of the aboriginal peoples is the assumption that this culture could be represented as a series of observable facts. They are to be a representation of the progress and present functioning of the band. But how is that one is able to measure progress? Edgar Dewdney, the Commissioner of Indian Affairs, stated that "there are three tests which mark the advance of the Indians towards civilization, viz., the adoption of the dress of the white man, engaging in agriculture, and the education of their children" (CSP vol. 54 no. $181891 \mathrm{pg}$ xxvi). Hayter Reed thought that the best measure of the progress of the aboriginal peoples is to know "the relative extent to which the Indians have been able to contribute towards their own maintenance." To measure this, Reed thought to look at the amount of provisions consumed by each of the bands: "it may be stated ... that during the year bands in an agency in which marked progress is being made have received $79.817 \mathrm{lbs}$ flour, $13460 \mathrm{lbs}$ bacon, and 23341 
lbs beef, while those in another agency, not so far advanced. but fewer in number, have been assisted to the extent of $119,468 \mathrm{lbs}$ flour, $.32,018 \mathrm{lbs}$ bacon, and 35.782 beef" (CSP vol. 54 no.18 1891 Reed, pg. 132). In this case, and to Hayter Reed, the observable reality was the amount of rations provided to the different bands. This "fact," or representation of reality. classified the hand who received a greater amount of rations as requiring more intensive government of their actions.

The amount of rations consumed by a band, Reed later states, while a good indicator of progress, did not represent the totality of the progress of the band (CSP vol. 54 no. 181891 Reed, pg. 132). To develop this knowledge further, government collected statistics on the actions of the aboriginal peoples. One part of the annual report to the department was the tabular statement. These statements provided the central authority with a very finely detailed knowledge of the actions of the aboriginal people. The statements included information on number of stables, barns and houses erected; the area under cultivation; implements used; number of ploughs present; livestock, including an increase or decrease; the increase/decrease in population; and finally the whereabouts of each and all aboriginal persons (McColl, 1989; CSP vol. 51 no.15 1888 McColl, pg. 165). Simply, as one agent explains, the tabular statements "contain as exact as possible an inventory of all I found on the reserve" (CSP, vol.45 no.6 1882, Agent Muckle, pg.63). But more than just providing information, data was presented in such a way that the actions of individuals, bands, and the whole of the population could easily be compared.

Included in the annual reports for the DIA were three tables which pertained only to, and were collected only in, the west. These were statements showing quantities of grain and 
roots sown and harvested on Indian reserves; statements showing the whereabouts of the Indians; and lastly, statements showing crops harvested by individual Indians. What is interesting for our purposes is the types of knowledge collected and represented. In an earlier section, I showed how the end of government intrusions into the aboriginal mode of life was the convergence of their actions with the prescribed Euro-Canadian one. This was to be accomplished through two other ends, to which a whole cluster of practices were disposed, and that is, settlement and the engagement in agriculture. Now, with these statistics the actions of the aboriginal peoples, in relation to these ends, become at once observable, and comparable. The first thing that becomes readily apparent is the easy of comparison that is evidenced in the tables. Each band is listed. Their agricultural output noted. The same is true for the individuals. The second facet that is apparent is how "progress" is measured. From the table we can see how each band, and each individual is fixed within a row and their progress can be measured in numerical fashion by moving to the right. If we move down, their "progress" can be compared to others. It can be compared, not only to bands in the west. but to the east, and the whole aboriginal population. Likewise with the table demonstrating the whereabouts of the aboriginal peoples. Thirdly, it is obvious how each and every aboriginal person becomes rendered observable and their progress marked in these statistics in terms of bushels produced and their whereabouts. While these statistics are important for measuring and comparing the present reality of each and all of the aboriginal peoples, they can also be used to mark the progress from year to year. The band and individuals can be compared with themselves, such as the manner in which Joseph Howe noted that one band had "seventy-four acres under tillage, being $41 / 2$ acres more than in 1885" (CSP vol.50 no.6 
1887 pg. xxxix).

Here then, we envision the organization of a comparative field of observations in relation to the actions of the aboriginal people. The table takes a complex reality and renders it into a series of objective facts which are then pulled together in a coherent and organized fashion. The table, by organizing facts of the objective reality in columns and rows. where each unit receives its own row, allows for comparison and knowledge of this reality. In tabular form aboriginal actions become observable, their "progress" known, and the gaps between them marked. By so doing, the table marks the gaps and distinctions between each unit of observation whether it be the band, or the individual. Marking the distinctions, the gaps. between the actions of each and all observable realities represented, allows government to "know" the aboriginal people. To know the aboriginal people and their actions in this way is also to "know" what is good for them.

The statistical observations of aboriginal actions, where each is fixed to a row in a table, allows for easy comparison. If, however, there is a glaring inconsistency between bands, or where individuals output of bushels of agricultural products is not up to par, or "where they have failed to keep pace with the march of civilization. . to such, special attention will be given" (CSP, vol. 54, no. 18. 1891, Reed, pg. 132). In one agency Reed reported in the Annual Report for 1888; "one band alone in this agency fails to exhibit such marks of progress, and that is White Bear's." (CSP vol. 52, no. 161889 , pg. 128). This band was marked by the table as one who required special attention, which in this case amounted to "placing an agent directly over them" (CSP vol. 52, no. 161889 , Reed, pg. 128). With this example we are abie to witness how it is that the table functions. By comparing this band 
with others, and with itself, it was seen that they were not progressing in the desired manner. With the aid of the table these actions are compared to those in the agency and seen to be deficient. To calibrate the actions of White Bear's Band. an agent of government was directed to reside directly over them in hopes that their actions could be shaped in relation to the others in the agency.

Information is the outcome of an agent of government who is in close proximity to the band rendering actions into observable facts which are located within a row on a table. By providing information in this way it pulls together facts from diverse locations and renders them into a form which makes it conducive to observation and diagnoses. Any anomalies in the "progress" of the aboriginal peoples can become known and calibrated through practices of government. Information is not neutral, it is not benign, but is caught up in the actions of government. It is a manner of observing a reality, marking it, and working on the deviations. Central authority depends on the observations of local agents in one place to make decisions in another (Rose and Miller 1992). By marking progress. gaps, knowledge and objective facts, when rendered into tabular form, allows central authority to act at a distance from itself. 


\section{Conclusion: Colonial Governmentality}

Recent years have witnessed a rise in theorizing about colonialism's past configurations. Much of this discussion has centred around colonial attitudes toward the colonized and questions surrounding exclusionary discourse. This stream of colonial inquiry owes much to Edward Said's (1979) work on Orientalism. in that it is centrally concerned with the forms of power/knowledge relations that have constituted the colonial other through language. Since Said, historians have endeavoured to unravel privileged ideological representations laid down by anthropologists, travel writers. and colonial authorities that have fashioned and constructed indigenous peoples as subjects (Thomas, 1994). These meanings, through which the privileged have defined and portrayed the indigenous through textual descriptions, can become displaced by drawing critical attention to the logic of representation. The post-colonial investigation starts from the premise that the aboriginal person or band is not simply what the discourse of history tells us, but is rather a symbolic representation that has been fixed and articulated by colonial authors. The formation of colorıal subjects takes place through power/knowledge relations in the form of textual practices and ideological representation that have assigned meaning to the indigenous other (Santiago-Valles, 1994).

The post-colonial mode of inquiry constitutes a valuable contribution to our understanding of the history of colonial government of the indigenous other. Moreover. 
however, what I have been arguing in these pages is that we also have to pursue concerns about colonialism beyond the representational relations of power, and introduce in its place an investigation of the practices and rationalities of colonial government which has shaped the lives of indigenous peoples. The effect of these practices of governing the domain of society has been extensively explored in relation to modern Western society by those who followed Foucault's later work on governmentality (cf. Barry, Osbourne, and Rose. 1996: cf. Burchell. Gordon, and Miller, 1991; Dean. 1991). An extension of this mode of inquiry situated in the context of colonialism would contribute to our understanding of how practices of government, and the connections between power and knowledge, transformed and reorganized colonial society (Asad, 1991).

In recent years Foucault's notion of governmentality has begun to intrude into postcolonial studies. These writers have argued that instead of privileging European "epistemological" violence and symbolic interpretations of the indigenous other we should turn our attention to how their mode of life was governed, shaped, and constituted by colonial regimes of government. That is, we should move our understanding beyond the bounded reality of European representation to the distinct context where colonialism exerts its influence. There exists, as Nicholas Thomas (1994) and David Scott (1995) have argued. many colonialism(s) diffused around the world that can only be captured by grounding analysis in the concrete space where its effects are exerted. The studies which have extended post-colonial projects to include colonial governmentality situate the rationalities, practices. and domains of government within the colonial relations which they intend to understand.

Examinations of colonialism which have incorporated elements of governmentality 
have tended to take one of three positions in relation to the literature. The first, while not fully embracing, or using governmentality as their starting point for research, is sympathetic to its intricacies. An example of this is Thomas' (1994) Colonialism 's Culture. Central to Thomas' argument is that we need to move to a "more nuanced understanding of colonial endeavours" (1994: 20). Essential to his understanding are the relations of government "that are present in particular fields of colonial representation" (Thomas, 1994: 5). While Thomas is sympathetic to the practices of government and how they constitute and shape indigenous society, he is more concerned with colonialism(s) attitude toward the colonized.

A second relationship of colonial studies to the governmentality literature observes researchers who address single practices of government. These researchers address practices such as techniques for the accumulation of knowledge, such as: the colonial use of numbers (Appadurai, 1994); the colonial census (Smith, 1985); and the use "disk lists" to govern indigenous peoples (Smith, 1993). Other individuals have focussed their attention on the practice of division and the control of space (Ronsbo, 1997; Salman, 1995). Disregarded in these histories is the cluster of relations which were invented and disposed in diverse colonial settings to structure the actions of the indigenous peoples.

Overlooked in these interpretations is how rationalities of government have effects for the way the colonized are governed. This leads us to consider a third relationship to the governmentality literature. In this third type of study historians have used governmentality as their starting point for analysis of colonial relations of government (Illbrahim, 1997; Smandych and Linden, 1996; Scott, 1995). I share with this mode of inquiry a concern to situate colonial analysis within the context which is under study (Scott, 1995). I also pay 
considerable attention to understanding and coming to terms with the implications the rationality of government has for the government of the colonized.

The position I have outlined above moves beyond the existing literature in three ways. First, in understanding colonial governmentality it is necessary to understand. not only the rationality of government which is of present concern. but the continuity and breaks with its preceding organization. Second, while it is essential to discern the rationalities of government, it is equally important to understand the mechanics of government which correspond to. and interpenetrate with. the rationality of government. Practices of government are essential to the ends which are pursued by the situated rationality of government. However. practices are conditioned by the rationality of government by which they are disposed. Accordingly, to come to an understanding of colonial governmentality it is necessary to understand the constitution of the ends/means relationship. Having said this. it is also important to envision that practices of government are not universal. but are given immediacy only within the domain where they induce their effects. This last statement leads us to consider my third point of deviation from the existing literature. In studies of colonial governmentality, resistance, with one notable exception (O'Malley, 1996a), has either been theorized separately trom practices of government or dismissed entirely as irrelevant. In the perspective layed out in the pages above, freedom is intertwined with the practices of government. There cannot be one without the other. Therefore, rationalities of government, practices. and resistance all interpenetrate and have effects for the other. To understand one, without the other, is to neglect a fundamental component of colonial governmentality. In the next section I endeavour to flesh out the ways I have attempted to add to the understanding 
of colonial relations of government.

\section{A Revised Colonial Governmentality}

To facilitate an understanding of colonial governmentality in any context the researcher must be attentive to the intrinsic problems confronted by the rationality of government, how problems became constituted as domains of intrusion. and how these domains were structured. By attending to the intrinsic exigencies confronted by the state it is then possible to move understanding beyond ideological representations of indigenous peoples perpetuated by Europe and situate the rationality of government in the domain governed. However, an analysis of colonial governmentality must also consider the mechanics of government, or the means through which government sought to structure the actions of the aboriginals. Here I am referring to the practices of government. These refer to clusters of techniques disposed to structure aboriginal actions in relation to a prescribed mode of life and intrude into every aspect of their traditional lives. Practices constitute the third requisite element of colonial governmentality.

Practices of government are essential to understanding how agents intruded into, and endeavoured to shape, the lives of the individuals and groups consitituted as the domain of government. Practices are constituted by five interelated and necessary conditions. First, they are linked to the end of governing the domain. That is, they seek to structure the actions of the aboriginals in a certain and definite direction. Above we evidenced how the practices of governing consumption and the use of laws (to name a few) were disposed to govern and shape the aboriginal mode of life in the direction of the prescribed valuts of the emergent order. They are not repressive, but seek to govern the choice among available actions by 
rendering the positive more attractive than the deviant. This implies a second condition, there is an attachment of value to actions. Government seeks to structure the negatively classified traditional actions of the aboriginals in a "positive" - according to the ends of government direction. In order to structure actions in the desired direction implies a double system of classification where positive actions are "rewarded" while "deviant" ones are subjected to the intrusion of practices. Third, practices are intrinsically linked to the conditions of life in the domain they are intruded into. In this way practices of government are not interpreted as universally applicable to all domains and all colonial contexts but intrinsic to the immediate domain of concern. Fourth, by stating that practices of government seek to structure the choice of actions implies an active subject. Freedom and agency are implied parts of government. If the aboriginals did not have choice, they are not granted agency, it would imply that they fully embraced the new mode of life. or that government totally dominated them. To govern choice, to structure actions, implies that there is actions to be governed. However, this does not imply the "event" centred analysis of the traditional historian. but a mundane and everyday history which evidences resistance as a constant of governmnet. Lastly, practices of government require the correcting and classifying gaze of an agent of government to induce their effects.

The mechanics of structuring the actions of the aboriginals is tied to a system of "correction" which is based on the logic of surveillance, classification. gratification and punishment, which is also linked to the conditions of existence, and tied to the logic contained in the ends of governing. However, the same process which "catches" aboriginal actions in the web of government practices also enters them into a technology of writing. 
This technology sketches their actions into observable "facts." When these facts are amalgamated in the form of the table the "progress" of individuals and groups can be measured and compared by moving up and down the columns and rows. Through this process. differences become observable and corrected. Knowledge, both local and central, is a necessary condition for effective government.

This is not to say that practices of government are in anyway "total." By this I mean that they completely converged and harmonized the domain of government constituted around the division of the 'other'. This points us to an interesting dimension of government. Government of the aboriginal mode of life through division, and practices, have never succeeded in living up to the promises made. From its inception, to the present, the practices of government to intrude a new mode of life have not eliminated the division constituted around this domain. They have not amalgamated the aboriginal people with the EuroCanadians, they have not erased the "binary distinctions" between the constituted domain of the "other." They have not been able to realize the ends which their advocates set out. Consider that in 1997 there are aboriginal peoples whose culture is still maintained and strong. There are people who still participate in traditional ceremonies, speak only the traditional language, and engage in many of the actions consistent with the traditional heritage. How is this possible? In order to answer this question, to partially come to terms with it, we must consider the nature of the practices of government in relation to the subjectivity of the aboriginal people. It is not possible to have one without the other. They are implied in each other. Each is what gives the other its immediacy, end and function.

To be total practices of government necessitates a "docile body", however, the 
aboriginal peoples, even when considering the conditions of existence, resisted the actions of government daily. This type of resistance is not what history is made of, but it is necessary, and essential when considering the nature, application, and shifts in the practice of government. The practices of government are not total, nor can they be. since they are mediated by the subjectivity of the aboriginal peoples. The question then, is not, why has the policy of government failed? But. how could it succeed? Or more accurately, how did the aboriginal people shape their lives in relation to these practices, to the conditions of existence, and the perception they have of their selves and their mode of life? By understanding practices of government in this way, analysis goes beyond coercion, resistance and rebellion. An understanding of the practices of government must include an understanding of the agency of the aboriginal peoples, the intrinsic nature of practices. the conditions of life experienced by the aboriginal peoples, and how all of these interpenetrate, and are reflexive.

Where are the "events" which are so commonly associated with the historical understanding of government and aboriginal relations in Canada? While I am sympathetic to the view that the 1885 rebellion was important in forming government policy for the West, I am still critical of this interpretation. Many of the actions commonly associated with originating in the aftermath of the rebellion - passes, destruction of the tribal structure. atomization of Indian affairs - can be found in their infancy in prior years. In addition, resistance to government intrusion is also overly associated with this event. Some have even referred to the rebellion as "sounding the last war drum." By focussing on sequential "events" of historical association the complex linkages between rationality of government, 
practices, and aboriginal resistance, become merged to historical monuments. When considered in this manner practices emergent in prior years are disregarded in the interests of the event. Rather, by focussing attention on the mundane, the every day, and the intrinsic disposition of government, resistance and freedom, are grounded in the domain of intrusion. This revised methodology enables the historian to identify and study the great complexity of relations of government, the agency of the aboriginals, and the implications this has for the present.

Throughout this thesis project I have endeavoured to show how aboriginal actions have been structured in many diverse ways. By focussing on the practices which have governed the aboriginal mode of life, and structure their agency, we are able to move beyond the traditional event centered history. To unfold a contextualized account of the government project - whether it is by the HBC, the liberal Canadian state, or another form of colonial government - at any historical moment in time the researcher must be cognizant of the constituted domain of government, the conditions of existence experienced by those governed, the intrinsic problems encountered, and the nature and effects of the political rationality which came before it. By observing these convergent constituents of the history of government/governed relations we are able to observe the complex linkages inherent to the colonial context.

\section{Conclusion: Implications for Future Study ...}

In this section I would like to put forth some directions for future study resulting from the framework I have set out above. First, it is essential for researchers to witness the fact that there are many colonialisms (Thomas, 1994; Scott, 1995). An understanding of the 
colonial governmentality of South Africa, although it shares many of the characteristics of the Canadian context (cf. Hoemle, 1969), should not be extended to incorporate all colonial nations as if colonialism is synonymous with this context. Rather. colonial governmentality is plural responding to the exigencies confronted when governing a complex of conditions of existence, mode of life of the population. and the prior rationality of government. The study I have articulated here has been confined to the administrative space of aboriginal governance in the Canadian prairies from 1870-1890, however, the position I have taken can easily be extended to other colonial regimes where other rationalities of government have sought to structure the actions of the indigenous other. By attending to rationality, domains. and practices of government. as well as. the requisite agency of the aboriginals. the understanding of colonial governmentality becomes situated and grounded in the domain in which it induces its effects. The shape taken by colonialism. and colonial governmentality, must not be interpreted as deriving from the privilege of Europe. but unfolded from the complex linkages between the inducted rationality of government and the agency of the indigenous people. However, these two realities are not independent of one another. but are reflexive, and structure the actions of the other. Colonial governmentality is complex, plural. and intricately interwoven with the agency of the indigenous people.

With the exception of Chapter two, where I discussed how missionary practices intruded upon the mode of aboriginal life. little else was discussed concerning their role in the governance of the aboriginals after confederation. Further study which follows the missionary practices from their emergence in Red River to confederation, and to the present, would help to elucidate the practices through which government structured the actions of the 
aboriginals toward amalgamation with Euro-Canadians. It would be beneficial for the historian to follow the course I have set out above. That is, to focus attention on the mundane and everyday reality of practices, techniques, domains, and the possibility of choices. Prior to confederation. when embedded within a domain of government which pursued the security of its own ends, the programme of evangelizing the aboriginals was arrested by this conflicting rationality. With confederation, and the shift in the rationality of government, the ends pursued by the missionaries became more consistent with the liberal mentality of rule. It would be beneficial to consider how it was that the missionaries' programme of government and intruding the "truth" of the Euro-Canadian mode of life shifted with this change in the rationality of government. It would also prove valuable to consider how the missionary practices linked up with the Department of Indian Affairs and the North-West Mounted Police.

In the final two chapters I discussed how knowledge was disposed as a technique of government to govern both, the immediate context of the domain of government, and from a distance. In these two chapters, I considered the use of knowledge and surveillance, not as monuments of the past reality left behind for future historical research, but as material upon which government is based. Knowledge and surveillance of actions are requisite conditions for the "effective" government of aboriginal actions. Above, I deliberated over the emergence of the table as a technology of comparison, the shifts in reports, and the locating of agents in closer proximity to the reserves. In order to more fully understand the use of knowledge as a reousite part of the government project, attention may be paid to understanding the use (and increased use) of the telegraph and typewriter as means through which knowledge was 
disseminated. In addition. attention could also be given to techniques of counting. such as. the use of metal tags at treaty payments and the role of the yearly census to determine the increase/decrease of population and their health and wellness (RG 10 vol. 3613, file 4062. Provencher to Laird, 1875). Finally, historians may want to explore more thoroughly how the agents of the DIA. secret service agents, (RG 10 vol. 3701 file 17169) and the NWMP linked together to execute a more exacting surveillance of the aboriginals (RG 10, vol. 3609, file 3316-2, Denny to Provencher, 1882).

The last point I would like to emphasize is related to both the methodology of the study and the history of the present reality of the aboriginals' conditions of life. Too often in the past, knowledge of aboriginal/Canadian relations of government and resistance have been tied to, and centred around, the "events" of history (the North-West Rebellion). When performing a historical excavation of these relations it is the purpose of the researcher to understand the present through the past. But, it is essential to ask, how is it that event centred history leads to a more coherent understanding of the present when so few nations and individuals participated in the North-West rebellion? The argument could be made that many of the policies which structured the actions of the aboriginals "originated" in this event, but this would be to neglect the emergence of these programmes in earlier years. I am not stating that these are unimportant events. Rather, I view them as part of complex and intricate processes of conditions and exigencies which evolved through relations of government when confronted by the agency of the aboriginals. The term agency must be qualified. It is not the material through which traditional history is made. It is the everyday choice of actions. It is the traditions, cultural practices, language, means of subsistence, ways of cooking. types of 
dwelling houses, and ceremonies. It is the aboriginal mode of life that was to be governed. Passes, structuring of the tribal organization, division of larger agencies, appointment of local agents, rations. - to name a few - emerge, not as the "result of" the events of history. but in relation to the freedom of choice of available actions.

To understand the present conditions of aboriginal life they must be seen as related to the historical labyrinth of every day and mundane relations of government and aboriginal choice. The history of present aboriginal/government relations is not a "cause and effect" resolution of "events" and the "coercive" strategy of governance, but is a product of the complicated linkages of agency (choice), conditions of existence (facilitated by the HBC and perpetuated by $19^{\text {th }}$ century liberal Canadian government), and the practices of government. In this way, the aboriginals must be observed, not as a dominated and coerced population of docile bodies where the present resistance and solidarity of the aboriginals is viewed as another "event" or a rupture with the present, but rather as part of a sedimented process of complex choices that is part of the everyday reality which they have confronted since contact with Europeans. 


\section{Notes}

\section{Chapter Three}

1. This quote from R. A. Butler (1872), an individual who made successive trips across the plains to the Rocky Mountains for the government, which resulted in the establishment of the NWMP, demonstrates the communal spirit of the aboriginal peoples:

He holds all things in common with his tribe - the land, the bison, the river, the moose. He is starving and the rest of the tribe wants food. Well, he kills a moose and to the last bit the coveted food is shared by all. There is but a scrap of beaver. a thin rabbit or a bit of sturgeon in the lodge; a stranger comes, and he is hungry; give him his share and let him be first served an best attended to. If one child starves in an Indian camp you may know that in every lodge scarcity is universal.

2. From here on this will be referenced as RG 10 fcllowed by the volume and file number.

3. Joseph Howe, the minister of the Interior, stated that: "In dealing with the new provinces of British Columbia and Manitoba, and the wide Territories of the NorthWest, it has become already apparent that Indian Affairs cannot be managed by the application of the old machinery which has been found to work so well in the Canadas [the east]" (CSP vol. 36 no. 23. Annual Report of the Department of the Interior. 1873. Pg.2). Clearly the intrinsic difficulties of the west could not be readily eradicated by the mere extension of the principles relied upon in the east.

4. Specifically this led to the encouraging of the "gradual progress of civilization among the Tribes" and "the gradual removal of all legal distinctions between them and other Canadians. An Act for the encouragement of the Gradual Progress of Civilization among the Indian Tribes (Statutes of Canada, 20 Vic., c.26).

\section{Chapter Four}

1. The buffalo was a staple of the aboriginal subsistence base. 


\section{Chapter Five}

1. Generally rations consisted of $\mathrm{ll} b$. of beef (later bacon) and $1 / 2$ lbs. of flour per aboriginal per day (Wadsworth to Agent Denny, RG 10 vol. 3609 file 3380 July 1882).

2. These land certificates should not be seen as giving the holder ownership to the land.

\section{Chapter Seven}

1. Denny to Provencher vol. 3609 file 3316-2, 1882. 
Appadurai, A. "Numbers in the Colonial Imagination." Pp. 314-339, in Orientalism and the Postcolonial Predicament: Perspectives on South Asia. Breckenridge, $\mathrm{C}$ and van der Veer, P. (eds.). Delhi: Oxford University Press.

Asad, T. 1991. "Afterword." Pp. 314-24, in Colonial Situations: Essays on the Contextualization of Ethnographic Knowledge. Stocking, G. (ed.). Wisconsin: University of Wisconsin Press.

Axtell. J. 1985. The Invasion Within: The Contest of Cultures in Colonial North America. New York: Oxford University Press.

Axtell, J. 1978. "Some Thoughts on the Ethnohistory of the Mission." Ethnohistory. 29: 3541.

Baron, F. 1988. "The Indian Pass System in the Canadian West, 1882-1935." Pp. 139-153, in 1885 and After: Native Society in Transition. Barron, F, and Waldram, I. (ed.). Regina: Canadian Plains Research Centre.

Barry, A., Osbourne, T, and Rose, N. (eds.). 1996. Foucault and Political Reason: Liberalism, Neo-Liberalism and Rationalities of Government. Chicago: University of Chicago Press.

Begg, A. 1894. History of the North-West. Toronto: Hunter, Rose and Company.

Bell, V. 1993. Interrogating Incest: Feminism, Foucault and the Law. London: Routledge Publishing Company.

Bindon, K. 1981. "Hudson's Bay Company Law: Adam Thom and the Institution of Order in Rupert's Land, 1839-1854." Pp. 34-56, in Essays in the History of Canadian Law. vol. I. Flaherty, D. (ed.). Toronto: Toronto University Press.

Binnema, T. 1996. "Old Swan, Big Man, and the Siksika Bands, 1794-1815." The Canadian Historical Review. 77(1): 1-32. 
Hogeveen, An Intrusive and Corrective Government

Black, M. 1967. An Ehtnoscience Investigation of Ojibwa Ontology and World View. Unpublished Ph. D dissertation, Stanford University.

Boldt, M. 1993. Surviviing as Indians: The Challenge of Self Government. Toronto: University of Toronto Press.

Braithwaite, J. 1991. Crime, Shame and Reintegration. Cambridge: Cambridge University Press.

Brogden, M. 1990. "Law and Criminal Labels: The Case of the French Metis in Western Canada." Journal of Human Justice. 1: 1-21.

Brown, D. 1979. "Unpredictable and Uncertain: Criminal Law in the Canadian North-West before 1886." Alberta Law Review. 17: 497.

Brown, R. 1964. Canada's national Policy, 1883-1900: A Study in Canadian-American Relations. Boston: Princeton University Press.

Burchell, G. Gordon, C. and Miller, P. (eds.). 1991. The Foucault Effect: Studies in Governmentality. Chicago: University of Chicago Press.

Burke. E. 1770. Thoughts on the Present Cause of Discontents. Dublin.

Eutler, R. 1872. The Great Lone Land: A Narrative of Travel and Aventure in the NorthWest of America. London: S. Law, Marston and Rivington.

Cambell. C. 1996. Parties, Leaders and Ideology in Canada. Toronto: McGraw-Hill. Ryerson.

Canada. 1867. British North America Act. King's Printer.

Canada. Debates. 1880. House of Commons.

Canada. Sessional Papers. 1870-79. Annual Report of the Department of the Interior. Ottawa: King's Printer.

Canada. Sessional Papers. 1880-1890. Annual Report of the Department of Indian Affairs. Ottawa: King's Printer.

Carter, S. 1990. Lost Harvests: Prairie Indian Reserve Farmers and Government Policy. McGill-Oueens University Press: Montreal and Kingston. 
Carter, S. 1985. "Controlling Indian Movements: The Pass System." NeWest Review. 8(1): 8-9.

Carter, S. 1983. "Agriculture and Agitation on the Oak River Reserve, 1875-1895." Manitoba History. 6(2): 2-9.

Clark, B. 1990. Native Liberty Crown Sovereignty: The Existing Right of Self-Government in Canada. Montreal-Kingston: McGill-Queen's Press.

Dean. M. 1996a. "Putting the Technological into Government". History of the Human Sciences. 9(3): 47-68.

Dean, M. 1996b. "Foucault, Government and the Enfolding of Authority". Pp. 209-229, in Foucault and Political Reason: Liberalism, Neo-Liberalism and Rationalities of Government, edited by Andrew Barry, Thomas Osboume and Nikolas Rose. Chicago: University of Chicago Press.

Dean, M. 1994. "A Social Structure of Many Souls: Moral Regulation, Government, and Self Formation." Canadian Journal of Sociology. 19(2): 145-168.

Dean, M. 1991. The Constitution of Poverty: Toward a Genealogy of Liberal Governance. London: Routledge.

Deleuze, G and Guttari, F. 1977. Anti-Oedipus: Capitalism and Schizophrenia. New York: Viking Press.

Dyck, N. 1991. What is the Indian Problem: Tutelage and Resistance in Canadian Indian Administration. St. John's: The Institute of Social and Economic Research.

Dyck, N. 1986. "An Opportunity Lost: the Initiative of the Reserve Agricultural Programme in the Prairie West." Pp. 121-138 in in 1885 and After: Native Society in Transition. Barron, F, and Waldram, J. (ed.). Regina: Canadian Plains Research Centre.

"Fairplay." 1891. "Editors Comments." The Canadian Indian.

Fanon, F. 1963. The Wretched of the Earth. New York: Grove Press.

Fitzpatrick, J. 1849. An Examination of the Charter and Proceedings of the Hudson's Bay Company.

Forbes, H. (ed.). 1985. Canadian Political Thought. Toronto: Oxford University Press. 
Foucault, M. 1991. "Governmentality". Pp. 87-104 in The Foucault Effect: Studies in Governmentality. Edited by Burchell, G. Gordon, C. and Miller, P. Chicago: University of Chicago Press.

Foucault. M. 1988a. "Technologies of the Self". Pp. 16-49, in Technologies of the Self: a Seminar with Michel Foucault, edited by L.H. Martin, H. Gutman, and P.H. Hutton. Amerst: University of Massachusetts Press.

Foucault, M. 1988b. "The Political Technology of Individuals". Pp. 145-162, in Technologies of the Self: a Seminar with Michel Foucault, edited by L.H. Martin, H. Gutman, and P.H. Hutton. Amherst: University of Massachusetts Press.

Foucault, M. 1988c. "Politics and Reason". Pp. 57-85, in Foucault: Politics, Culture and Philosophy, interviews and Other Writings. Edited by Kritzman, L. New York: Routelage.

Foucault, M. 1983. "The Subject and Power". Pp. 208-216 in Michel Foucault: Beyond Structuralism and Hermeneutics, edited by Hubert L. Dreyfus and P. Rainbow. Chicago: University of Chicago Press.

roucault. M. 1981 a. "Michel Foucault, "History of Systems of Thought, 1978"'. Philosophy and Social Criticism. 8(1): 238-241.

Foucauli. M. 1981 b. "Michel Foucault, "History of Systems of Thought, i 979"'. Philosophy. and Social Criticism. 8(2): 353-369.

Fcucault. M. 1980. Power/Knowledge: Selected Interviews and Other Writings, 1972-19-7. New York: Pantheon Books.

Foucualt, M. 1977. Discipline and Punish: the Birth of the Prison. New York: Random House.

(:arland, D. 1996. "Governmentality" and the Problem of Crime. Paper presented at the "New Forms of Governance Workshop, Toronto, October, 25-26, 1996.

Garland. D. 1985. Punishment and Welfare: A History of Penal Strategies. London: Aldershot Publishers.

Gladstone, A. 1857. The Hudson's Bay Company versus Magna Charta, and the British people. New Haven: Research Publication. 
Hogeveen, . In Intrusive and Corrective Government

Gordon, C. 1991. "Governmentality: an Introduction." Pp. 1-52 in The Foucault Effect: Studies in Governmentality. Burchell, G. Gordon, C. and Miller, P. (eds.). Chicago: University of Chicago Press.

Graham, A. 1969. Andrew Graham's Observations on Hudson's Bay, 1767-91. London: Hudson's Bay Record Society.

Grant. J. 1984. . Loon of Wintertime: . Wissionaries and the Indians of Canada in Encounters Since 1534. Tronto: University of Toronto Press.

Great Britain. House of Commons. 1749. Report from the Committee on the State of the Hudson's Bay Company. Irish University Press Series.

Great Britain. House of Commons. 1837. Report from the Select Committee on Aborigines (British Settlements). Irish University Press Series.

Great Britain. House of Commons. 1858. Report from the Select Committee on the State of the British Possessions in Vorth America which are under the Administration of the Hudson's Bay Company, with Minutes of Evidence. Irish University Press Series.

Gyles, J. 1869. Lemoirs of Odd Adventures, Strange Deliverences, etc., in the Captivin of John Gyles.

Hacking, I. 1991. "How Should we do the History of Statistics?" Pp. 181-195 in The Foucault Effect: Studies in Governmentality. Burchell, G. Gordon, C. and Willer. P. (eds.). Chicago: University of Chicago Press.

Hacking. I. 1990. The Taming of Chance. New York: Cambridge University Press.

Hacking, I. 1986. "Bio-Power and the Avalanche of Printed Numbers." Humanities in Sociery. 5(1): 279-295.

Hallowell. I. 1969. The Ojibway of Berens River: Ethnography into History. For Worth: Hartcourt. Brace. Jovanovich College Publishers.

Henderson, J. 1991. First Nations Legal Inheritance. Canadian Legal History Project: University of Manitoba.

Hoemle. R. 1969. South African Native Policy and the Liberal Spirit. New York: Negro University Press. 
Hoxie, F. 1984. A Final Promise: The Campaign to Assimilate the Indians, 1885-1920. Lincoln: University of Nebraska Press.

Hudson's Bay Company. Cumberland House Journals and Inland Journals, 1775-82. London: Hudson's Bay Record Society.

Huel, R. 1996. Proclaiming the Gospel to the Indians and the Metis. Edmonton: University of Alberta Press.

Hunt. A. and Wickham, G. 1994. Foucault and Law: Towards a Sociology of Law as Governance. London: Pluto Pres.

Ilbrahim, A. 1997. "Tale of Two Sudanese Courts: Colonial Governmentality Revisited." African Studies Review. 40(1): 13-33.

Isbister, A. K. 1857. A few words on the Hudson's Bay Company: with a statement of the grievances of the Native and half-caste Indians, addressed to the British Government through their delegates now in London. London: C. Gilpin Publishers.

Isham, James. 1749. Observations on Hudson's Bay, and Notes and Observations on a Book Entitled "A Voyage to Hudson's Bay in the Dobbs Galley". Turonto: Chaplains Society.

Jackson, C. and Galli, M. 1977. A History of the Department of Indian Affairs and it Activities Among the Indians. Ottawa: Treaties and Historical Research Centre.

Journals of the Legislative Assembly of Canada. 1858. Red River Expedition. Volume 21. Appendix 3.

Kelley, R. 1969. The Transatlantic Persuasion: the Liberal Democratic . Vind in the Age of Gladstone. New York: Knopf Publishers.

Knafla, L. 1986. "From Oral to Written Memory: The Common Law Tradition in Western Canada." in Law and Justice in a New LandL Essays in Western Canadian Legal History. Knafla, L (ed.). Toronto: Carswell Publishers.

LaPrairie, C. 1992. "Aboriginal Crime and Justice: Explaining the Present, Exploring the Future." Canadian Journal of Criminology. 15: 281-298.

Larmour, J. 1980. "Edgar Dewdney Indian Commissioner in the Transition Period of Indian Affairs 1879-1884." Saskatchewan History. 33(1): 13-24. 
Laurier, W. 1887. Lecture on Political Liberalism Delivered by Wilfred Laurier Esq. . L.P. on the $26^{\text {th }}$ June in the Music Hall Under the Auspices of the "Canadian Club". Quebec: Morning Chronicle.

Lewis, C. and Clark, C. n.d. History of the Expedition under the Command of Captains Lewis and Clark to the Sources of the Missiouri, across the Rocky Mountains, down the Columbia River to the Pacific in 1804-1806. Toronto: G.N. Morang.

Loo, T. 1994. Making Law, Order, and Authority in British Columbia, 1821-1871. Toronto: University of Toronto Press.

Long. J. 1987. "Manitu, Power, Books and Wihtikow: Some Factors in the Adoption of Christianity by Nineteenth-Century Western James Bay Cree." Native Studies Review. 3(1): 1-30.

MacCleod, R. and Rollason, H. 1997. "Restrain the Lawless Savages: Native Defendants in the Criminal Courts of the North-West Territories, 1878-1885. Journal of Historical Sociology. 10(2): 157-183.

Mandelbaum, D. 1940. "The Plain's Cree." Anthropological Papers of the American Museuin of Natural History. 37: 163-316.

Miller, J. 1996a. Shingwauk's Vision: A History of Native Residential Schools. Toronto: University of Toronto Press.

Miller, J. 1996b. Big Bear [Mistahimusqua]: A Biography. Toronto: ECW Press.

Miller. J. 1991. Skyscrapers Hide the Heavens: A History of Indian-White Relations in Canada. Toronto: University of Toronto Press.

Milloy. J. 1990. The Plains Cree: Trade, Diplomacy and War, 1790-1870. Winnipeg: University of Manitoba Press.

Morris, A. 1880. The Treaties of Canada with The Indians of Manitoba and the .Vorth-West Territories including the Negotiations on which they were based. Toronto: Belfords. Clarke, and Company Publishers.

Morton. A. (ed.). 1929. The Journal of Ditncan McGillvray of the North-West Company at Fort George Saskatchewan. 179+-1795. Toronto: MacMillan of Canada.

Oliver, E. (ed.). 1914. The Canadian Northwest: Early Development and Legislative Records, vol. I. Ottawa: Government Printing Bureau. 
O'Malley, P. 1996a. "Indigenous Governance". Economy and Society. 25(3): 310-326.

O'Malley, P. 1996b. "Consuming Risk: Harm Minimisation. Risk Management and the Governance of Drug Users." Paper Presented at the New Forms of Governance workshop. Toronto, October 25-26, 1996.

Pavlich, G. 1996a. Justice Fragmented: Mediating Community Disputes Under Postmodern Conditions. London: Routledge.

Pavlich, G. 1996b. "Ommes et Singulatim in Criminological Theory." Pp. 393-409. in PostCritical Criminology. O'Reilly-Fleming, T. (ed.). Scarborough: Prentice Hall.

Pettipas, K. 1994. Severing the Ties that Bind: Government Repression of Indigenous Religious Ceremonies on the Prairies. Winnipeg: University of Manitoba Press.

Pfeifer, K. 1996. "Modernization and Indigenous Knowledge." Peace and Social Change. 6: $41-59$.

Pomeldi, M. 1986. Transcending European Presuppositions: Early Native Approaches to Morality. Unpublished Ph.D dissertation.

Pratt, J. 1996. "Governmentality, Neo-Liberalism, and Dangerousness: Reflections on Recent Trends Towards the Punishment of Persistence." Paper presented at the New Furms of Governance workshop. October, 25-26.

Public Archives of Canada. Record Group 10. Department of Indian Affairs Records.

Public Archives of Canada. Hayter Reed Papers.

Rich, E. 1991. "Trade Habits and Economic Motivation among the Indians of North America. Pp. 157-179 in, Sweet Promises: A Reader on Indian-White Relations in Canada, edited by, Miller, J. Toronto: University of Toronto Press.

Rich. E. 1951. Cumberland House Journals and Inland Post Journal 1775-1779. The Hudson's Bay Company Record Society. Volume 14.

Ronsbo. H. 1997. "State Formation and Property: Reflections on the Political Technologies of Space in Central America." Journal of Historical Sociology. 10(1): 56-73.

Rose, N. and Miller, P. 1992. "Political Power Beyond the State: Problematics of Government." British Journal of Sociology. 43(2): 172-20.5. 
Rose, N. 1995. "Governing by Numbers: Figuring Out Democracy." Accounting Organizations and Society. 16(7): 673-692.

Rose, N. 1993. "Government, Authority and Expertise in Advanced Liberalism." Economy and Society. 22(3): 283-300.

Ross, A. 1856. The Red River Settlement: its Rise, Progress and Present State, with some account of the Native Races and its General History to the Present Day. London: Smith, Elder and Company.

Said, E. 1979. Orientalism. New York: Vintage Books.

Salman, M. 1995. "Nothing Without Labour: Penology, Discipline and Independence in the Philippines under United States Rule." Pp. 113-132, in Discrepant Histories: Translocal Essays on the Philippines. Rafael, V. (ed.). Philadelphia: Temple University Press.

Salı atore, R. i 996. "North American Travel Narratives and the Ordering/Othering of South America." Journal of Historical Sociology. 9(1): 85-110.

Santiago-Valles, K. 1994. Subject People and Colonial Discourses: Economic Transformation and Social Disorder in Puerto Rico, 1898-19+7. New York: State University of New York Press.

Satzewich, V. 1997. “'Where's the Beef?': Cattle Killing, Rations Policy and First Nations 'Criminality' in Southern Alberta. 1892-1895." Journal of Historical Sociology. 9(2): 188-212.

Satzewich, V. 1996. "Patronage, Moral Regulation and the Recruitment of Indian Affairs Personnel, 1879-1900." Canadian Review of Sociology and Anthropology. 33(2): 213-234.

Scott. D. 1995. "Colonial Governmentality." Social Text. 5(3): 191-220.

Scort. D.C. 1914. "Indian Affairs in Canada, 1840-1867." Pp. 331-62, in Canada and its Provinces: A History of the Canadian People and their Institutions by One Hundred Associates, vol. V, edited by Shortt. A. and Doughty, A. Toronto: Glasgow, Brook and Company.

Simpson. G. 1847. Narrative of a Journey Round the World, during the Years 1841-42. I ondon: Colburn Publishers.

Sioui, G. 1992. . or An Amerindian Autohistory. Kingston-Montreal: McGill-Queen's Press. 
Smandych, R. (forthcoming). "The Exclusionary Effect of Colonial Law: Indigenous Peoples and English Law in the Canadian West to 1860." In Law for the Buffalo, Law for the Musk Ox: Studies in the History of Law and Society in the Canadian North-West Territories and Prairie Provinces, 1670-1990, Knafla. L. and Swainger, J. (eds.). Toronto: University of Toronto Press.

Smandych, R. and McGillivary, A. 1998. "Images of Aboriginal Childhood: Contested Governance In The Canadian West to 1850." in Empire and Others: British Encounters with Indigenous Peoples, 1600-1850, Halpern, R. and Daunton. M. (ed.). London: University College London Press.

Smandych, R and Linden, R. 1996. "Administering Justice Without the State". Canadian Journal of Law and Society. 11(1): 21-61.

Smandych, R and Linden, R. 1995. "Co-existing Forms of Aboriginal and Private Justice: A Historical Study of the Canadian West". Pp. 126-147, in Legal Pluralism and the Colonial Legacy: Indigenous Experiences with Justice in Canada, Australia and New Zealand, edited by K. Hazlehurst. Cambridge: Cambridge University Press.

Smandych, R and Sacca, K. 1996. "The Development of Criminal Law Courts in Pre-1870 Manitoba." Manitoba Law Journal.

Smandych, R. 1995. "Willian Osgoode, John Graves Simcoe, and the Exclusion of the English Poor Law from Upper Canada." Pp. 99-129, in Law. Society and the State: Essays in Modern Legal History, edited by Knafla. L., anci Binnie, S. Turonto: Iniversity s, Toronto Press.

Smith, D. 1993. "The Emergence of Eskimo Status: An Examination of the Eskimo Disk List System and its Social Consequences, 1925-1970." Pp. 41-74 in Anthropology. Public Policy and Native Peoples in Canada, edited by Dyck, $\mathrm{N}$ and Waldram, J. Kingston and Montreal: McGill-Queen's Press.

Smith. R. 1985. "Rule by Records and Rule by Reports: Complementary Aspectsof the British Imperial Rule of Law." Contributions to Indian Sociology. 19(1): 153-176.

Stanley, G. 1960. The Birth of Western Canada: a History of the Riel Rebellions. Toronto: University of Toronto Press.

Stenson, K. 1996. "Cirime Control, Governmentality and Sovereignty." Paper presented at New Forins of Governance Conference, Toronto, October, 25-26. 
Stenson, K. 1993. "Community Policing as a Governmental Technology." in Punishment and Social Control. Blomberg, T. and Cohen, S. (eds.). New York: Walter deGuyer.

Stonechild, B. and Waiser, B. 1997. Loyal Till Death: Indians and the North-West Rebellion. Calgary: Fifth House Publishing.

Surtees, R. 1969. "The Development of an Indian Reserve Policy in Canada." Ontario History: $61: 87-95$.

Thomas, N. 1994. Colonialisms Culture: Anthropology. Travel and Government. New Jersey: Princeton University Press.

Thompson, D. 1960. Alexander Mackenzie: Clear Grit. Toronto: MacMillan Company of Canada.

Thom, A. 1845. A Charge Delivered to the Grand Jury of Assiniboia, $20^{\text {th }}$ February, $18+5$ by Adam Thom. Esq.. Recorder of Rupert's Land. London: Couchman Publisher.

Titles, B. 1986. A Narrow Vision: Duncan Cambell Scott and the Administration of Indian Affairs in Canada. Vancouver: University of British Columbia Press.

I obias, J. 1983. "Canada's Subjegation of the Plains Cree, 1879-1885." Canadian Historical Review. 64(4): 127-144.

Tobias, I. 1977. "Indian Reserves in Western Canada: Indian Homelands or Devices for Assimilation." Pp. 89-103, in Approaches to Native History in Canada. Muise. D. (ed.). Cittawa: National Museums of Canada.

Underhill. F. 1960. In Search of Canadian Liberalism. Toronto: MacMillan Company of Canada.

Upton, J. 1973. "The Origins of Canadian Indian Policy." Journal of Canadian Studies. 8: $51-61$.

Wise, S. 1974. "Liberal Consensus or Ideological Battleground: Some Reflections on the Hartz's Thesis." Canadian Historical Association, Historical Papers. 1-14.

Wise, S. 1965. "Tory Factionalism: Kingston Elections and Upper Canadian Politics, 18201836." Ontario History. 47: 205-225. 
West, J. n.d. :The British North West American Indians with Free Thoughts on the Red River Settlement, 1820-1823." Typescript Copy of original held at St. John`s College Library at the University of Manitoba.

West, J. 1824. The Substance of a Journal during a Residence at the Red River Colony and frequent Excursions among the North-West American Indians, in the years 1820. I821, 1822, 1823. London: L.B. Seeley and Son. 


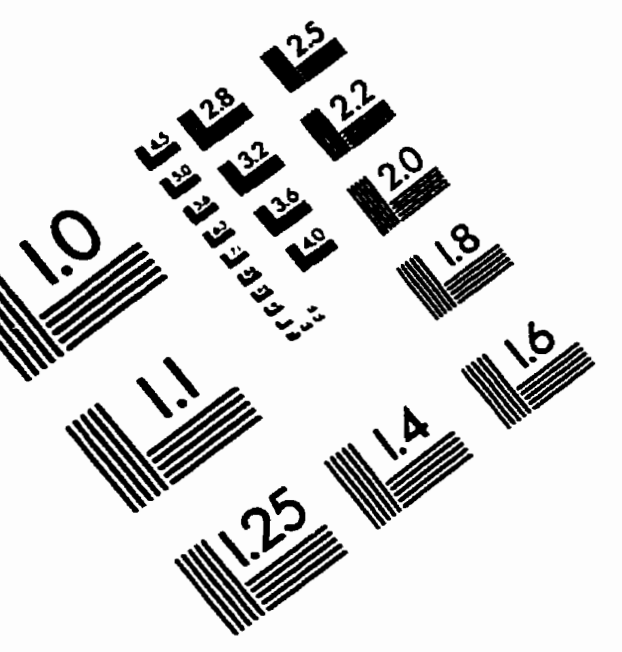

\section{IMAGE EVALUATION \\ TEST TARGET (QA-3)}

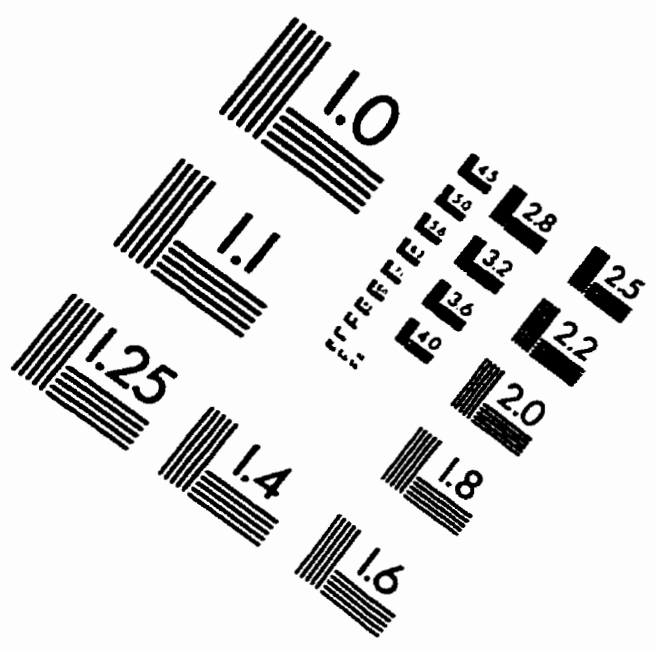

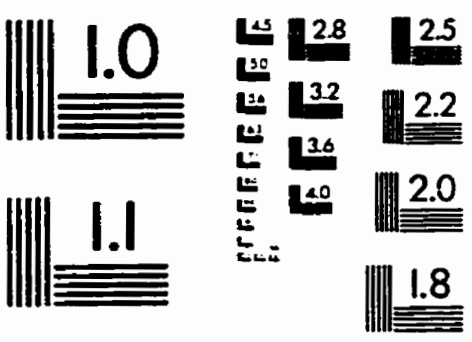

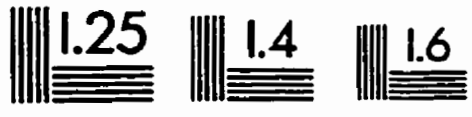
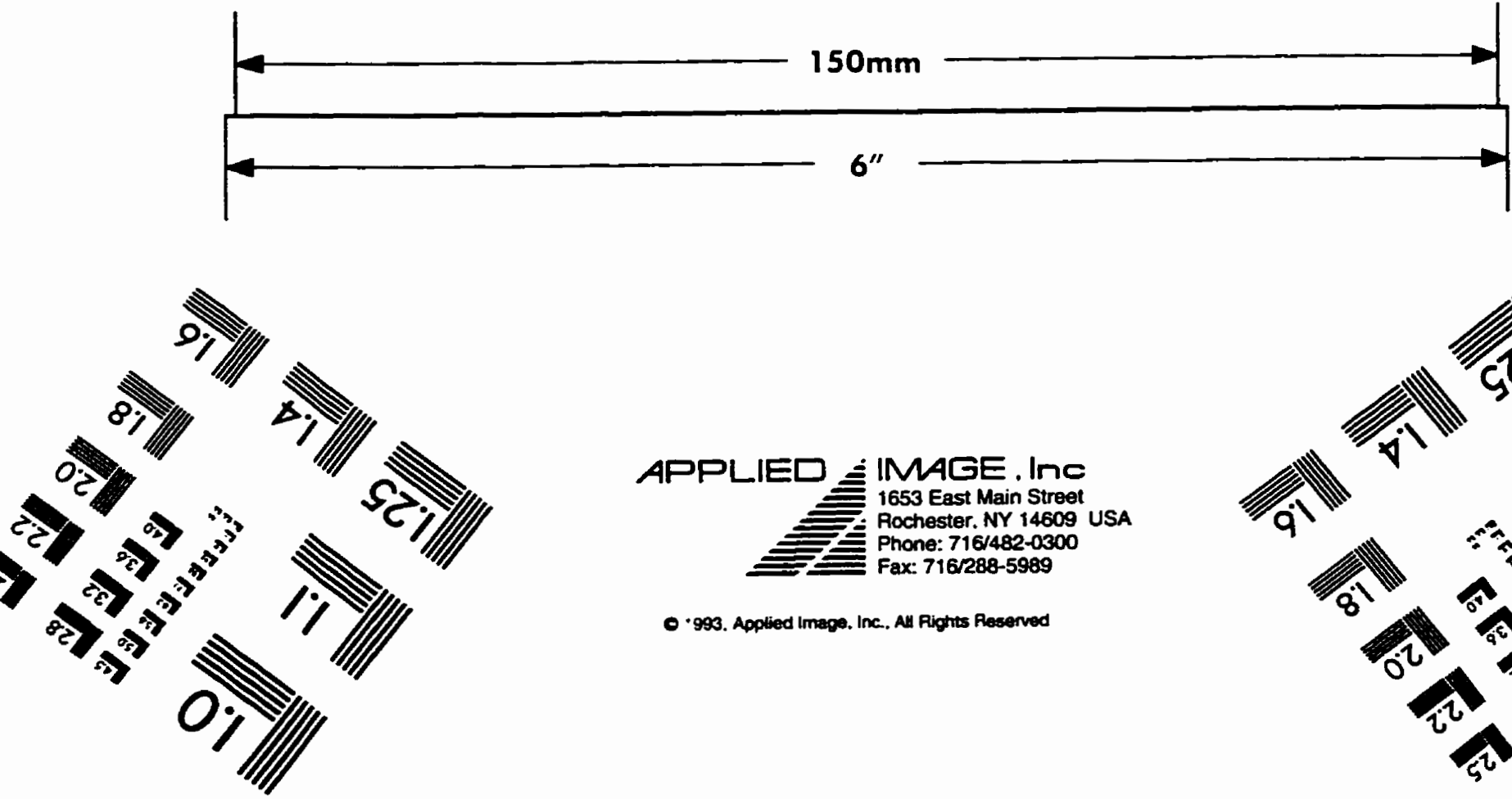

APPLIED $\doteq$ IMAGE. Inc

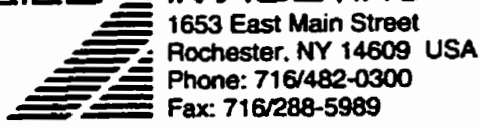

- 993. Applied Image, inc. All Pights Reserved

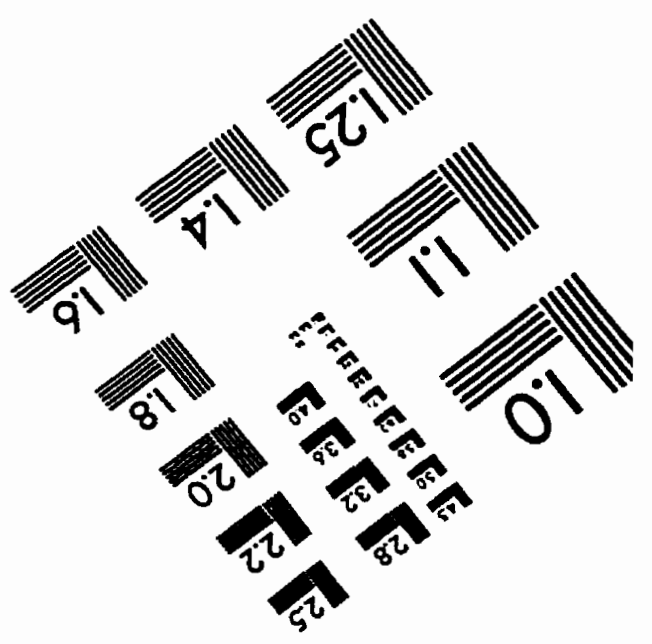

